\title{
th. 465
}

DOE/JPL/954589-5

DEVELOPMENT OF A PROCESS FOR HIGH CAPACITY ARC HEATER PRODUCTION OF SILICON FOR SOLAR ARRAYS

Low-Cost Solar Array Project, Silicon Materials Task; Quarterly Technical Report, January-March 1978

By

William H. Reed

Work Performed Under Contract No. NAS-7-100-954589

Westinghouse Electric Corporation

Power Circuit Breaker Division

Trafford, Pennsylvania
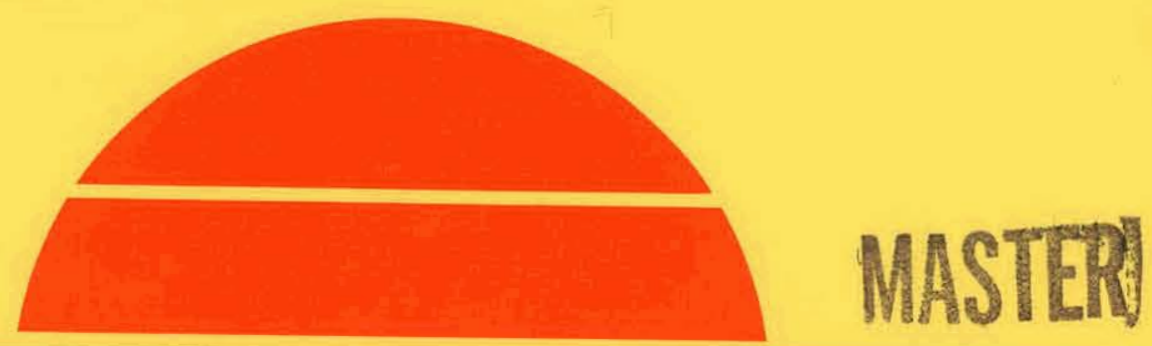

\section{U.S. Department of Energy}




\section{DISCLAIMER}

This report was prepared as an account of work sponsored by an agency of the United States Government. Neither the United States Government nor any agency Thereof, nor any of their employees, makes any warranty, express or implied, or assumes any legal liability or responsibility for the accuracy, completeness, or usefulness of any information, apparatus, product, or process disclosed, or represents that its use would not infringe privately owned rights. Reference herein to any specific commercial product, process, or service by trade name, trademark, manufacturer, or otherwise does not necessarily constitute or imply its endorsement, recommendation, or favoring by the United States Government or any agency thereof. The views and opinions of authors expressed herein do not necessarily state or reflect those of the United States Government or any agency thereof. 


\section{DISCLAIMER}

Portions of this document may be illegible in electronic image products. Images are produced from the best available original document. 


\section{NOTICE}

This report was prepared as an account of work sponsored by the United States Government. Neither the United States nor the United States Department of Energy, nor any of their employees, nor any of their contractors, subcontractors, or their employees, makes any warranty, express or implied, or assumes any legal liability or responsibility for the accuracy, completeness or usefulness of any information, apparatus, product or process disclosed, or represents that its use would not infringe privately owned rights.

This report has been reproduced directly from the best available copy.

Available from the National Technical Information Service, U. S. Department of Commerce, Springfield, Virginia 22161.

Price: Paper Copy $\$ 7.25$

Microfiche $\$ 3.00$ 
LOW COST SOLAR ARRAY PROJECT

SILICON MATERIALS TASK
This report was prepared as an account of work sponsored by the United States Govemment. Neither the United States nor the Uniterd States Department of Energy, nor any of their employees, nor any of their cons any any labilly or responsibuty for the accuracy, completeness or usefulness of any information, apparatus, product or process disclosed, or represents that its use would not infringe privately owned rights.

DEVELOPMENT OF A PROCESS FOR HIGH CAPACITY

ARC HEATER PRODUCTION OF SILICON FOR SOLAR ARRAYS

Contract No. 954589

Quarterly Technical Report: January - March, 1978

\author{
Maurice G. Fey, Program Manager \\ Westinghouse Electric Corporation \\ Power Circuit Breaker Division \\ Trafford, Pennsylvania 15085
}

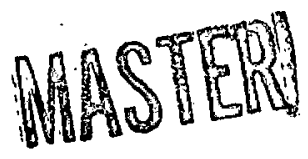

The JPL Low-Cost Solar Array Project is sponsored by the U. S. Department of Energy and forms part of the Solar Photovoltaic Conversion Program to initiate a major effort toward the development of low-cost solar arrays. This work was performed for the Jet Propulsion Laboratory, California Institute of Technology by agreement between NASA and DOE.

$\because \quad$ Prepared by:

Approved:
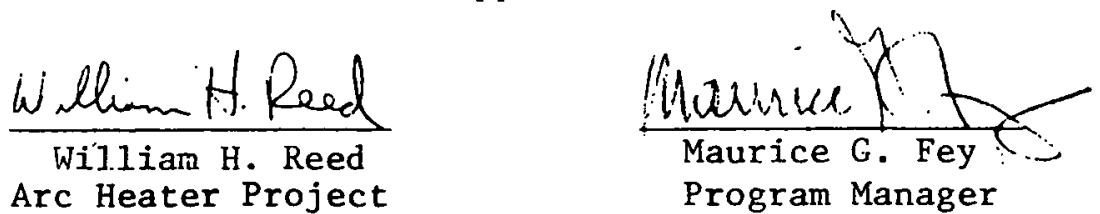
TABLE OF CONTENTS.......................... ii

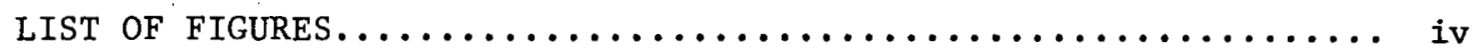

LIST OF TABLES............................... vi

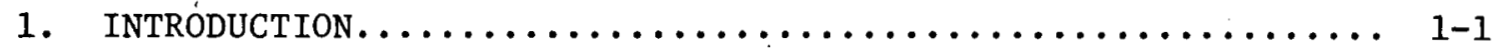

1.1 Program Description........................ 1-1

2. PROGRAM SUMMARY............................. 2-1

3. PROCESS ENGINEERING ANALYSIS................... 3-1

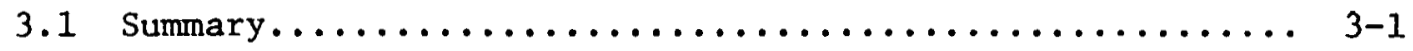

3.2 System Purity Analysis...................... 3-1

3.3 Process Economic Analysis..................... 3-5

4. TEST SYSTEM PREPARATION....................... 4-1

4.1 Summary.............................. $4-1$

4.2 System Components......................... 4-2

4.2 .1 Instrumentation and Control............. 4-2

4.2.2 Plasma Reactor-Separator.................. 4-4

$4.2 .3 \mathrm{SiCl}_{4}$ System.......................... 4-13

4.2 .4 Sodium System....................... 4-18

4.2.5 Silicon Collection System................ 4-20

4.2.6 Effluent Disposal System............... 4-23

4.3 Test System-Laboratory Integration............... 4-26

4.3 .1 Electrical system...................... 4-26

4.3 .2 Gas System.......................... 4-29

4.3.3 Cooling Water System................... 4-3I

4.3 .4 Gas Burnoff Stack.................... 4-31

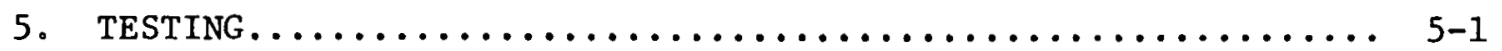

6. INJECTION TECHNIQUES......................... 6-1

6.1 Summary.............................. $6-1$

6.2 Work Description........................... 6-1

6.2 .1 Particle Sizing of Sodium Droplets.......... 6-5

6.2 .2 Sodium Droplet Freezing ................. 6-9

6.2 .3 Sodium Testing........................ 6-12 
TABLE OF CONTENTS (con' $t$ )

$\underline{\text { Page }}$

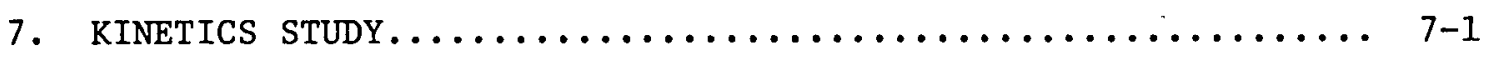

7.1 Summary..................................

7.2 Task Description........................... 7-1

7.3 Work Accomplished......................... 7-2

7.3 .1 Test System DesIgn.................... 7-2

7.3 .2 Scrubber Design....................... 7-7

7.3 .3 Laser Vapor Detection.................. 7-13

7.3 .4 Particle Diagnostics.................... 7-16

$7.3 .5 \mathrm{SiCl}_{4}$ Injection System................. 7-16

8. REACTION DEMONSTRATION. ..................... $8-1$

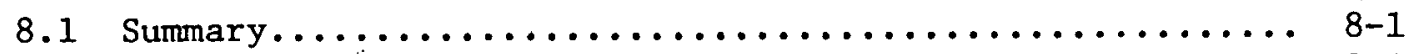

8.2 Work Accompiished.......................... $8-1$

9. PRODUCT SEPARATION ANALYSIS...................... 9-1

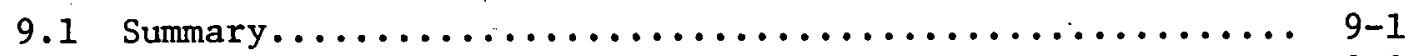

9.2 Product Separation By Condensation................ 9-2

9.3 Heterogeneous Reaction Analysis.................... 9-9

9.3.1 Low Temperature Reaction Mode1............. 9-15

9.3.2 Thermal Treatment Mode1.................. 9-18

9.3.3 Results............................ 9-25

9.4 Reactor Design........................... 9-28

10. CONCLUSIONS................................ 10-1

11. PRoject Status.............................. 11-1

11.1 Present Status.............................. 11-1

11.2 Future Activity.............................. 11-1

12. REFERENCES................................. 12-1

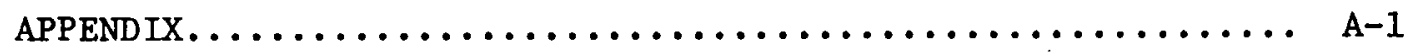




\section{LIST OF FIGURES}

Figure

$\underline{\text { Page }}$

4.1 Preliminary Instrumentation And Control Schematic 4-3

4.2. Silicon Process Reactor Assembly 4-6

4.3 Layout Drawing of The Sodium Injector 4-7

4.4 Layout Drawing of The Outlet Piping For The Silicon 4-8 Cyclone

4.5 Assembly Drawing For The Arc Heater 4-9

4.6 Drawing of The Arc Heater Plenum 4-10

4.7 Drawing of The Silicon Cyclone Body 4-11

4.8 Details of The 4000 Gallon $\mathrm{SiCl}_{4}$ Storage Tank 4-14

4.9 Details of The $200 \mathrm{Gallon} \mathrm{SiCl}_{4}$ Day Tank 4-15.

4.10 $\mathrm{SiCl}_{4}$ Flow System Schematic 4-17

4.11 Sodium Supply System Schematic + 4-19

4.12 Electrical Equipment Layout Drawing 4-27

4.13 Plan View of The Gas System 4-30

6.1 Photograph of The Sodium Storage Tank, 6-3

6.2 Schematic of The Sonicore 312 Nozzle 6-4

6.3 Particle Size Analysis Ranges 6-6

6.4 Schematic of The Sodium Particle Collection System 6-10

6.5 Photograph of The Sodium Chamber Base Flange 6-11

6.6 Water Testing Shroud 6-13

6.7 Sonicore Nozzle Performance For Water Spray Tests . 6-15

7.1 Assembly Drawing of Kinetics Test Apparatus 7-3

7.2 Reactant Injection Nozzle 7-4 
7.3 Homogeneous Reaction Test Section 7-5

7.4 Product Separation Test Section 7-6

7.5 Viewing Port Assembly 7-8

$7.6 \quad \mathrm{HCl}_{2} \mathrm{H}_{2} \mathrm{O}$ Mole Fractions 7-10

7.7 HCl Scrubber System 7-14

7.8 Schematic of The $\mathrm{SiCl}_{4}$ Supp1y System 7-17

8.1 Schematic of The Test System For The Reaction 8-2

Demonstration Studies

8.2 Sketch of The Furnace Reaction Tube 8-4

8.3 Schematic of The $\mathrm{SiCl}_{4}$ System 8-5

8.4 Schematic of The Sodium System 8-7

9.1 Local Nusselt Number Ratio vs. Distance Ratio 9-6 Obtained From Boelter And Coworkers' Measurements On A Circular Tube With Right Angle Bend Entrance

9.2 Dependence of Product Separation (Beta), Condensation 9-10 Location ( $T$ Star) and Heat Flux $\left(Q_{w}\right)$ Upon Axial Position (Equilibrium)

9.3 Schematic Representation of Silicon Reactor System In Which The Reduction of $\mathrm{SiCl}_{4}$ Is Carried Out In $\mathrm{A}$ Heterogeneous Mode

9.4 Extent of Reaction, $\xi$, As A Function of The Axial 9-26 Distance For The Reaction Model

9.5 Temperature And Radius Resuits For Droplets With 9-27 An Initial Sodium Flowrate of $3.6 \mathrm{mols} / \mathrm{s}$, An Initial $\mathrm{SiCl}_{4}$ Flowrate of $0.9 \mathrm{mols} / \mathrm{s}$ And $10 \%$ Conversion 


\section{LIST OF TABLES}

Table

$\underline{\text { Page }}$

3.1 Results of System Purity Analysis For Mo, $\mathrm{Zr}, \mathrm{Cu}, \quad 3-3$ And $\mathrm{Ti}$

3.2 Summary of Typical Results For All Impurities 3-4 Analyzed

3.3 Estimation of Silicon Product Cost 3-6

4.1 Spectroscopic Analysis of The Alumina Ceramic- 4-21. Fiber Felts

9.1 Equilibrium Properties 9-8

9.2 Nomenclature For Condensation Analysis 9-11

9.3 Nomenclature For Heterogeneous Analysis 9-29 


\section{INTRODUCTION}

\subsection{Program Description}

A program has been established at Westinghouse to develop a high temperature silicon production process using existing electric arc heater technology. Silicon tetrachloride and a reductant will be injected into an arc heated mixture of hydrogen and argon. Under these high temperature conditions, a very rapid reaction is expected to occur and proceed essentially to completion, yielding silicon and gaseous sodium chloride. Techniques for high temperature separation and collection of the molten silicon will be developed using standard engineering approaches, and the salt vapor will later be electrolytically separated into its elemental constituents for recycle. Preliminary technical evaluations and economic projections indicate not only that this process appears to be feasible, but that it also has the advantages of rapid, high capacity production of good quality molten silicon at a nominal cost. 1,2

As currently envisioned, the Westinghouse program consists of a four-phase effort directed to the development and implementation of this technology. The initial phase of the program, Phase I, was an eleven-month study funded by JPL which was completed in September, 1977. While the overall program objective is to produce 1000 metric tons of high quality silicon per year on a continuous basis, Phase I was defined as a comprehensive feasibility and engineering review of the reaction process, and a formulation of the design for a test system to experimentally verify the high temperature reaction.

Phase II, currently underway, involves a multi-task approach including (1) a detailed engineering analysis of the entire process (2) design, fabrication, and assembly of the experimental system (3) experimental testing of the reduction reaction to produce silicon and (4) complementary research programs to augment the experimental 
system design. The Phase II effort was Initiated in October, 1977, and work is progressing on the vartous stages of this effort. 


\section{PROJECT SUMMARY}

During the quarter, the System Purity Analysis which utilizes the CHEMEQ computer program to predict impurity concentrations at equilibrium in the liquid silicon product based on initial amounts in the feedstocks was completed. The impurities that were analyzed include molybdenum, zirconium, copper, and titanium. For all four metals, the entire amount of the initial impurity is present in the liquid silicon product for the sodium reduction case, while $100 \%$ of the Mo, $92 \%$ of the $\mathrm{Cu}, \sim 35 \%$ of the $\mathrm{Ti}$, and $\sim 14 \%$ of the $\mathrm{Zx}$ is contained in the molten silicon product for the hydrogen reduction case.

The process economic analysis was reevaluated in order to determine the silicon product cost based on a homogeneous reaction mode. Results of this analysis are presented for both heterogeneous and homogeneous reaction modes.

During the reporting period, detailed design effort continued for the test system preparation. The test system has been divided into two main categories: 1) system components and 2) test system-laboratory integration. Included in the system components are the following systems: a) instrumentation and control (I\&C), b) plasma reactor-separator, c) $\mathrm{SiCl}_{4}$ storage and injection, d) sodium storage and injection, e) silicon collection, and f) effluent disposal. The test system-laboratory integration category includes: a) electrical distribution system, b) arc heater gas system, c) cooling water system, and d) the gas burnoff system.

Development of unit requirements, component specifications, and a system schematic was undertaken for the I\&C system. Design and drawing effort continued for the arc heaters, plasma reactor and cyclonic separator. In addition, analyses were initiated to evaluate shell materials for the reactor components based on the physical and chemical properties of the candidate materials. The final design configuration for the $\mathrm{SiCl}_{4}$ system was completed based 
on the preliminary design developed during Phase $I$ of the project. Specifications for safety requirements, storage tanks, and $\mathrm{SiCl}_{4}$ monitors were initiated for the $\mathrm{SiCl}_{4}$ storage and injection system. Detailed designs for both the sodium storage-injection system and the NaK cooling circuit were completed, components specified and procurement initiated. Initial operating sequences for the sodium system were also identified. Analyses continued for the silicon collector and the effluent system to provide design information for the drawing effort which is in progress in addition to vendor interface for these systems. For the test system-laboratory integration, activity continued on detailed design, component specification and selection in preparation for procurement of components.

Fabrication and assembly of the sodium injectirn chamber for the Injection Techniques continued throughout the reporting period. Nozzles have been procured for sodium and silicon tetrachloride injection, and preliminary testing with water has been initiated. Methods of particle size measurement have been estiriated; sieving and inertial impaction have been identified as the nost appropriate techniques for this task.

The design of the entire Kinetics test apparatus, including the injection nozzle, three test sections, scrubber and the $\mathrm{SiCl}_{4}$ injection subsystem, have been finalized. Fabrication of all system components is currently in progress. Initial tests with a tunable dye laser indicate that the laser absorption technique is capable of detecting the presence of silicon vapor. A zirconium oxide filter will be used for particle slze determination during initial experiments.

The design of the test system for Reaction Demonstration has been completed and the majority of the equipment and system materials of construction have been procured. Fabrication of the sodium and silicon tetrachloride generation subsystems is in progress. Based on a detailed comparison of internal and external generation 
of sodium vapor, the external approach was selected because of the very large sodium containment crucible required for internal generation. The overall system design was discussed in detail by staff from both the R\&D Center and PCB at a task design review.

During the quarter, analyses have continued for the purpose of defining a design which provides effective silicon product separation. Two approaches to product separation have been pursued. The first separation mode examines silicon separation via condensation following a high temperature reaction producting superheated silicon vapor. The condensation model results indicate that $80 \%$ of the silicon can be removed via condensed silicon collecting at the reactor wall. The design has been modified to accomodate the higher temperature process (e.g., initial product gas stream temperature of $3500^{\circ} \mathrm{K}$ ).

The second approach depends upon a heterogeneous reaction mode which permits effective product separation. An analysis examined a partial low temperature reaction followed by a high temperature thermal treatment process step.

From the results of the product separation study, it was concluded that the Phase II design will be based upon the condensation mode. Even though high product separation efficiency is indicated for a reactor operated in this manner, considerations of both power requirement and reactor product flow rate may justify a slight modification of the reactor to examine heterogeneous mechanisms for the actual process. Fortunately, the basic reactor is readily adaptable to the various heterogeneous operating modes. 


\section{PROCESS ENGINEERING ANALYSIS}

Task Investigators: F. J. Harvey, W. H. Reed

\subsection{Summary}

During the quarter, the System Purity Analysis which utilizes the CHEMEQ computer program to predict impurity concentrations in the liquid silicon product based on initial amounts in the feedstocks was completed. The impurities that were analyzed include molybdenum, zirconium, copper, and titanium. For all four meta1s, the entire amount of the initial impurity is present in the liquid silicon product for the sodium reduction case, while $100 \%$ of the Mo, $92 \%$ of the $\mathrm{Cu}, \sim 35 \%$ of the $\mathrm{Ti}$, and $\sim 14 \%$ of the $\mathrm{Zr}$ is contained in the molten silicon product for the hydrogen reduction case.

The process economic analysis was reevaluated in order to determine the silicon product cost based on a homogeneous reaction mode. Results of this analysis are presented for both heterogeneous and homogeneous reaction modes.

With the completion of the System Purity Analysis, this task is now complete; thus, all aspects of the Process Engineering Analysis are fulfilled.

\subsection{System Purity Analysis}

The control of metallic impurities is critical to the processes that are currently being developed for the low cost, high capacity production of solar grade silicon. The two principal sources of impurities in all metallurgical and chemical processes are the feedstocks and materials of construction. In the present analysis, thermochemical calculations have been carried out to determine the maximum impurity levels that could result in the liquid silicon produced by the arc heater process as a result of impurities presient In the $\mathrm{Na}$ and $\mathrm{SiCl}_{4}$ feedstocks. The metallic impurities that have been considered during the present quarter include Mo, $\mathrm{Zr}$, Cu and $\mathrm{T} 1$; while $\mathrm{Al}, \mathrm{B}, \mathrm{Cr}, \mathrm{Fe}, \mathrm{Mn}, \mathrm{P}$ and $\mathrm{V}$ have been previously 
analyzed ${ }^{2}$. Since the arc heater process involves a multicomponent system, i.e., $\mathrm{Si}-\mathrm{H}-\mathrm{Cl}-\mathrm{Ar}\left(\mathrm{H}_{2}\right.$ reduction) and $\mathrm{Si}-\mathrm{H}-\mathrm{Cl}-\mathrm{Na}-\mathrm{Ar}$ ( $\mathrm{Na}$ reduction), the free minimization computer program CHEMEQ was used for the analysis. The calculations have been carried out for binary solutions of liquid silicon and the various impurities. Because the range of impurity concentrations is small, the results can also be used to approximate multicomponent solutions of liquid silicon. Activity coefficients, which are required for the calculations, are not available for Mo, $\mathrm{Zr}, \mathrm{Cu}$ or $\mathrm{Ti}$. The coefficients were estimat $\triangleq d$ based on experimental data for $\mathrm{Fe}-\mathrm{Si}$ and $\mathrm{Cr}-\mathrm{Si}$ solutions where these coefficients range from $1 \times 10^{-2}\left(1700^{\circ} \mathrm{K}\right)$ to $4.5 \times 10^{-2}$ $\left(2200^{\circ} \mathrm{K}\right)$.

The results for both hydrogen and sodium reduction are shown in Table 3.1 for initial conditions that are representative of projected process conditions. For all four metals, the entire amount of the initial impurity is present in the liquid silicon for sodium reduction, while $100 \%$ of the Mo, $92 \%$ of the $\mathrm{Cu}, \sim 35 \%$ of $\mathrm{Ti}$ and $\sim 14 \%$ of the $\mathrm{Zr}$ is contained in the molten product for $\mathrm{H}_{2}$ reduction. As previously discussed, ${ }^{1}$ the behavior of the impurities is a result of the stability of the impurity chlorides relative to the reductant chlorides, i.e., $\mathrm{NaCl}$ and $\mathrm{HCl}$, as well as the activity coefficient of the metals in liquid silicon. In the case of zirconium, for example, less impurity is present in the silicon for hydrogen reduction than for sodium reduction because $\mathrm{HCl}$ is less stable thin $\mathrm{NaCl}$.

A summary of representative results for all impurities analyzed is given in Table 3.2, in terms of the percent of feedstock impurity that is present in the liquid silicon. These values represelt the maximum amount of impurity possible in the molien silicon since the analysis is based on the equilibrium condition. Under actual process condition, the amount of impurity that is present may be considerably less due to kinetic factors. For arc heater reduction by sodium, the results indicate that purity levels should substantially improve with respect to $\mathrm{P}$ and $\mathrm{Al}$, moderately so for $\mathrm{Mn}$, and not at all. 
TABLE 3.1

RESULTS OF SYSTEM PURITY ANALYSIS FOR Mo, Zr, Cu, Ti

\begin{tabular}{|c|c|c|c|c|c|}
\hline Impur1ty & Reductant & $\begin{array}{l}\text { Temp. } \\
\left({ }^{\circ} \mathrm{K}\right) \\
\end{array}$ & $\begin{array}{l}\text { Impurity } \\
\text { Content in } \\
\text { Feedstocks } \\
\text { (g-atm) }\end{array}$ & $\begin{array}{c}\text { Impurity } \\
\text { Content in } \\
\text { Si(l) }(g-a t m) \\
\end{array}$ & $\begin{array}{l}\text { Impurity } \\
\text { Mole Fraction } \\
\text { in Si(l) } \\
\end{array}$ \\
\hline \multirow{6}{*}{ Molybdenum } & \multirow{3}{*}{$* \mathrm{Na}$} & 1900 & $1 \times 10^{-4}$ & $9.99 \times 10^{-5}$ & $1.01 \times 10^{-4}$ \\
\hline & & 1900 & $1 \times 10^{-5}$ & $1.00 \times 10^{-5}$ & $1.01 \times 10^{-5}$ \\
\hline & & 1900 & $1 x \cdot 10^{-6}$ & $1.00 \times 10^{-6}$ & $1.02 \times 10^{-5}$ \\
\hline & \multirow{3}{*}{$* * \mathrm{H}_{2}$} & 2200 & $1 \times 10^{-2}$ & $1.00 \times 10^{-2}$ & $2.80 \times 10^{-?}$ \\
\hline & & 2200 & $1 \times 10^{-3}$ & $1.00 \times 10^{-3}$ & $2.94 \times 10^{-3}$ \\
\hline & & 2200 & $1 \times 10^{-4}$ & $9.99 \times 10^{-5}$ & $2.96 \times 10^{-i t}$ \\
\hline \multirow{6}{*}{ Zirconium } & \multirow{3}{*}{$*_{\mathrm{Na}}$} & 1900 & $1 \times 10^{-4}$ & $1.00 \times 10^{-4}$ & $1.00 \times 10^{-i}$ \\
\hline & & 1900 & $1 \times 10^{-5}$ & $1.00 \times .0^{-5}$ & $1.01 \times 10^{-i}$ \\
\hline & & 1900 & $1 \times 10^{-6}$ & $1.00 \times 10^{-6}$ & $1.01 \times 10^{-6}$ \\
\hline & \multirow{3}{*}{$* * \mathrm{H}_{2}$} & 2200 & $1 \times 10^{-2}$ & $1.44 \times 10^{-3}$ & $4.15 \times 10^{-i}$ \\
\hline & & 2200 & $1 \times 10^{-3}$ & $1.39 \times 10^{-4}$ & $4.11 \times 10^{-t / t}$ \\
\hline & & 2200 & $1 \times 10^{-4}$ & $1.38 \times 10^{-5}$ & $4.10 \times 10^{-i}$ \\
\hline \multirow{6}{*}{ Copper } & \multirow{3}{*}{$*_{\mathrm{Na}}$} & 1900 & $1 \times 10^{-4}$ & $1.00 \times 10^{-4}$ & $1.01 \times 10^{-!}$ \\
\hline & & 1900 & $1 \times 10^{-5}$ & $1.00 \times 10^{-5}$ & $1.01 \times 10^{-i}$ \\
\hline & & 1900 & $1 \times 10^{-6}$ & $1.00 \times 10^{-6}$ & $1.01 \times 10^{-i}$ \\
\hline & \multirow{3}{*}{$\star * \mathrm{H}_{2}$} & 2200 & $1 \times 10^{-2}$ & $9.25 \times 10^{-3}$ & $2.60 \times 10^{-!}$ \\
\hline & & 2200 & $1 \times 10^{-3}$ & $9.22 \times 10^{-4}$ & $2.72 \times 10^{-3}$ \\
\hline & & 2200 & $1 \times 10^{-4}$ & $9.22 \times 10^{-5}$ & $2.73 \times 10^{-1}$ \\
\hline \multirow{4}{*}{ Titanium } & ${ }^{*} \mathrm{Na}$ & 1900 & $1 \times 10^{-4}$ & $9.98 \times 10^{-5}$ & $1.01 \times 10^{-.4}$ \\
\hline & \multirow{3}{*}{$* * \mathrm{H}_{2}$} & 2200 & $1 \times 10^{-2}$ & $3.57 \times: 0^{-3}$ & $1.02 \times 10^{-!}$ \\
\hline & & 2200 & $1 \times 10^{-3}$ & $3.52 \times 0^{-4}$ & $1.04 \times 10^{-:}$ \\
\hline & & 2200 & $1 \times 10^{-4}$ & $3.50 \times 10^{-5}$ & $1.03 \times 10^{-}$ \\
\hline
\end{tabular}

\footnotetext{
*Initial conditions: $1900^{\circ} \mathrm{K} ; 4.0 \mathrm{mols} \mathrm{Na}, 1 \mathrm{~mol} \mathrm{SiCl}{ }_{4}, 0.66 \mathrm{~mol} \mathrm{Ar}$, $2.65{\text { mols } \mathrm{H}_{2}}_{2}$
}

**Initial conditions: $2200^{\circ} \mathrm{K} ; 25$ mols $\mathrm{H}_{2}, 1 \mathrm{~mol} \mathrm{siCl}_{4}$ 
TABLE 3.2

SUMMARY OF TYPICAL RESULTS FOR ALL

IMPURITIES ANALYZED

\begin{tabular}{|c|c|c|}
\hline \multirow[b]{2}{*}{ Impurity* } & \multicolumn{2}{|c|}{$\begin{array}{c}\text { Percent of Initial Impurity } \\
\text { in Liquid Silicon }\end{array}$} \\
\hline & $\mathrm{Na}$ Reduction** & $\mathrm{H}_{2}$ Reduction $\star * *$ \\
\hline Aluminum & 19 & 0.2 \\
\hline Boron & 100 & 52 \\
\hline Chromium & 100 & 81 \\
\hline Copper & 100 & 92 \\
\hline Iron & 99 & 94 \\
\hline Manganese & 71 & 0.7 \\
\hline Molybdenum & 100 & 100 \\
\hline Phosphorus & 1 & 0.3 . \\
\hline Titanium & 100 & 35 \\
\hline Vanadium & 100 & 100 \\
\hline Zirconium & 100 & 14 \\
\hline
\end{tabular}

*Initial amount is $1 \times 10^{-4} \mathrm{~g}$-atm for all impurities.

**Initial conditions: $1900^{\circ} \mathrm{K} ; 4.0 \mathrm{mols} \mathrm{Na}, 1 \mathrm{~mol}$ $\mathrm{SiCl}_{4}, 0.66 \mathrm{~mol} \mathrm{Ar}$, $2.65^{4} \mathrm{mols}_{2}$

$* * *$ Initial conditions: $2200^{\circ} \mathrm{K} ; 25 \mathrm{~mol}^{\mathrm{s}} \mathrm{H}_{2}, 1 \mathrm{~mol} \mathrm{S1Cl}_{4}$ 
for $\mathrm{B}, \mathrm{Cr}, \mathrm{Cu}, \mathrm{Fe}, \mathrm{Mo}, \mathrm{T} 1, \mathrm{~V}$ and $\mathrm{Zr}$. In the case of hydrogen

reduction, there is essentially complete impurity removal for $\mathrm{Al}$, Mn, and $\mathrm{P}$, significant removal for $\mathrm{B}, \mathrm{Ti}$ and $\mathrm{Zr}$ and little or no removal for $\mathrm{Cr}, \mathrm{Fe}$, Mo and $\mathrm{V}$.

\subsection{Process Economics}

As a result of the Product Separation Analysis which examined a homogeneous (condensation) reaction mode, the process economics as reported previously ${ }^{2}$ have been revised to accomodate both the heterogeneous and homogeneous reaction modes. Table 3.3 presents the economic projections for both flxed capital and silicon product cost (without profit) based on a $500 \mathrm{MT} /$ year batch process and a $3000 \mathrm{MT} /$ year recycle process for the arc heater-silicon process. The respective DOE/JPL cost goals for silicon are as follows:

$$
\begin{array}{r}
500 \mathrm{MT} / \mathrm{yr} ; \$ 25 / \mathrm{kg} \mathrm{Si}(1975 \text { dollars) } \\
3000 \mathrm{Mt} / \mathrm{yr} ; \$ 10 / \mathrm{kg} \text { Si (1975 dollars) }
\end{array}
$$

Thus, both reaction modes are projected to meet the DOE/JPL cost goals for the silicon product. 
Table 3.3

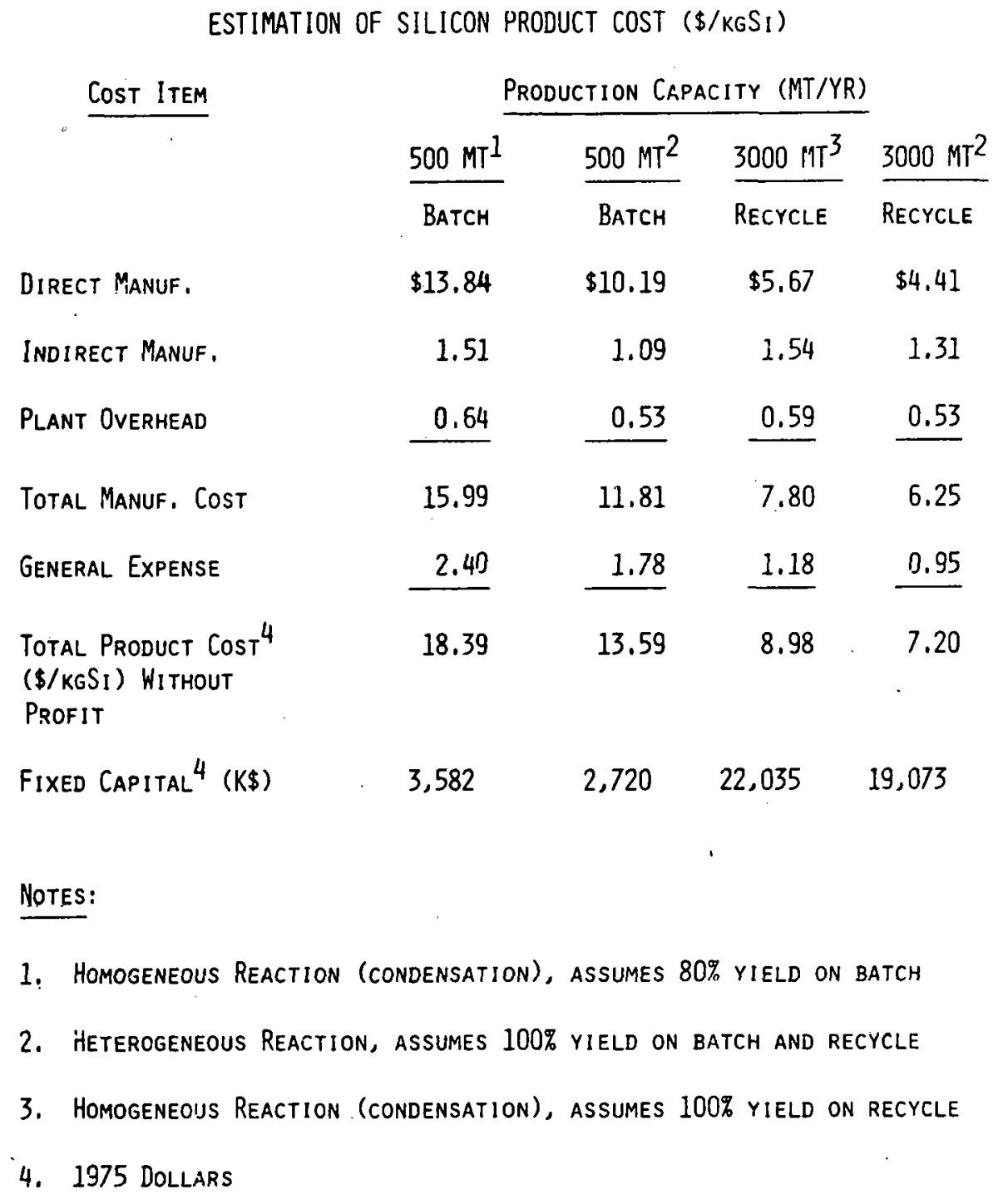




\section{TEST SYSTEM PREPARATION}

\subsection{Summary}

During the quarter detailed design effort continued for the test system preparation. The test system has been divided into two main categories: 1) system components and 2) test system-laboratory integration. Included in the system components are the following systems: a) instrumentation and control (I\&C), b) plasma reactorseparator, c) $\mathrm{SiCl}_{4}$ storage and injection, d) sodium storage and injection, e) silicon collection, and $f$ ) effluent disposal. The test system-laboratory integration category includes: a) electrical distribution system, b) arc heater gas system, c) cooling water system, and d) the gas burnoff system.

Development of unit requirements, component specifications, and a system schematic was undertaken for the I\&C system. Design and drawing effort continued for the arc heaters, plasma reactor and cyclonic separator. In addition, analyses were initiated to evaluate shell materials for the reactor components based on the physical and chemical properties of the candidate materials. The final design configuration for the $\mathrm{SiCl}_{4}$ system was completed based on the preliminary design developed during Phase I of the project. Specifications for safety requirements, storage tanks, and $\mathrm{SiCl}_{4}$ monitors were initiated for the $\mathrm{SiCl}_{4}$ storage and injection system. Detailed designs for both the sodium storage-injection system and the NaK cooling circuit were completed, components specified and procurement initiated. Intitial operating sequences for the sodium system were also identified. Analyses continued for the silicon collector and the effluent system to provide design information for the drawing effort which is in progress in addition to vendor interface for these systems. For the test system-1aboratory integration, activity continued on detailed design, component specification and selection in preparation for procurement of components. 
Specific activities and status of both categories which comprise the test system preparation are presented in Sections 4.2 and 4.3.

During the next report period, component procurement and fabrication will begin for the test system in addition to completing the various detailed drawings and design.

\subsection{System Components}

4.2.1 Control \& Instrumentation (J. W. George, I. N. Bova)

During the quarter, the determination of individual unit requirements was completed for the current design of each subsystem. Any subsequent design changes that may be made to the subsystems will necessitate only slight revisions to the unit requirements.

A preliminary instrumentation and control schematic has been completed for the overall test system (see Figure 4.1). The schematic was reviewed with the task investigators of the various subsystems. Comments and suggested revisions are currently being resolved and the diagram is being revised accordingly. The schematic may also be used for designing a a graphic type control panel which is being considered.

The instrumentation and control component specifications for the cooling water system were completed and submitted for comments and approval to the task investigators of both the cooling water and electrical systems. Following the review, the document will be finalized and released to prospective suppliers for quotations and delivery dates.

Specifications for the gas $\left(\mathrm{H}_{2}\right.$ and $\left.\mathrm{Ar}\right)$ manifold and mixing chamber were completed and realeased to a vendor for a proposed design and quotation. As specified, the manifold package will include all required instrumentation and controls.

Quotations for hydrogen and oxygen level detectors which will monitor the quality of air in the test cell were received. 


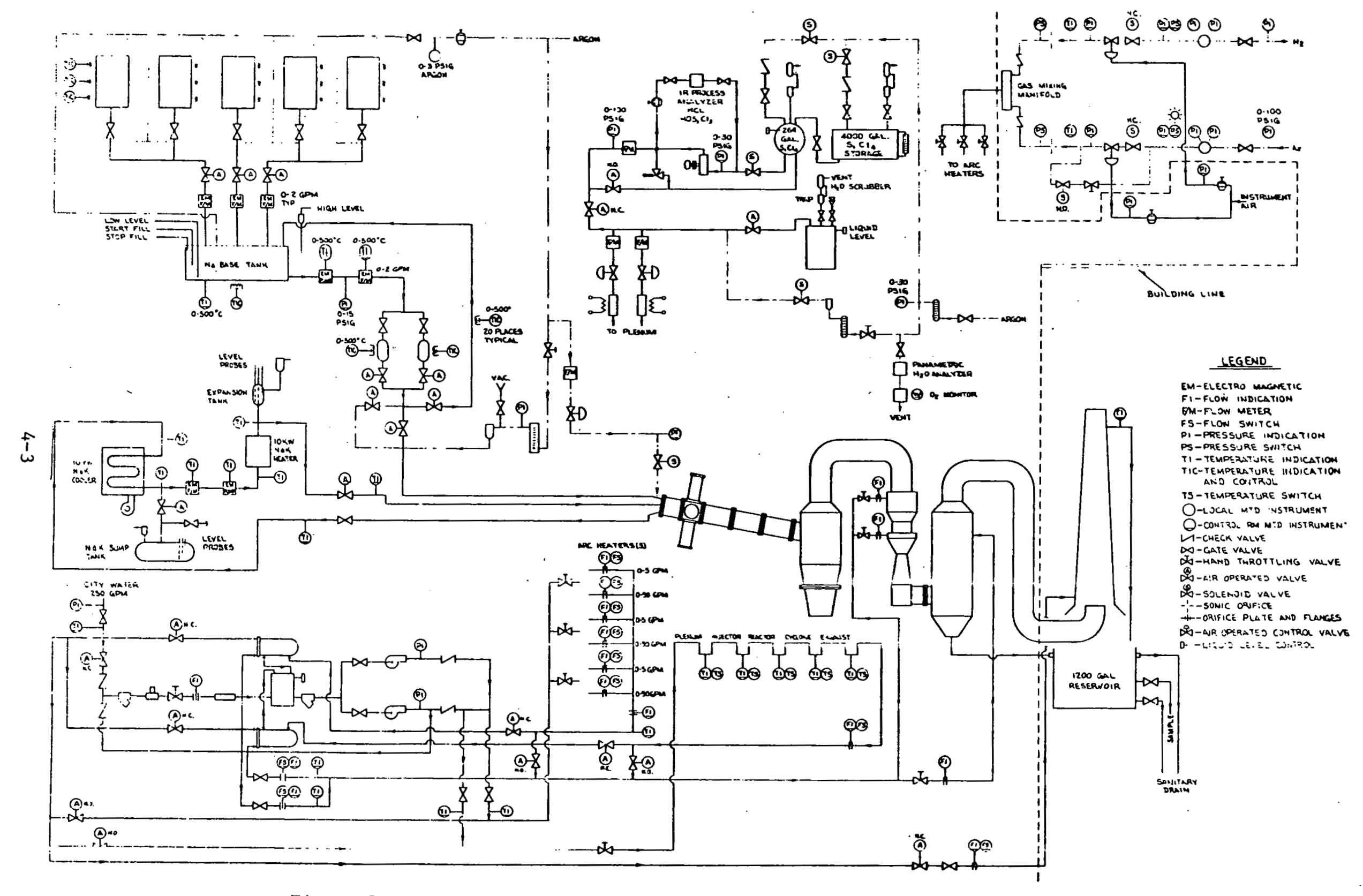

Figure 5.1 - Preliminary Instrumentation And Control Schematic 
An engineering evaluation of the vendors proposal concluded that the oxygen level detector was much more sophisticated than necessary for the intended application. The vendor was requested to submit a revised proposal for a less complex detector system.

The specifications for instrumentation and control components for the other subsystems are in various stages of completion.

During the upcoming quarter, it is planned to complete the specifications for instrumentation and control for all subsystems. As the specifications are completed, the procurement phase for instrumentation and control equipment will be initiated.

4.2.2 Plasma Reactor-Separator (C. B. Wolf, T. N. Meyer, J. R. Meyer)

During the quarter, design and layout drawings for the reactor components were initiated based on the results of the Product Separation Analysis (see Section 9). Initial results of the analysis indicated that the reactor length of 5 meters will be adequate for silicon collection by condensation. The reactor bore diameter will be approximately 15 centimeters.

For silicon separation via condensation within the tubular reactor, the cyclone is not depended upon for product separation. The internal cyclone surface will provide additional condensation area. However, to maximize the particulate or droplet collection efficiency, the cyclone design has been modified. The cyclone design analysis shows that higher inlet velocities and reduced body diameters will collect higher percentages of small diameter particles, but will have a higher overall pressure drop. The design chosen will be approximately $45 \mathrm{~cm}$ inside diameter of liner, and the inlet velocity will be greater than $100 \mathrm{~m} / \mathrm{s}$. Collection 
efficiency will be nearly $100 \%$ for all particles exceeding $4 \mu \mathrm{m}$ diameter. The pressure drop will be less than $0.1 \mathrm{~atm}$.

Preliminary heat transfer analysis of the reactor liner combination of graphite and refractory insulation indicate that by varying the thickness of these components, the inside diameter of the water-cooled shells of the reactor sections can remain constant at approximately $30 \mathrm{~cm}$.

With the results of the separation analysis indicating reactor diameter and length, and having sized the cyclone upon a collection efficiency basis, layout and detailed design are progressing. Figure 4.2 is a preliminary layout of the overal1 reactor assembly mounted on a frame structure. The arc heater plenum and reactor sections are inclined at a $10^{\circ}$ angle. The liquid silicon being continuously collected onto the inner walls will flow into the collector. The arc heater connections are inclined at a $30^{\circ}$ angle to provide for improved mixing of the hot gases. Figure 4.3 is a crosssection layout of the sodium injector mounting. This design provides for axial adjustment of the sodium nozzle by the addition (or subtraction) of refractory liner sections and corresponding adjustment of the retaining studs. Figure 4.4 is a cross-section layout of a portion of the cyclone outlet piping and refractories. The cyclone cover is included as part of this piping. Figure 4.5 presents the assembly drawing of the arc heater design which will be used tior the test system. The downstream portion (shown on left of Figure 4.5) is designed to extend into the plenum inlet to minimize inlet heat losses and reduce insulation requirements at this location Figure 4.6 and 4.7 are preliminary sketches with dimensioning of the arc heater plenum and the cyclone body. Final manufacturing drawings of these and all other reactor components will begin, pending the completion of a material and stress analysis now in progress. 


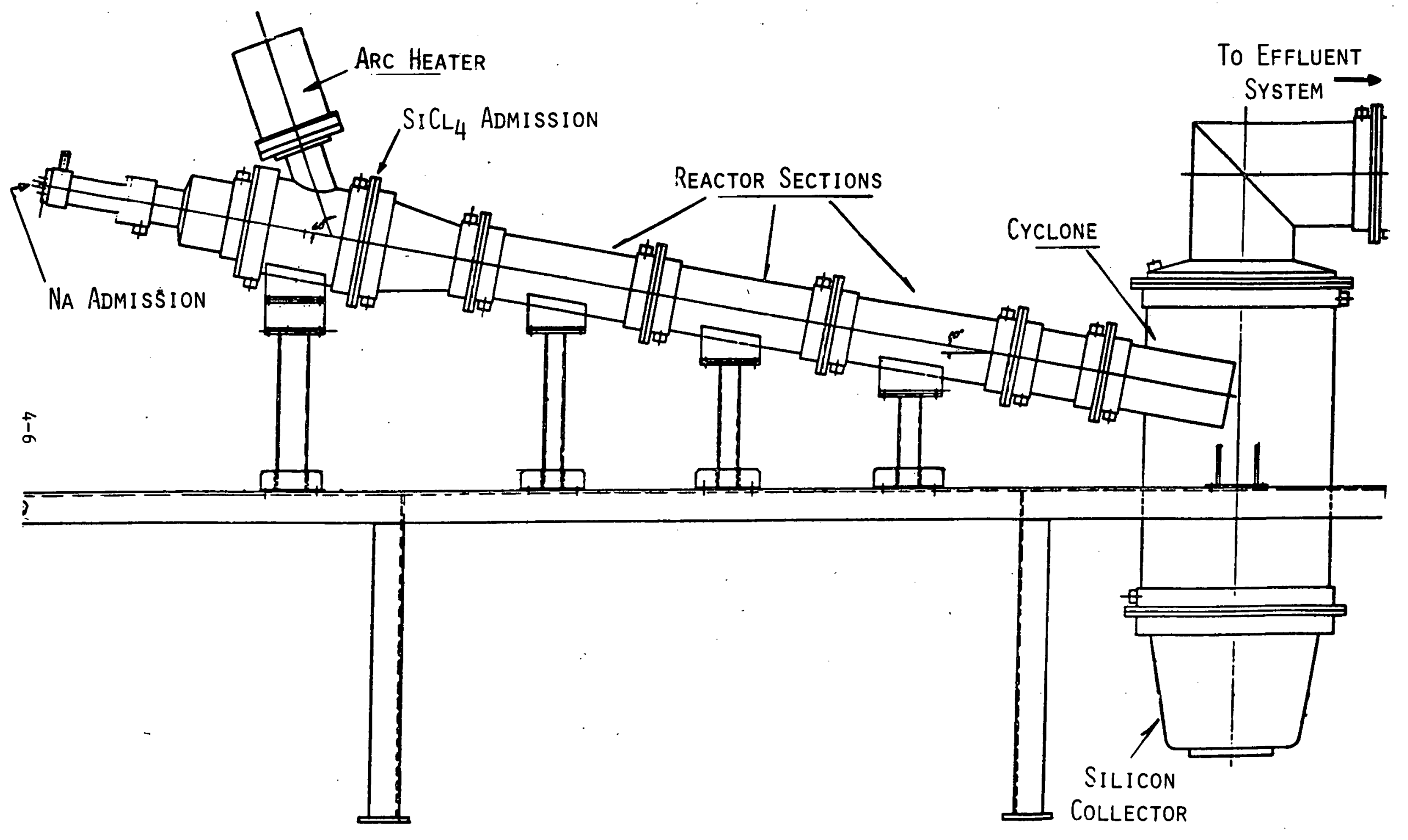

FIGURE 4.2- SILICON PROCESS REACTOR ASSEMBLY 


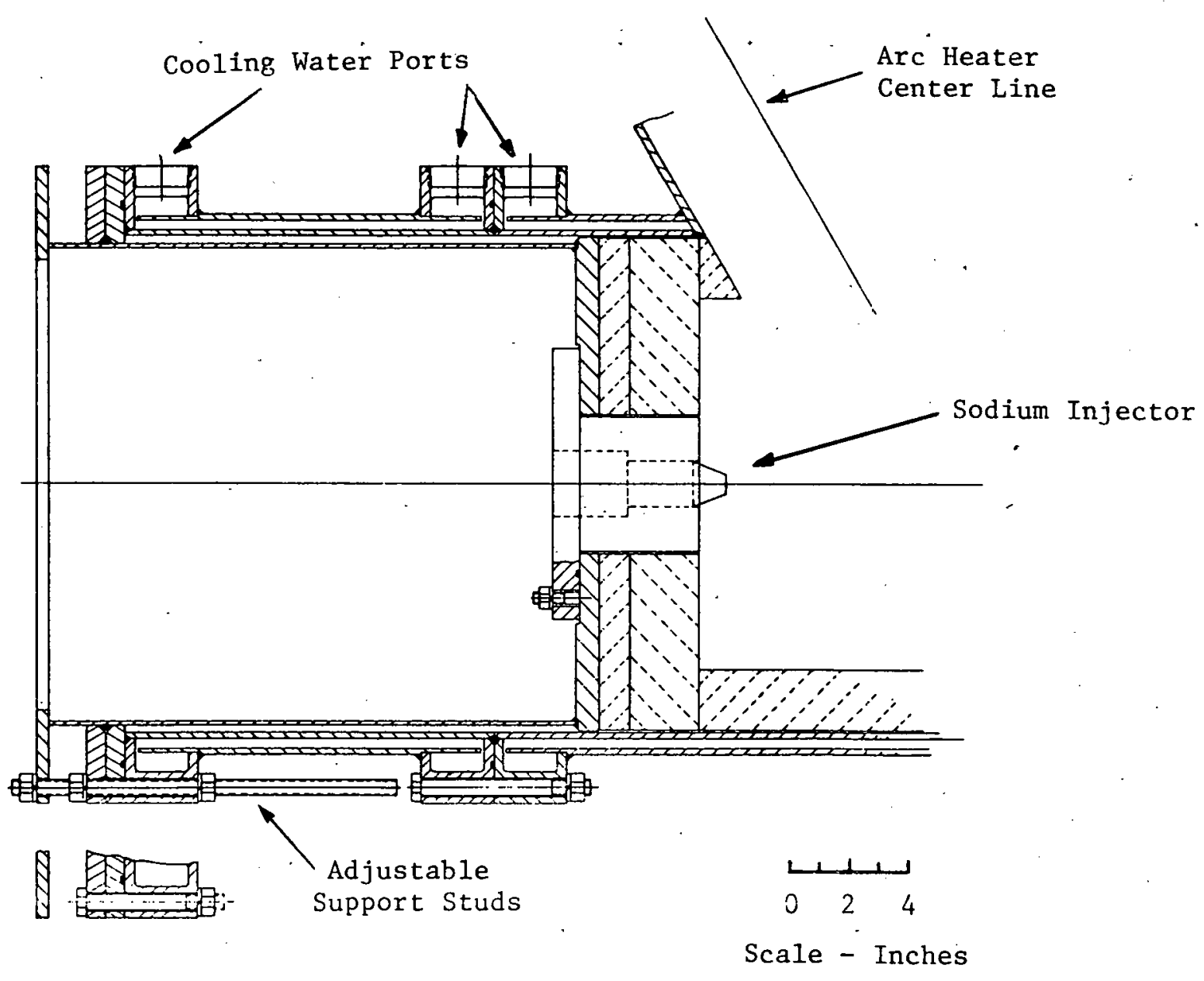

Figure 4.3 - Layout Drawing of Sodium Injector 


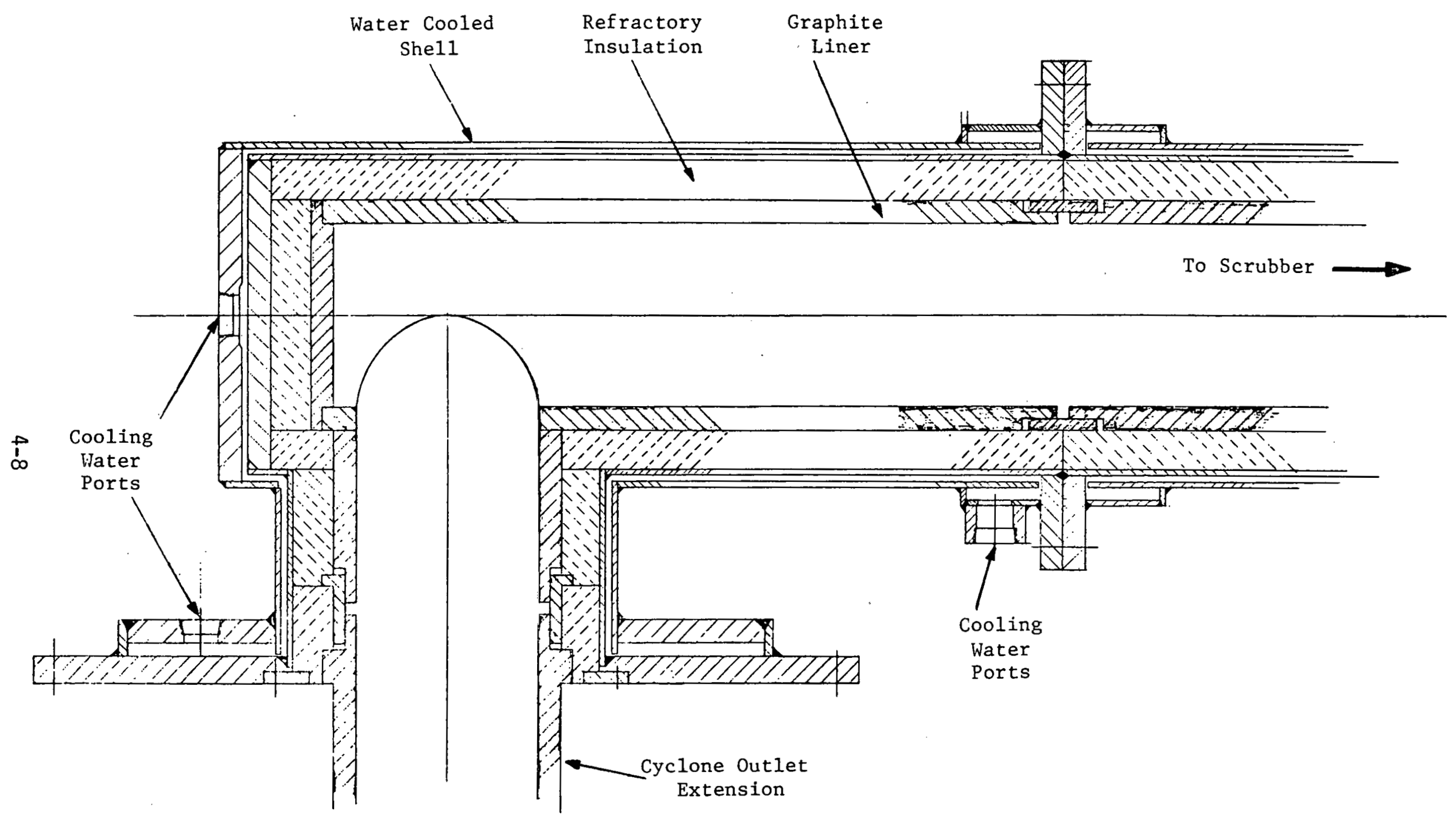

Figure 4.4 - Layout Drawing of The Outlet Piping For The Silicon Cyclone 


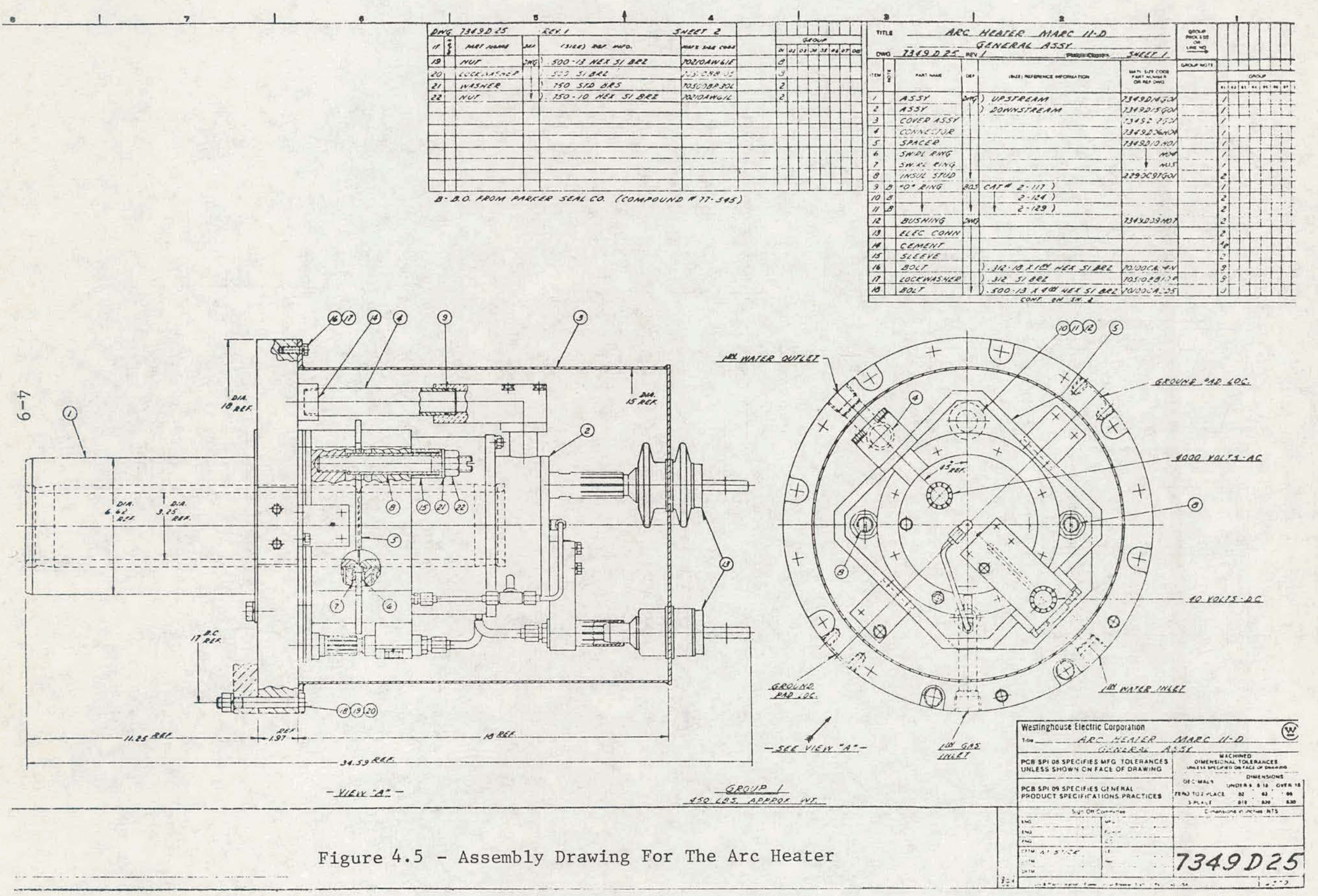




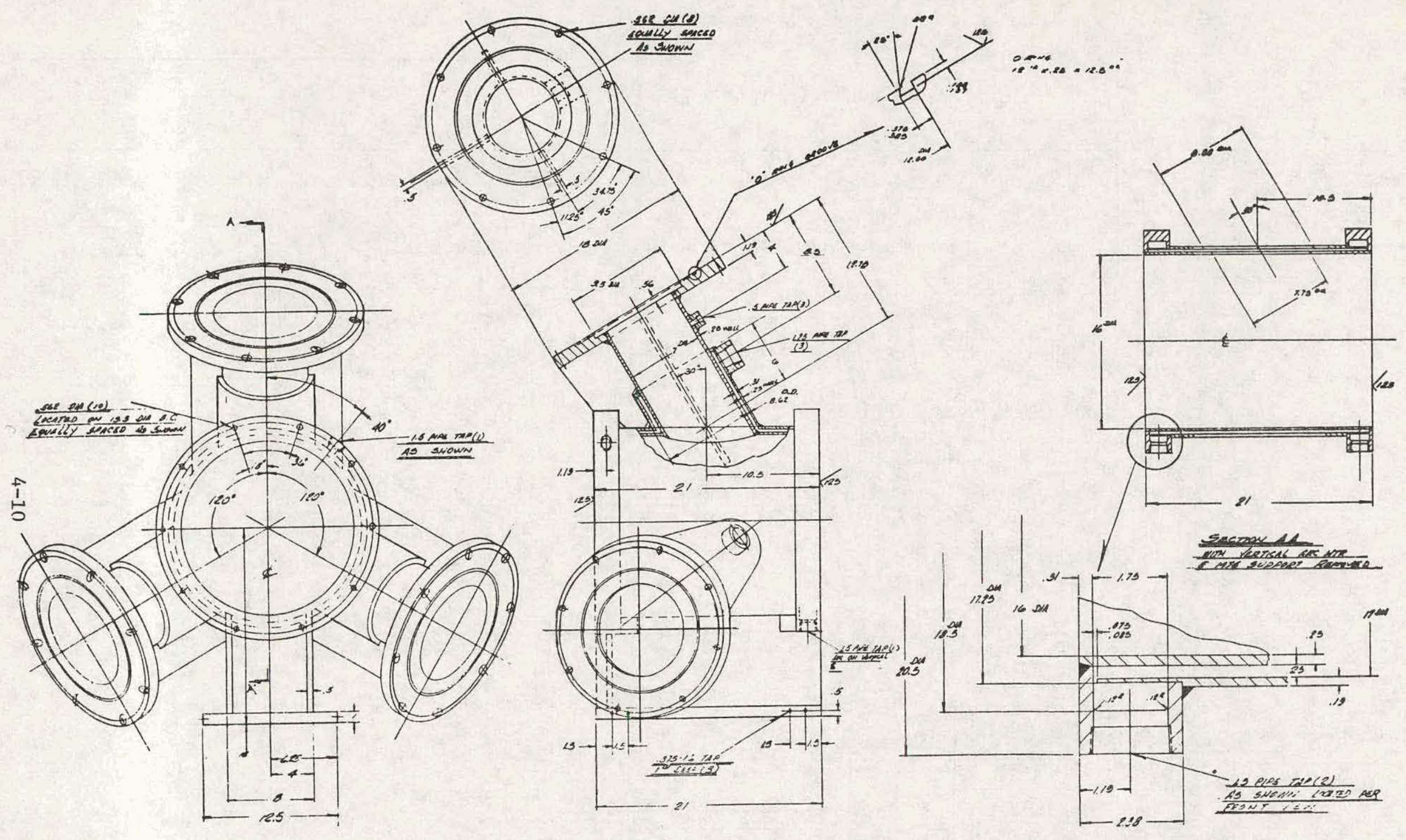

Figure 4.6- Drawing of Arc Heater Plenum 


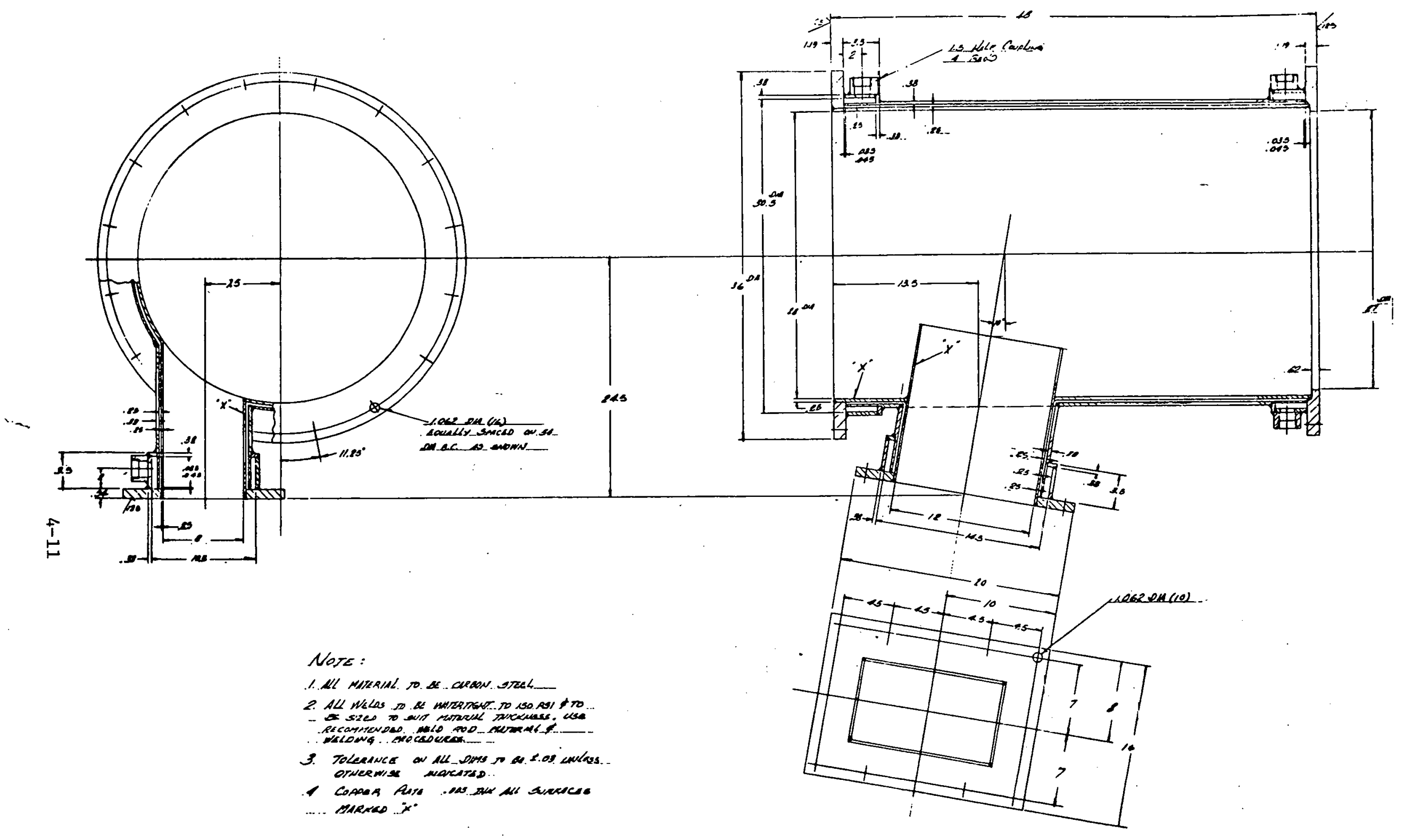

Figure 4.7 - Drawing of Silicon Cyclone Body 
Heat transfer rates and, therefore, material temperature gradients are higher for the presently proposed vapor condensation method of collecting silicon. Prior stress analysis of materials for the heterogeneous (liquid silicon particles) collection indicated that Type 316 stainless steel is a suitable material. Higher thermal stresses for the condensation collection mode may rule out the use of stainless steel. A complete stress and compatibility analysis of all candidate materials is in progress. Materials to be included are stainless steel, Inconel 625, Incoloy 825, Monel 400, carbon steel, copper, aluminum, and nicke1 200. Primary factors which will affect selection are; chemical compatibility, thermal stress, yield strength, buckling stress, availability, and fabricating constraints such as joining and vendor limitations. For improved chemical compatibility of materials, protective platings such as copper or nickel will be considered. For example, if aluminum or carbon steel are found to be superior in other respects, then plating may become a necessity. Chamber material stress calculations include the following 1ist:

1. Radial and axial stresses of outer and inner shells due to internal water pressure.

2. Radial and axial internal. stress of inner shell due to temperature gradient thru the wall.

3. Axial stress of inner and outer shells due to differential thermal expansion.

4. Buckling of inner shell due to water pressure. As mentioned earlier, preliminary calculations of refractory thickness requirements were conducted to determine metal chamber diameters. Early in the next reporting period, detailed analysis of all graphite and refractory components will be completed. Final component design will depend on 
heat transfer properties, thermal stress, thermal expansion, material compatibility, availability, and formability.

Material interface designs are being considered for alignment, containment, and sealing purposes.

4.2.3 $\underline{\mathrm{SiCl}}_{4}$ System (R. E. Witkowski, G. C. Burrow)

The activities for this quarter, as summarized below, were primarily concerned with finalizing the design of the $\mathrm{SiCl}_{4}$ storage and injection system.

- The specifications and engineering drawings for the $\mathrm{SICl}_{4}$ storage tanks were sent to vendors for cost quotations and delivery dates.

- The details of the $\mathrm{SiCl}_{4}$ transfer lines were received from the vendor.

- The final design of the $\mathrm{SiCl}_{4}$ storage and injection loop was completed.

- OSHA and NIOSA safety requirements for the safe handling of $\mathrm{SiCl}_{4}$ were established.

- Three suppliers of room HCl monitors were located and contacted.

- The specifications for the infrared on-1ine process analyzer were prepared for the vendor.

The specifications and engineering drawings, see Figures 4.8 and 4.9 , for the main (4016 gal. capacity) and loop (264.gal. capacity) $\mathrm{SiCl}_{4}$ storage tanks were prepared and delivered to vendors for costing and delivery date information. Quotations were requested for fabrication of 304 or 316 stainless steel or carbon steel with a rubber lining (or other lining compatible with $\mathrm{SiCl}_{4}$ as discussed In the MCA-102 Chlorosilanes Data Sheet). ${ }^{3}$ The Van De Mark Chemical Co., Inc. provided the information necessary to interface the storage tank facility with their $\mathrm{SiCl}_{4}$ delivery 


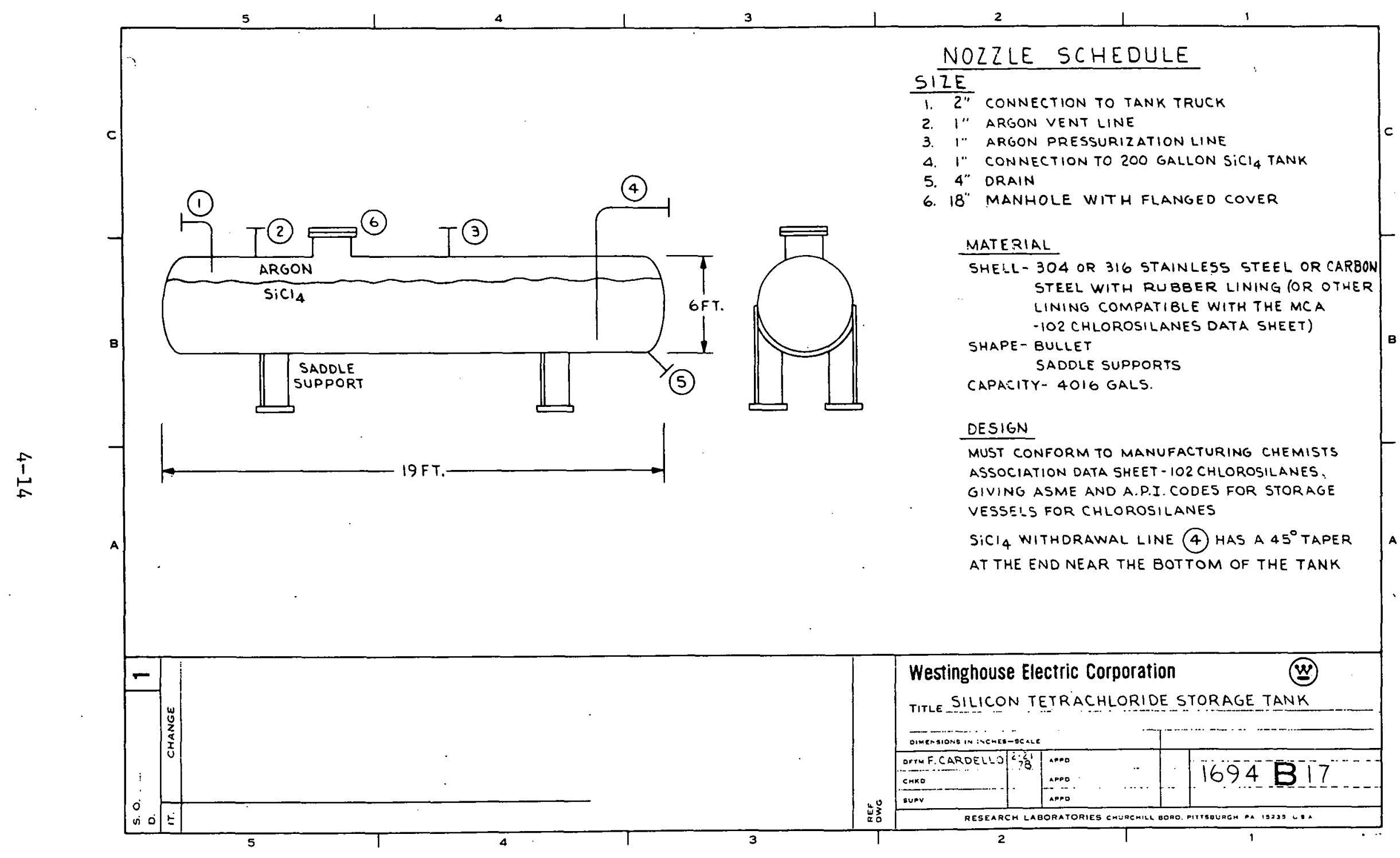

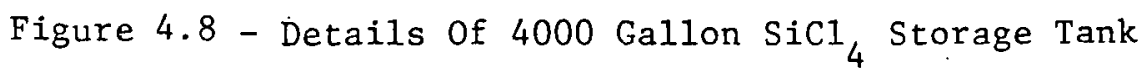




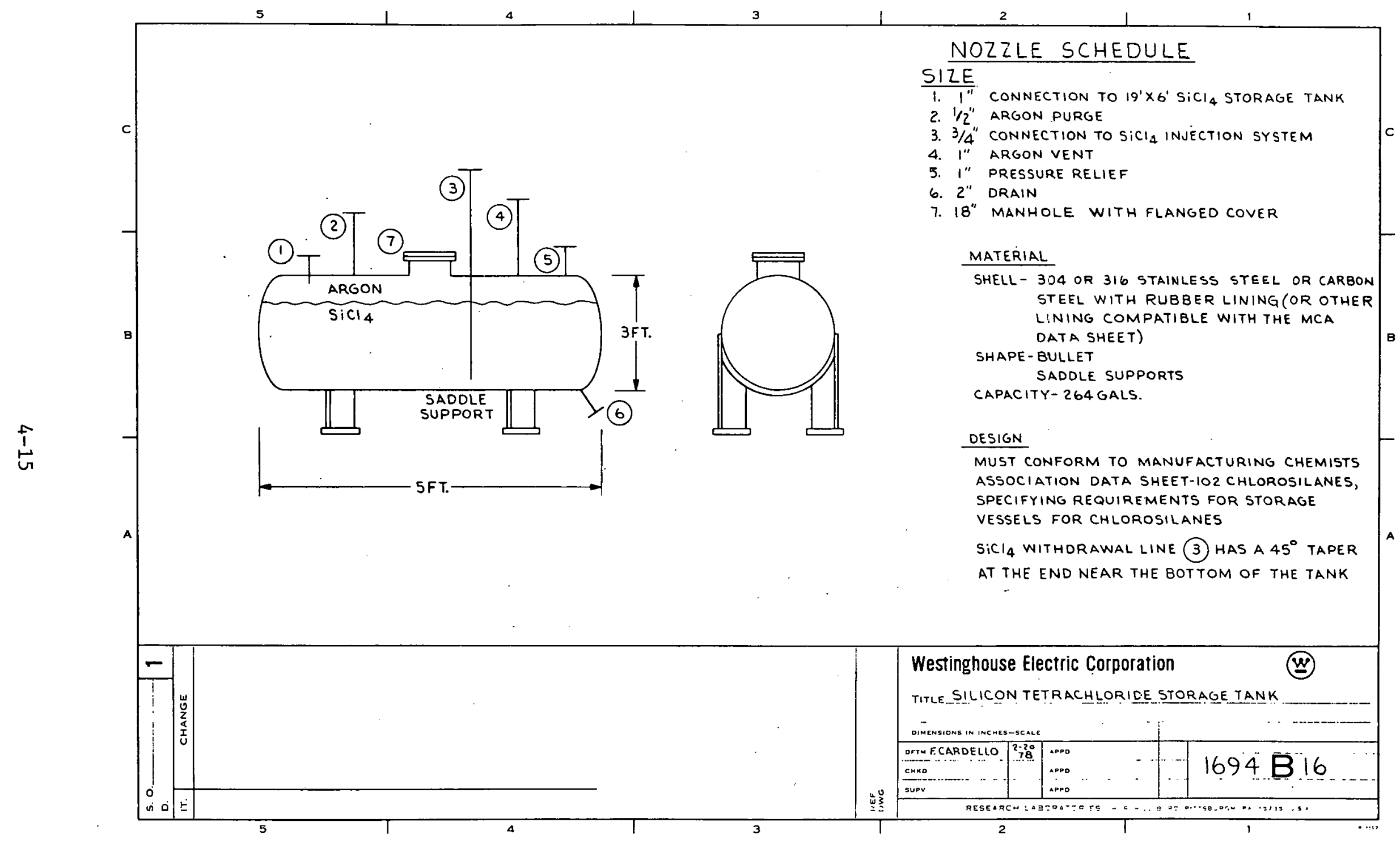

Figure 4.9 - Details of 200 Gallon $\mathrm{SiCl}_{4}$ Day Tank 
tank truck. The truck is equipped with a 2 inch-cast iron companion flange and the dry air (inert gas) padding line is equipped with a $1 / 2$ inch Air-king hose coupling. The maximum pressure required to unload the $\mathrm{SiCl}_{4}$ is $25 \mathrm{psig}$; dry air (at a minimum $-40^{\circ} \mathrm{F}$ dewpoint) or dry nitrogen may be used.

An updated flow diagram was prepared of the $\mathrm{SiCl}_{4}$ injection 1oop (see Figure 4.10) and details of its operation were provided to the Instrumentation and Control. (I\&C) Task.

Discussions were held with the Westinghouse Industrial Hygiene Group concerning the OSHA and NIOSA requirements for establishing and maintaining a safe working environment and appropriate personnel protection. Three potential suppliers for a room air $\mathrm{HCl}$ monitor were located and contacted for information.

The $\mathrm{SiCl}_{4}$ on-line monitoring specifications were detailed for the supplier of the IR process analyzer for the purpose of finalizing instrument operation parameters.

A suitable working area for the storage of components and assembly of the $\operatorname{SiCl}_{4}$ loop was evaluated and acquired.

The selection and specification of all $\mathrm{SiCl}_{4}$ loop components has been completed, purchase requisitions will be issued in the second quarter. Upon receipt of costing and delivery dates from the storage tank vendors, procurement details for fabrication will be initiated. Efforts will continue in preparing $\mathrm{SiCl}_{4}$ loop operational specifications including details regarding shutdown procedures; considering both normal and emergency conditions. Work will also continue on the $\mathrm{SiCl}_{4}$ system user's manual. 


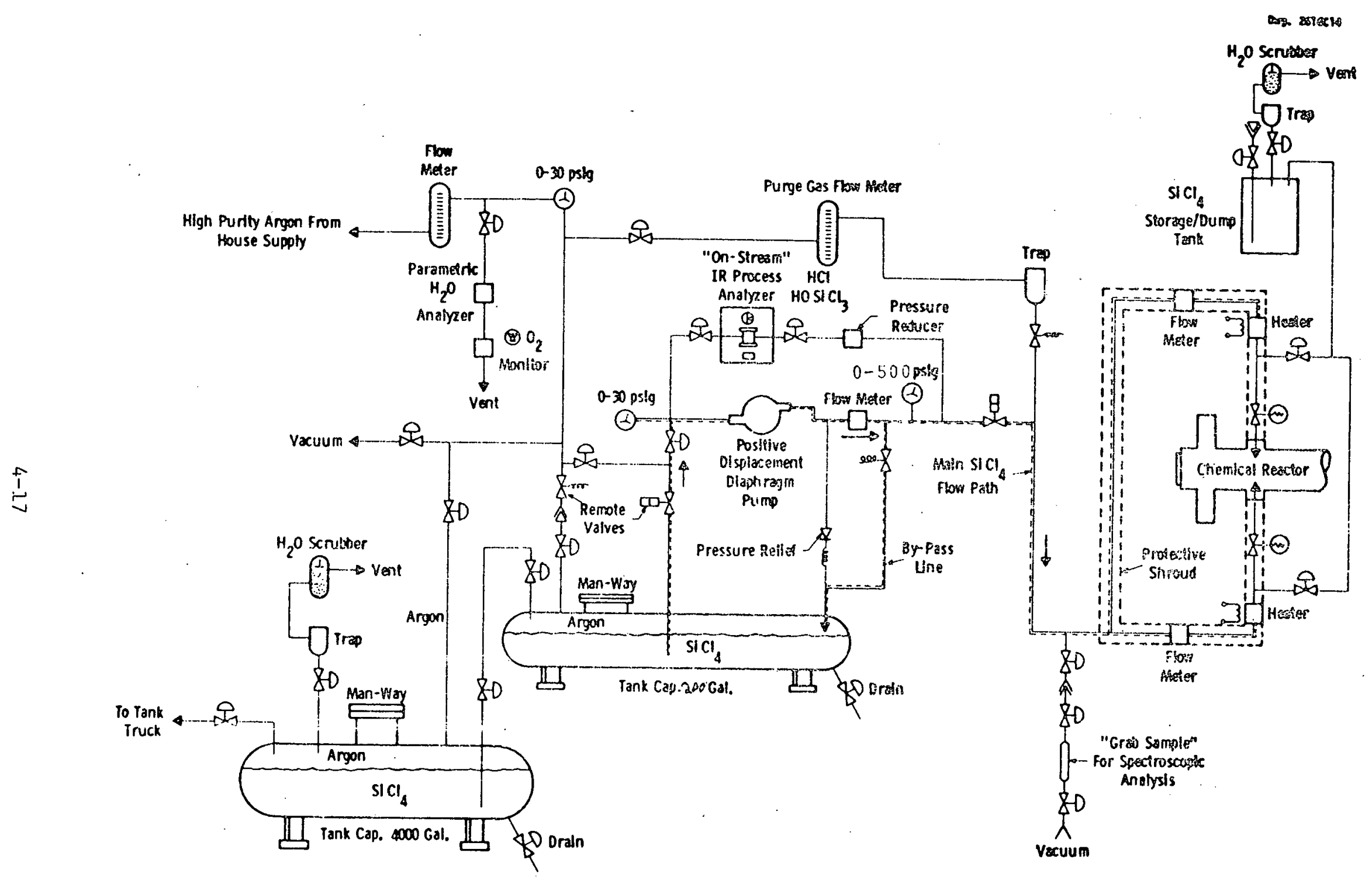

Figure $4.10-\mathrm{SiCl}_{4}$ Fiow system schematic 


\subsubsection{Sodium System (A. R. Keeton)}

Detailed design of the sodium system and the $\mathrm{NaK}$ thermal control loop was completed. Component arrangement and piping layout in the sodium room was finalized. Procurement of long lead components and raw materials for parts fabrication was initiated. Fabrication of the sodium base tank and drum heating jackets was started.

The sodium system schematic drawing was revised and is presented in Figure 4:11. This drawing shows the features of the gravity drain system for emptying the sodium transport drums into the base tank. Operation of the system is described as follows:

A flow path from one of the sodium drums (B) is established to the base tank (A) by opening the proper manual and automatic valves. Sodium is drained from the drum as necessary to maintain the desired sodium level in the base tank. This is accomplished automatically by a level control system (I) in the base tank. Gas pressure is independently controlled in the drums and in the base tank to facilitate draining.

When the active sodium drum is empty a full drum is automatically switched on line. The empty drum is then replaced and the sodium melting sequence is started so that, the replacement drum will be ready for draining when it is required. Thus each drum is drained and replaced individually allowing continuous operation over an extended period of time.

Sodium is pumped from the base tank by electromagnetic (EM) pump (C) through one of the filters (E) and into the plasma reactor. Flow rate is sensed by electromagnetic (EM) flow meter $(J)$ which is part of an automatic sodium flow control system that controls power to the EM pump. Remotely actuated valves provide the capability of recirculating the 
Dug. 1693873

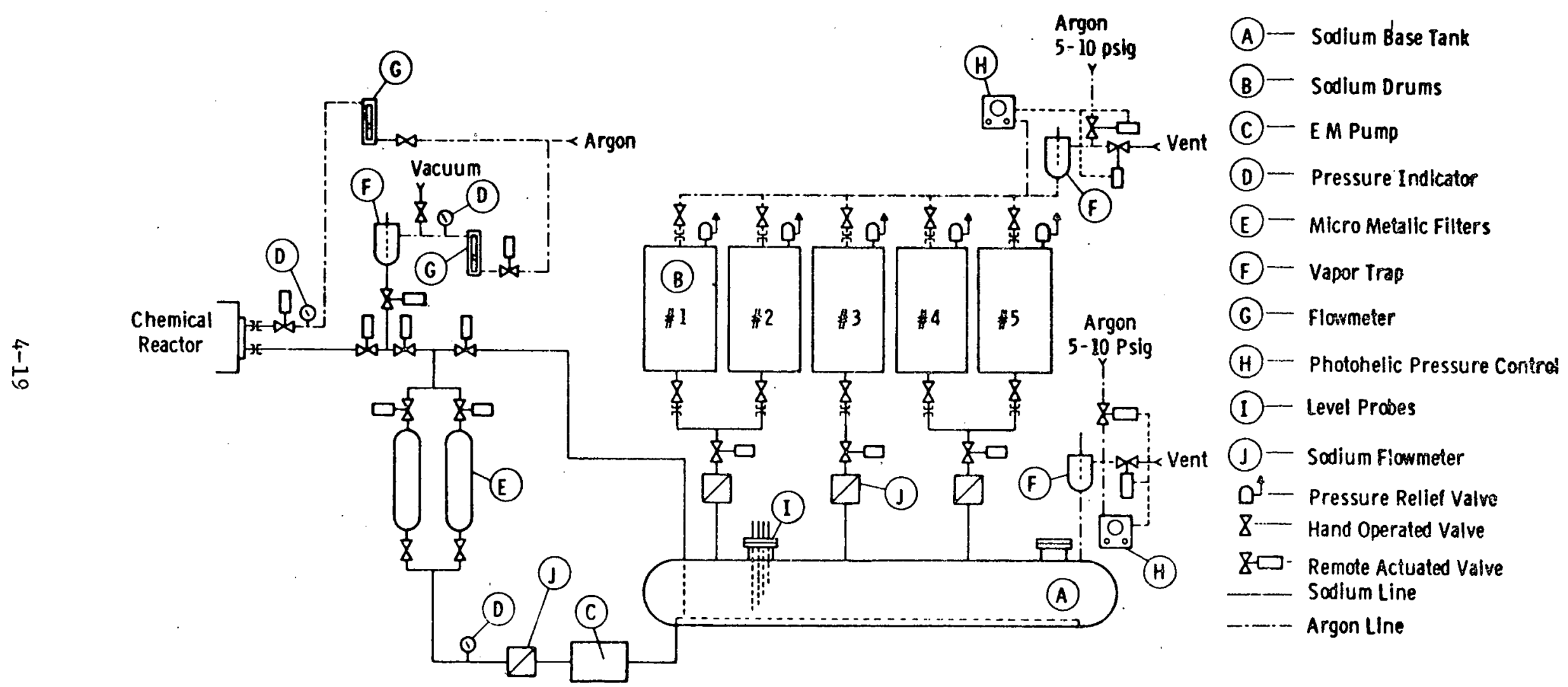

Figure 4.11 - Sodium Supply System Schematic 
sodium back to the base tank instead of into the plasma

reactor. This mode is desirable for startup, shutdown and. checkout of the system.

\subsubsection{Silicon Collection System (I. E. Kanter)}

A substitute insulation material of alumina ceramic fiber is proposed for use to cushion the quartz crucible and along sealing surfaces. A set of preliminary system dimensions have been used to estimate the system weight at $22651 \mathrm{bs}$. The preliminary dimensions were also used to perform a steady state heat transfer calculation assuming free convection at the external surface. This surface is not expected to rise appreciably over $700^{\circ} \mathrm{F}$ whlle molten silicon is in the crucible. A detalled layout drawing of the assembly is under preparation.

A substitute material was evaluated to replace the graphite felt previously planned for use to cushion the fused quartz crucible and along sealing surfaces of the silicon collection system. The reason for the change was due to the fragile nature of graphite felt which could transport impurities throughout the system.

The candidate substitute material is a vacuum formed high-alumina ceramic fiber with an inorganic binder. It is avallable as a moist felt which can be manipulated into Irregular shapes and air dried to a rigid configuration. Type WRP-X material is usable to $2300^{\circ} \mathrm{F}\left(1650^{\circ} \mathrm{C}\right)$. The analytical analysis of the alumina ceramic fiber felts WRP-X-AW, sample "I", and WRP-XA-AW, sample "II", is given in Table 4.1. Although the results indicate high Fe ( 300-500 ppm) content similar to the purified graphite, it is expected that this material will not be subject to widespread dispersal and should, therefore, be acceptable for use. The material will be investigated for use as an insulator elsewhere in the test system. 
Table 4.1 - Spectroscopic Analysis of The Alumina Ceramic-Fiber Felts

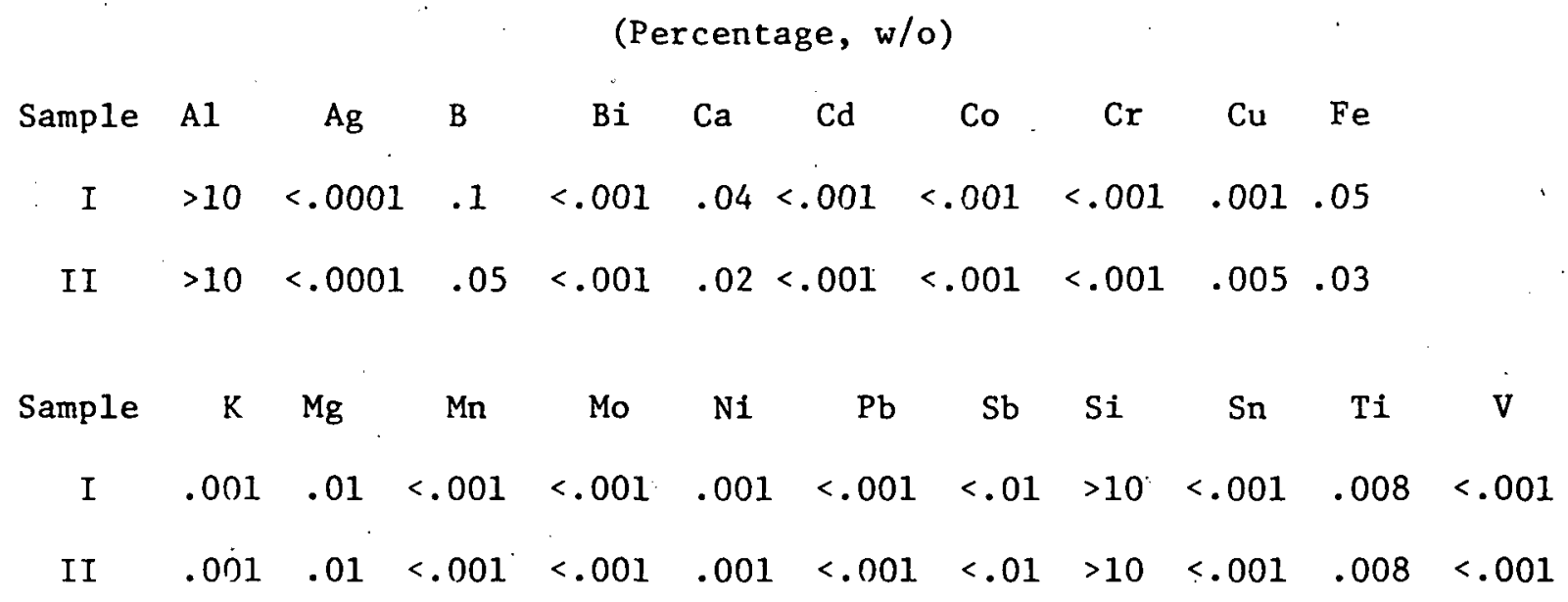

Sample $\quad \mathrm{Zn} \quad \mathrm{Zr} \quad \mathrm{Na}$

I $\quad<.01 \quad .005 \quad .55$

II $\quad<.01 \quad .005 \quad .22$ 
Estimates have been made of the weight of the silicon. collection system components. Using the preliminary dimensions, a total system weight of 2,265 pounds was calculated and broken down as follows:

\section{Component}

Steel housing and support ring

Insulating brick

Graphite crucible

Felt insulation

Quartz crucible

Silicon (full. charge)
Weight

1,155 1bs.

415 Ibs.

345 lbs.

ح 50 lbs.

$\sim 50$ 1bs.

250 1bs.

Total 2,265 1bs.

Stress analysis of the graphite crucible which holds the quartz crucible has been performed to determine the adequacy of the design to hold the $200 \mathrm{lb}$. charge of silicon at temperature. Maximum stresses d due to the bending moment at the bottom corner of the cylindrical wall were determined to be $\sim 2$ psi if the bottom surface is fully supported. This negligible stress implies that only thermal stresses will control the design configuration in this case. Changes will be made in the design to Insure that the bottom surface is fully supported and that the load is not transferred to the upper 11p. Adequate clearances will be provided in the present design and an additional felt layer will be added between the bottom of the graphite crucible and the top layer of insulating bricks.

A dimensional sketch of the collection system assembly has been submitted for preparation of a detailed layout drawing. Cold assembly gaps have been included to prevent interference while at temperature. The elliptical bottom contour for the quartz crucible has been verified by the vendor and incorporated in the preliminary drawing. 
A steady state heat transfer calculation has been made on the collector assembly using the preliminary dimensions. Radial heat flow was assumed with free convection at the collector outer diameter and hot molten silicon $\left(1649^{\circ} \mathrm{C}\right)$ in the crucible. For this case the steel housing will attain a steady state temperature of approximately $700^{\circ} \mathrm{F}$. Residual gaps may drop this value by $\sim 100^{\circ} \mathrm{F}$. An external insulation layer may be applied to prevent a personnel hazard during cooldown.

\subsubsection{Effluent Disposal System (J. W. George, J. McDonald)}

During the quarter, a preliminary design drawing was made of the lined pipe which extends from the silicon cyclone to the effluent scrubber unit. The lining consists of three separate-layered materials. The inside layer is a $2^{\prime \prime}$ thick, 10" (ID) tube of SiC-infused graphite; surrounding the graphite is a $2 "$ thick $75 \%$ Saffil, $25 \%$ Kaowool sleeve. This combination is wrapped in a Fiberfrax blanket and inserted into the water-jacketed pipe. The pipe will consist of two mitered ells, forming a "U" configuration.

A design review meeting was held during February to review the venturi scrubber design. It was noted that the effluent design must be capable of handling full flow of unreacted $\mathrm{Na}$ or $\mathrm{SiCl}_{4}$ for a minimum time to be determined. The liner interface between the cyclone and the effluent pipe must not permit contamination of the product via contaminated material returning to the silicon collector.

The design specification and the information requested with the quotation is given as follows:

\section{Design Specification For The Scrubber}

1. General Description of Process

The scrubber will be used in a process in which $\mathrm{SiCl}_{4}$ and $\mathrm{Na}$ are reacted to form $\mathrm{Si}$ and $\mathrm{NaCl}$. The products 
of the reaction are passed from the reactor to a cyclone in which the $\mathrm{Si}$ is separated out as a liquid. The NaCl, as a vapor, and the carrier gas, $\mathrm{H}_{2}$ and $\mathrm{Ax}$, flow from the cyclone to the scrubber at a temperature of $2300^{\circ} \mathrm{K}$ $\left(3680^{\circ} \mathrm{F}\right)$. The gas composition is as described in 3 below. The gas must be cooled to below $355^{\circ} \mathrm{K}\left(180^{\circ} \mathrm{F}\right)$, and scrubbed to remove the $\mathrm{NaCl}$. An entrainment separator will be used to remove the bulk of the water from the:gas.

This scrubber-separator unit should be designed for use with brine as well as water.

2. Reason For Cleaning The Gas

To eliminate atmospheric pollution and recover the salt ( $\mathrm{NaCl}$ ) for subsequent use or disposal.

3. Composition And Flow Rate of Gas To The Scrubber

$\begin{array}{cc}\text { Gas } & \begin{array}{c}\text { F1ow Rate } \\ \text { SCFM }\end{array} \\ & 187.5 \\ \mathrm{H}_{2} & 150 \\ \mathrm{Ar} & 37.5\end{array}$

4. Total - 375 SCFM @ $32^{\circ} \mathrm{F} \& 30^{\prime \prime} \mathrm{Hg}$

5. Approximate Temperature $-1750^{\circ} \mathrm{K}\left(2690^{\circ} \mathrm{F}\right)$

6. Actual volume $/ \mathrm{min}-2890 \mathrm{cu} \mathrm{ft} / \mathrm{min}$ as of $1750^{\circ} \mathrm{K}$ or . $\left(3680^{\circ} \mathrm{F}\right)$ and atmospheric pressure.

7. The gas upstream of the scrubber can have a pressure of from 0 to 2 psig.

8. State of Contaminate

$\mathrm{NaC1}$ is the contaminate; it enters the scrubber as vapor and is condensed to a solid. The solid must be dissolved in the scrubbing liquid (water or brine). 
9. Particle Size

Submicron to granular,. condensed from the vapor.

10. Amount of Scrubbing Liquid Available

$\begin{array}{ll}\text { Water } & -200 \mathrm{gpm} \\ \text { Pressure } & -75 \mathrm{psig} \\ \text { Temperature } & -120^{\circ} \mathrm{F} \max \end{array}$

11. Material of Construction Requested

Incoloy $825 \ldots$ Incoloy. 825 is used because of its corrosion resistance in the presence of chloride ion.

12. An entrainment separator should be supplied with the scrubber.

Information Requested With The Quotation

1. Sketches indicating (1) the location of connecting pipes, (2) pipe size and (3) overall dimensions of the individual units and their separations.

2. The materials of construction of any items not of Incoloy 825 such as a wire mesh or tower packing.

3. A description of how the hot gas will be introduced into the scrubber without build up on cold surfaces such as water pipes or water-cooled walls; also at wet-dry boundaries.

4. The water flow and water pressure required for each unit of the scrubber.

5. The pressure drops in the gas flow through the scrubber system.

The above design specifications for the effluent scrubber were sent to four vendors; Koch Engineering, Ametek, Croll-Reynolds and Sly Manufacturing. Quotations have been received from three of the vendors with the fourth 
quotation promised for delivery during the first week of April. However, Sly Manufacturing was requested to review their proposal because the cooling water requirement of their scrubber appears to be insufficient to cool the incoming gases $\left(\mathrm{NaCl}, \mathrm{H}_{2} \& \mathrm{Ar}\right)$ from $2300^{\circ} \mathrm{K}$ to $355^{\circ} \mathrm{K}$.

During the next quarter, work will continue on designing a neutralization system for the scrubber water. The design of the pipe liner-joint interface between the pipe from the silicon collection cyclone and the gas scrubber will be completed. A design review will be conducted to evaluate the interface design and the scrubber system including the neutralization system. Suppliers for the scrubber system and the neutralization systein will be selected and the equipment ordered.

\subsection{Test System-Laboratory Integration}

\subsubsection{Electrical System (P. E. Martin, W. J. Melilli)}

Based on the initial design and layout information provided in the fourth quarter of 1977, Plant Engineering has completed most of the electrical power system drawings during the past quarter. As refinements were made in each of the subsystems this initial information was updated during periodic meetings with Plant Engineering.

In genera1, these drawings include electrical equipment layout, distribution panel layouts, cable size and routing, and schematic diagrams.

Figure 4.12 depicts the general electrical equipment arrangement in the Arc Heater facility as per the layout drawings. As shown in this figure, the master control room will house two main system control panels; 1) the silicon test cell and 2) the existing test cell. Power equipment for the silicon process apparatus DC arc heater power supply, 


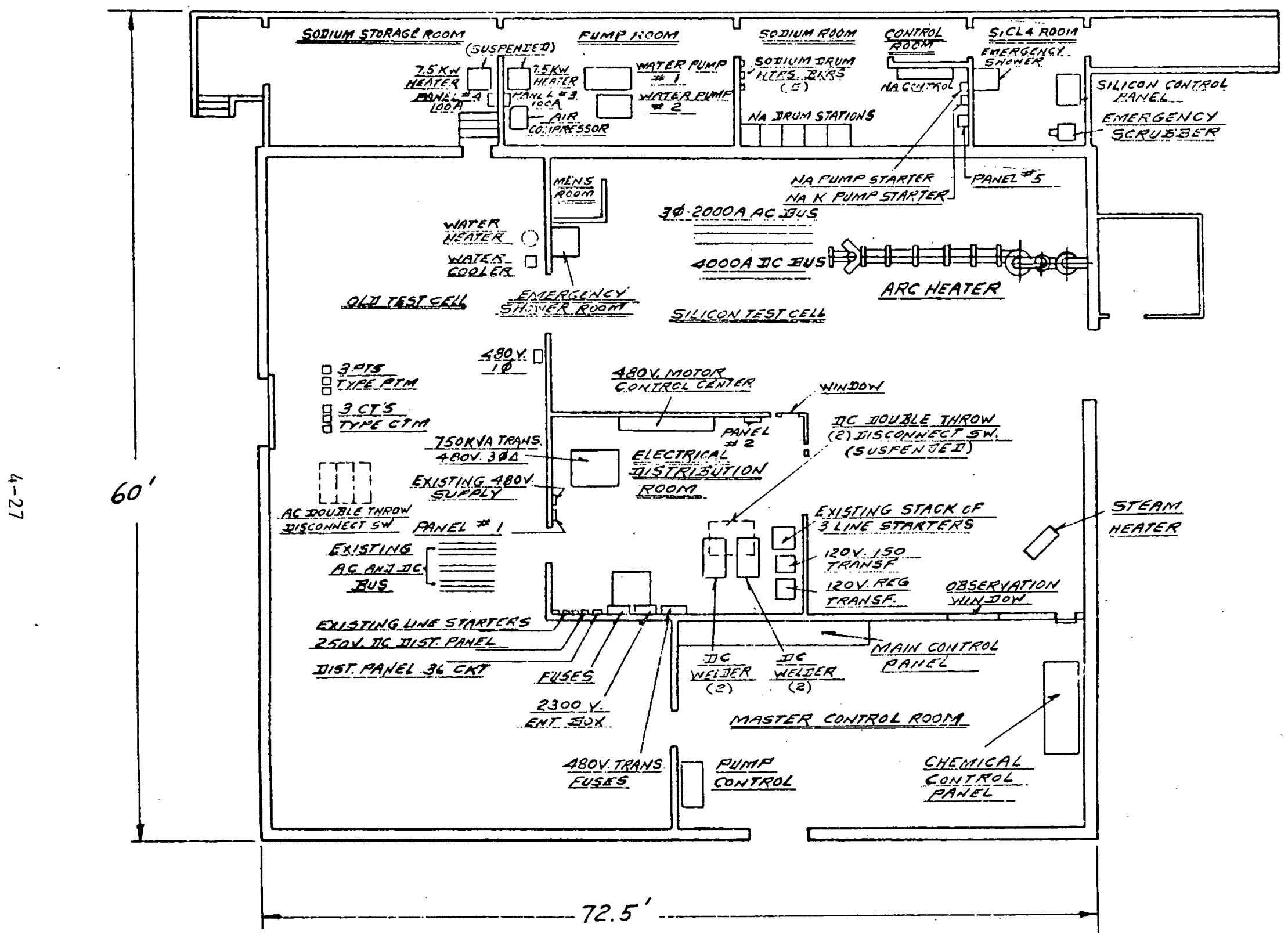

Figure 4.12 - Electrical Equipment Layout For The MX-10 Facility (Arc Heater Test Laboratory) 
distribution equipment and panels are located in the electrical distribution room. The sodium room contains a local control panel and a rack with heaters for the sodium drums. The pump room houses both cooling water pumps and the compressor for instrument air. Various disconnect switches and bus work have been added for distribution of the arc heater power system.

Due to the redistribution of the I.C. arc heater field coils, the original scheme of series/parallel combination of the D.C. power supplies has been changed. The present configuration will use the four supplies in parallel to provide a maximum field coil current of 4000 amps $(45 \mathrm{~V}$ D.C. The power cables for the field current, as well as the A.C. arc heater power, will be routed through enclosed cable trays with ventilation fans in each duct to prohibit gas from collecting around the cables during testing.

A control and interlock scheme has been developed for the heating and ventilation system. This scheme assures the emergency vent system has power available and locks out the normal heating and venting system when the emergency system is manually or automatically energized.

The disassembly of the present control system has been started and the remaining useful circuits have been traced and tagged. These circuits will be consolidated into the existing panels to accomodate the silicon test cell controls. The layout consolidating these controls has been completed with the schematic and connection diagram scheduled to start shortly.

During the upcoming quarter, design and layout work will continue on the electrical control system. In addition, review of component specifications for the control system 
and procurement of long lead electrical items will be initiated.

4.3.2 Gas System: (C. B. Wolf, J. W. George, W. J. Meli11i)

Plant Engineering prepared a laboratory gas piping drawing based on a schematic and layout piping sketch prepared in the previous quarter. This drawing is shown in Figure 4.13. It includes an outline of the building with the routing of the argon and hydrogen lines overlaid on the building plan. Also shown is the location of the argon-hydrogen mixing panel, valve sizes and the air piping.

Several meetings were held during the quarter with representatives of Air Products, a gas system supplier, to discuss the argon-hydrogen system. One of the sessions was held at the Arc Heater Laboratory. At this meeting, a member of their technical staff examined the site and made several suggestions on equipment and storage areas. A sketch and schematic of the gas system was provided to Air Products for further comment. At present Air Products is reviewing this information and preparing design recommendaticns for the gas storage and mixing equipment.

A meeting is scheduled for the early part of the quarter with Air Products to review their recommendations and finalize the facility requirements. Based on these meetings and Air Products design recommendations, the gas system drawings will be revised to include any changes.

After reviewing the requirements for compressed air, it was decided to eliminate the added expense of a compressor with its large volume capability and replace it with a bottled nitrogen system. Most of the pneumatically operated equipment require little gas volume to operate so that, the dry nitrogen system will be adequate and especially 


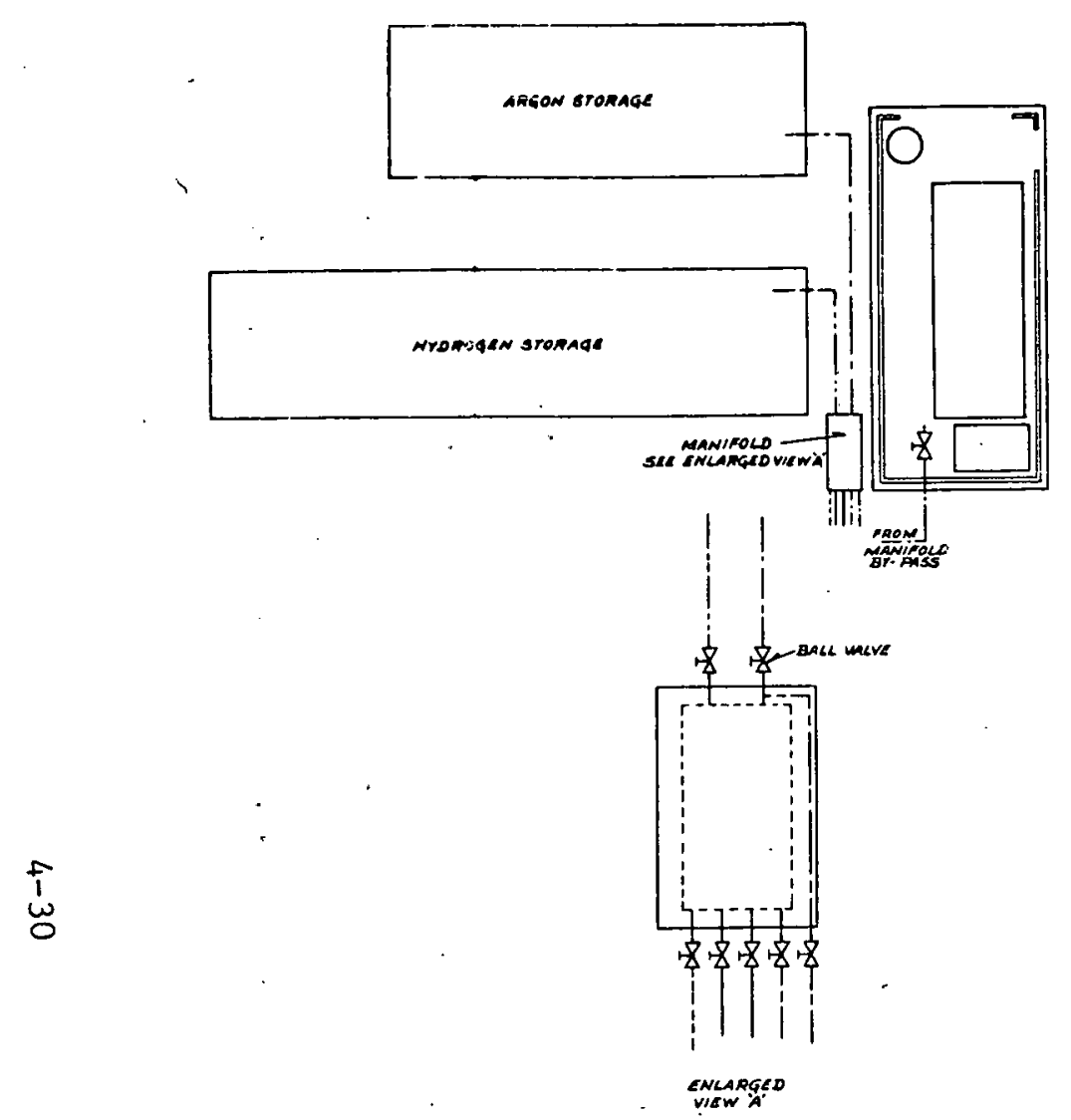

ENG nores

4 ALL WYDROGEN (WG) AND ARGON (N) LINES ARE TO BE

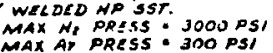

2. MAN MAOCD AAR LINES ARE ROBE 25 \% SST TUBC

3. PLANT ENGRG TO PURNISH BQLL VALVES (I) $\mathrm{N}_{2}$ + (10) AIR

TO BC SUPPLIED BY

S. COMPRESSOR AIR LINES ARE TO BE . S' STL TUBE.

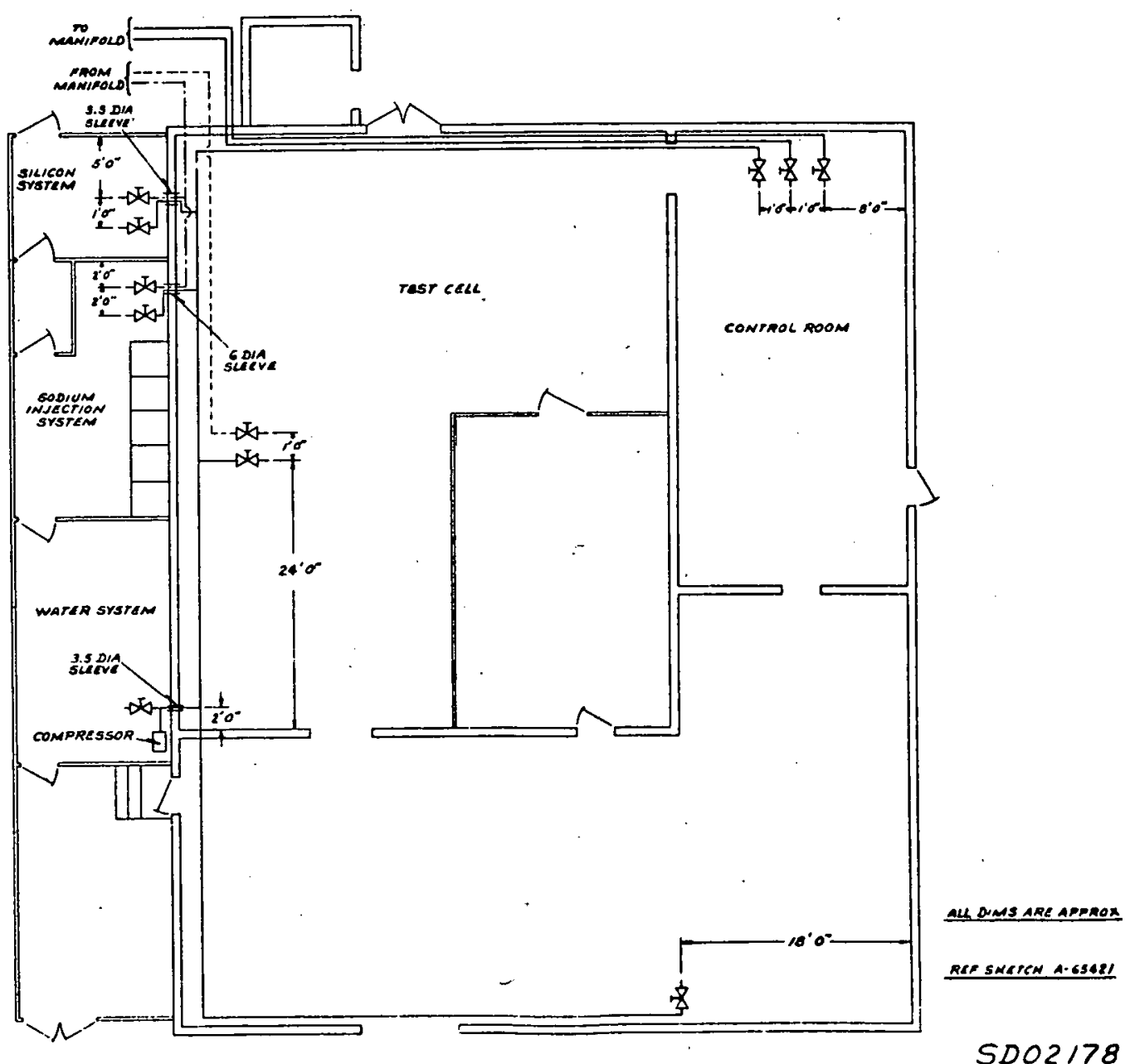

Figure 4.13 - Plan View Of Gas Systems 
suited for pneumatic valve use.

\subsubsection{Cooling Water System (C. B. Wolf)}

The engineering phase of this task is nearly complete. The preliminary water system schematic was distributed to task investigators for review. 'Ihis information was then transferred to a plan view of the silicon test facility (Arc Heater Laboratory) with all water system components schematically shown and located. Included are pipe sizing and flow rate information. A preliminary plan view layout

- of the pump room components was prepared. With these inputs, Plant Service Engineering began, and have nearly finalized complete installation drawings for the pump room and the test cell manifolding.

The Control and Instrumentation task investigators have reviewed the plan view schematic, and are preparing detailed procurement specifications for all the control and instrumentation components. Included are temperature sensing elements, flow measuring devices, pressure sensors and switches, and liquid level controllers.

Similar detailed specifications for the mechanical components such as pumps and heat exchangers will be finalized during the next reporting period. Procurement for the longer lead-time items will begin. In addition, piping materials, valves, and installation materials will be procured which include the surge tank and heat exchanger support frame.

\subsubsection{Gas Burnoff Stack (C. B. Wolf)}

As described in the previous Quarterly Report, the gas burnoff stack is a water-cooled vertical-exhaust pipe supported by an iron structure over a waste water reservoir at the base. ${ }^{2}$ The bore diameter required was determined by estimating the area required at the inlet for natural 
convection admission of combustion air to be admitted at a rate of at least $200 \%$ excess. The reservoir at the base of the stack serves as a holding tank for both effluent system water and stack cooling water. Drawings of the stack are complete. Plant Service Engineering drawings of the stack base are near completion but, approval is delayed pending the requirements of the waste water treatment system. For example, the holding capacity may have to be increased to provide longer residence time of waste water.

Plans for the required stack igniter system are in progress; considerations include type (gas torch or electrical spark), flame detection, and safety circuitry. 


\section{TESTING}

\subsection{Task Description}

As a task of the Phase II program, a series of tests will be conducted to establish and verify the process reaction for the arc heater-sodium reduction of $\mathrm{SiCl}_{4}$ to produce liquid silicon. The verification test system that is designed, fabricated, assembled and installed at the Arc Heater Laboratory located at the Westinghouse East Pittsburgh Site will be operated to produce silicon on an experimental basis. This test system has been described in the previous section (Section 4).

Prior to system operation each subsystem (i.e., arc heaterreactor, $\mathrm{SiCl}_{4}$ system, $\mathrm{Na}$ system, gas system, etc.) will undergo shakedown operations. The initial series of tests to produce silicon are entitled shakedown tests which will develop operating data, procedures optimization, and produce silicon for preliminary purity evaluation. The final series of verification tests are defined as demonstration tests which are.intended to produce silicon and test data for evaluation of the process. This test series for verification of the process are scheduled to be conducted in the November, 1978 through February, 1979, time frame with appropriate data reduction, system evaluation, and results being compiled during and after the test phase. 


\section{INJECTION TECHNIQUES}

Task Investigators: M. G. Down, J. Bauerle, A. R. Keeton, F. J. Harvey

\subsection{Summary}

Fabrication and assembly of the sodiun injection chamber continued throughout the reporting period. Nozzles have been procured for sodium and silicon tetrachloride injection, and preliminary testing with water has been initiated. Methods of particle size measurement have been estimated; sieving and inertial impaction have been identified as the most appropriate techniques for this task.

A detailed test plan (see Appendix A) for the task has been compiled and approved by a review meeting of Westinghouse. staff both from the R\&D Center and PCB.

During the next quarter the final stages of assembly will be completed and sodium injection phase of the nozzle testing commence. In parallel with this, water testing will be continued using high speed video recordings and strobe photography to determine measurement parameters for the analytical equipment. Work will continue on the design and assembly of the silicon tetrachloride and coinjection systems for use with the test chamber.

\subsection{Work Description}

Fabrication of the stainless steel test chamber for sodium and silicon tetrachloride injection studies is almost complete. Several aspects of the system design have been given detailed attention since the previous quarterly report. These include the design and construction of a heater for preheating the nozzle gas and thereby preventing premature freezing of the sodium. Also the flow of both argon and liquid sodium will be controlled by fast acting-electrically operated valves linked to a programmable controller to enable the accurate control of short injection bursts. The output potential from the sodium flow meter will be 
recorded on a high speed (160 inches per second) chart recorder to provide a detailed flow profile for short duration (1 second) injections. The sodium storage tank, Figure 6.1, has been fabricated and leak tested. The tank is constructed from type 304 schedule 10 stainless steel (24" $\times 6^{\prime \prime}$ ) and is designed to provide a minimum liquid sodium pressure of 14 psi plus line losses at a flow rate of 100 gallons per hour. It has a capacity of 3 gallons and incorporates 2 level-probes for detecting when the tank is completely full or empty.

Control consoles are being constructed for the monitoring and adjustment of the sodium and argon heaters, flow meter outputs and thermocouple voltages (11 in a11).

Stainless steel test nozzles have been procured for both silicon tetrachloride and liquid sodium injection tests. The former is a hydraulic atomizing nozzle (Spraying Systems Co. $1 / 4 \mathrm{LN}-\mathrm{D} 6$ ) with a capacity of $13.4 \mathrm{gph}$ at $200 \mathrm{psi}$ and $16.5 \mathrm{gph}$ at 300 psi. For 1iquid sodium injection a sonic atomizing nozzle has been chosen for testing which is shown in Figure 6.2. This nozzle utilizes a field of sonic energy to accomplish liquid atomization. Advantages over conventional air atomization are large orifice diameter which will reduce the likelihood of blockage, and a high liquid flow capacity while maintaining small spray particle size. The selected nozzle (Type 312T, Sonic Development Corporation) can operate at $100 \mathrm{gph}$ liquid and 36 SCFM gas, a liquid to gas mass ratio considerably higher than that of more conventional air atomizing nozzles. 4,5

While the manufacturers claim that this nozzle produces an extermely fine spray, they are unable to provide detailed particle size data. It is, therefore, the chief aim of this task to fully characterize nozzle performance and to this end, preliminary testing has been initiated using water as the spraying fluid. 


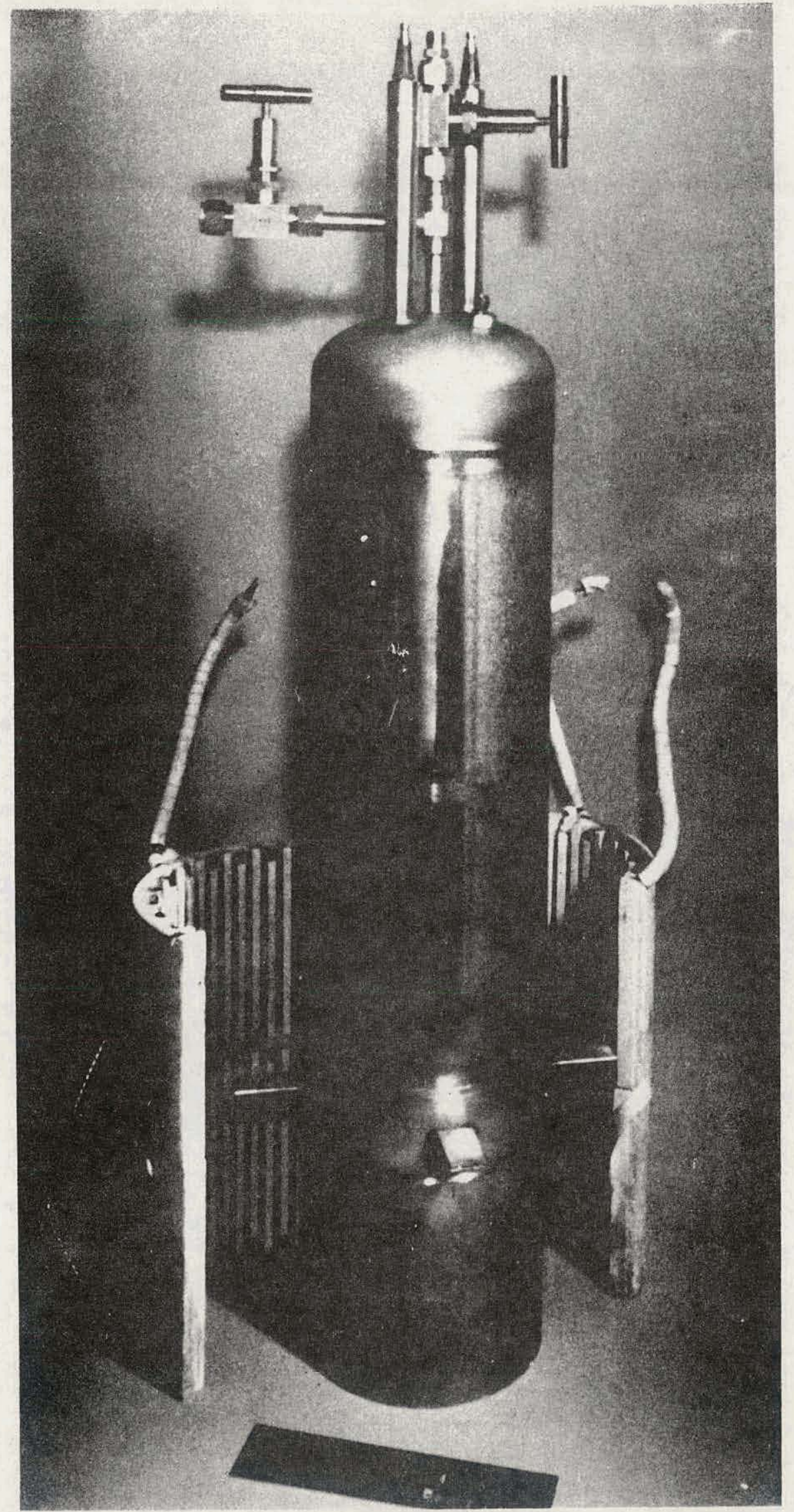

Figure 6.1 - Photograph of The Sodium Storage Tank 6-3 

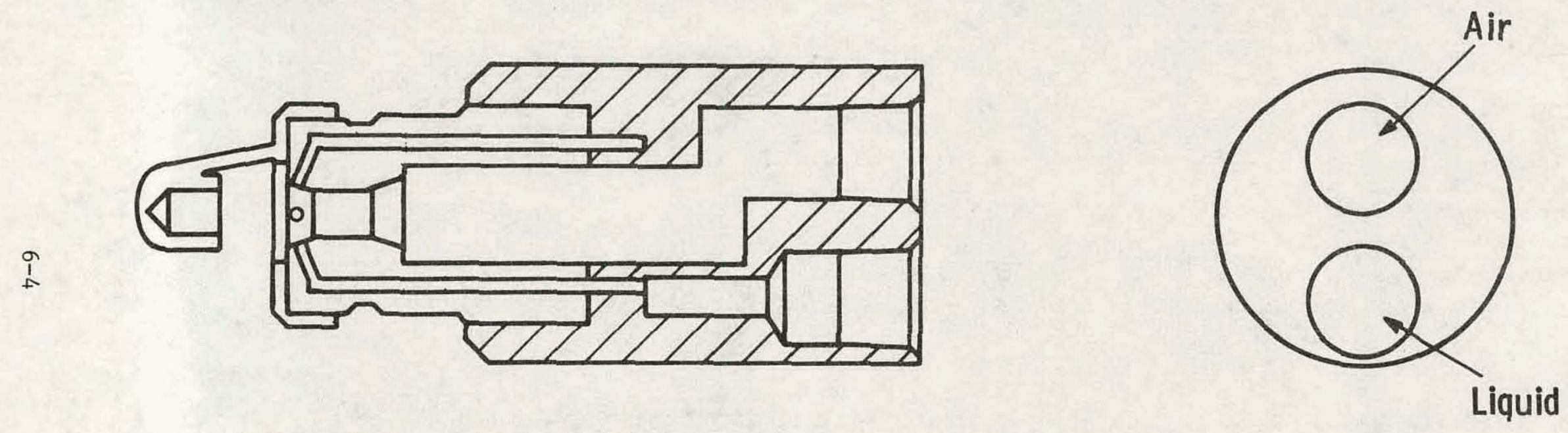

Fig. 6.2- Schematic of sonicore 312 nozzle 


\subsubsection{Particle Sizing Of Sodium Droplets Collected From The} Injection Tests

It is important that the droplets generated by the sodium injection system be quite small, i.e., less than 100 microns in diameter.

Four techniques for size distribution determination were considered and were discussed with Westinghouse $R \& D$ personnel having actual experience with the techniques:

- Microscopy (plus T.V. image analysis)

- X-ray sedimentation

- Cascade impactor separation

- Sieving

Figure 6.3 gives an indication of the particle size ranges appropriate for these methods. Brief discussions of the essential characteristics for each technique follow:

\section{$\underline{\text { Microscopy }}$}

In this technique the sodium particles are dispersed in a liquid, and a sample placed on a slide under a microscope. The particle size distribution is then determined automatically by a T.V. camera (coupled to the microscope) plus a processor which analyzes the pulses in the T.V. scans.

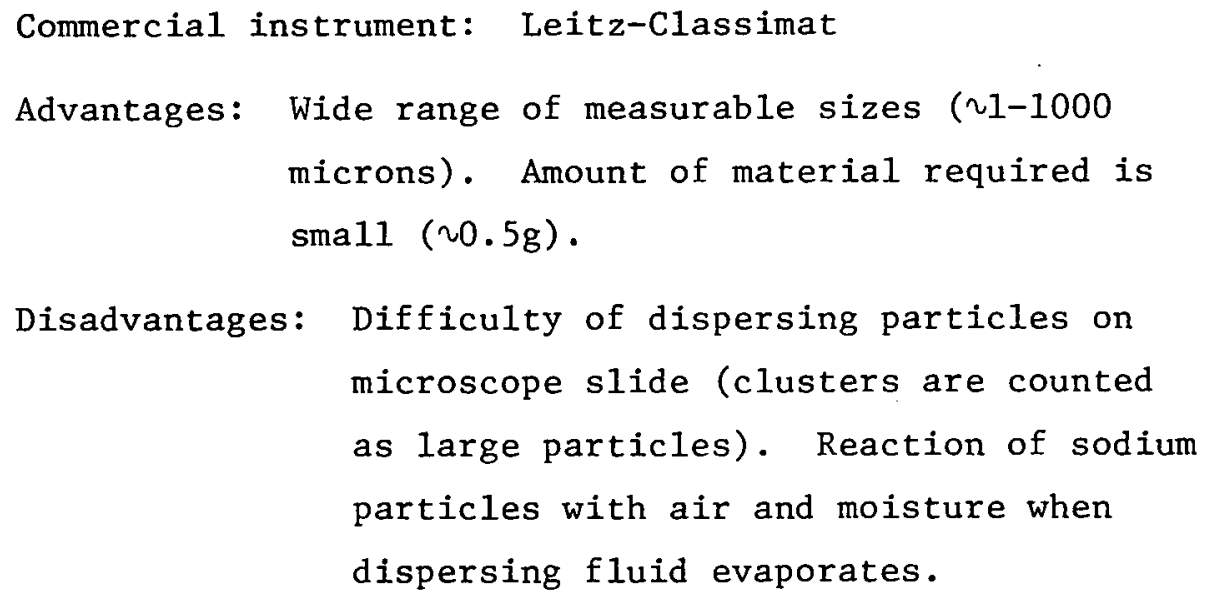


Dwg. 6434A55

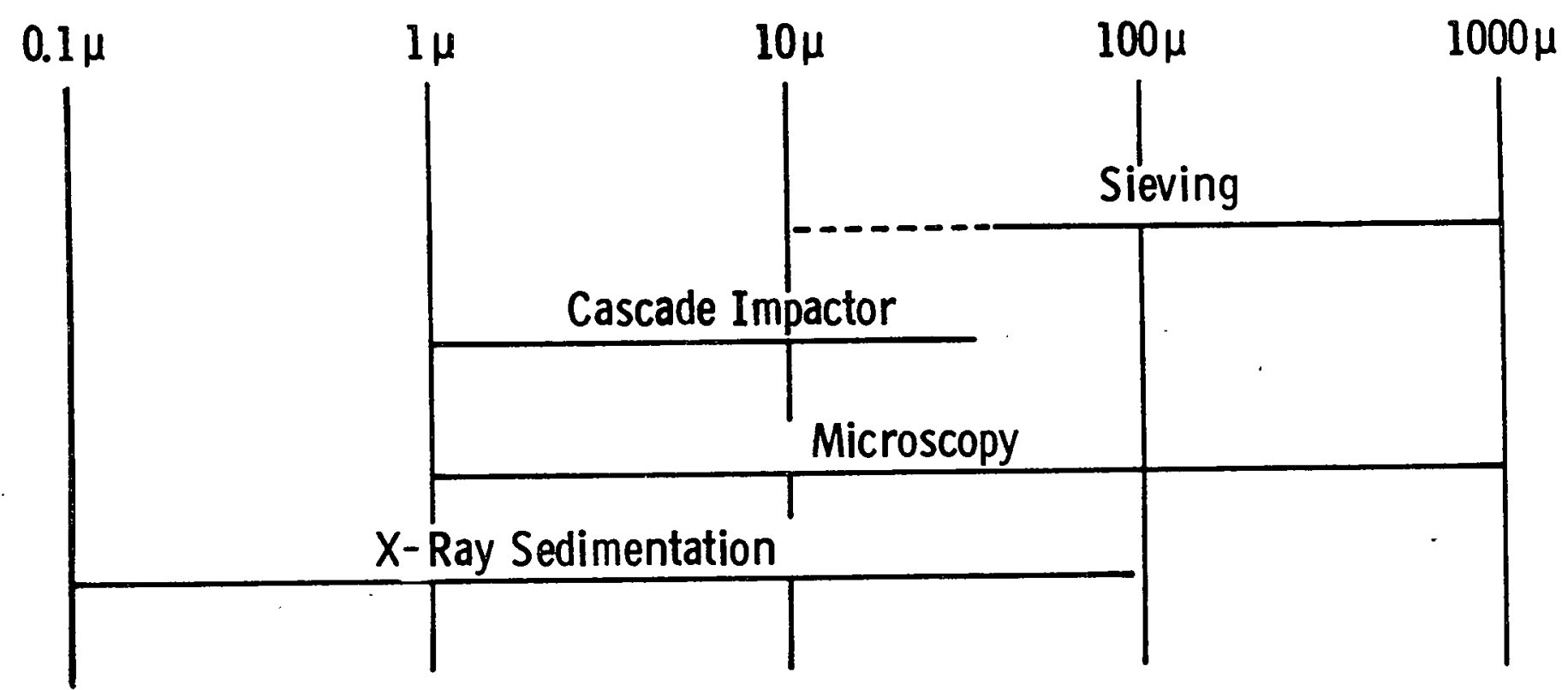

Fig.6.3- Particle size analysis ranges 
X-Ray Sedimentation

In this technique, the sodium particles are dispersed in a liquid of appropriate density and viscosity and placed in a flat vertical cell. A beam of soft $x$-rays traversing the cell is used to monitor the mass of particles in the cell at a given position, as a function of time. The rate of settling of the particles is used to determine the particle size distribution; this is automatically calculated by the instrument and recorded graphically.

Commercial instrument: Micromeritics Sedigraph 5000D Particle Size Analyzer

Advantages: Automated operation and recording of results. Disadvantages: Agglomeration of particles can produce erroneous results. Large amount of particle material is needed $(5-10 \mathrm{~g})$. Peristaltic pump used in instrument may deform clusters of soft metal particles. Upper size measurement limit is low (50-100 microns).

\section{Cascade Impactor}

This technique differs from the previous ones in that it would employ direct sampling of the sodium aerosol generated in the sodium injection test chamber. The cascade impactor is a multi-stage, inertial separation device. Each stage contains orifices and a collection plate toward which aerosol flow from the orifices is directed. The size of the particles which impact on the collection plate of a particular stage depends on its aerosol flow velocity (determined by orifice sizing). Weighing the individual collection plates enables one to obtain the size distribution of material collected. 


$$
\begin{aligned}
& \text { Commercial Instrument: } \begin{array}{l}
\text { Sierra } 226 \text { Source Cascade } \\
\text { Impactor. }
\end{array} \\
& \begin{aligned}
& \text { Advantages: } \text { Direct collection and sizing from sodium } \\
& \text { aerosol generated in the injection test. }
\end{aligned} \\
& \text { Disadvantages: Upper size limit of particles collected } \\
& \text { is too low (15-30 microns). Time- } \\
& \text { consuming procedure. }
\end{aligned}
$$

\section{Sieving}

Sieving is a well-known technique which employs a series of wire-screen separators of decreasing size plus some type of mechanical agitation to effect the particle separation. The size distribution is then obtained by weighing the separated fractions. For sodium droplet sizing the entire procedure, of course, would be carried out in the inert atmosphere of a glove box. Refinements in sieving technique which may be useful for this work are: sonic, or ultrasonic agitation; wet sieving methods employing a carrier liquid; and the use of special ultra-fine sieves (5-50 microns).

Commercial apparatus: $\begin{aligned} & \text { Fisher Scientific Co., stainless } \\ & \text { steel sieves (37-1000 microns), } \\ & \text { nickel mesh sieves (5-50 microns), } \\ & \text { various types of agitation } \\ & \text { equipment. }\end{aligned}$
Advantages: Flexibility in choice of size range
(5-1000 microns). Particle size in terms
of mass percent obtained directly. Small
amount of material required ( $1 \mathrm{lg})$.
Possible problem of particle clustering
or adherence to sieves (alleviated by
wet sieving). Time-consuming procedure.


From the four techniques discussed above, sieving has been chosen as the primary method for determining sodium droplet sizes. The features which make it attractive are directness, reliability, and flexibility for covering different ranges of size. At this time it appears that the distribution of particle sizes in the range of 50 to 200 microns will be critical in determining whether the subsequent evaporation and reaction processes take place efficiently. Sieving methods should be nearly ideal for this range. If it becomes essential to obtain detailed information on the particle distribution for sizes less than 30 microns, the cascade impactor technique would be added.

\subsubsection{Sodium Droplet Freezing In The Sodium Injection Tests}

In order to collect the droplets generated in the sodium injection tests for size analysis, they must be frozen before contact with any test chamber surface. The particles will then settle to the bottom of the chamber where the collection system, Figures 6.4 and 6.5 is 1ocated.

A minimum condition for freezing the sodium droplets is that a suitable overall heat balance be achieved. The injection conditions assumed are that $1.5 \mathrm{gpm}$ of sodium at $150^{\circ} \mathrm{C}$ and $35 \mathrm{SCFM}$ of nitrogen at $150^{\circ} \mathrm{C}$. A calculation shows that $24.6 \mathrm{~kW}$ of cooling power would be required to achieve this final condition.

Continuous operation of the injector under these conditions might be achieved by continuously flowing precooled gas through the injection chamber to supply the necessary cooling; however, this would require 263 SCFM of nitrogen at $-100^{\circ} \mathrm{C}$ or $160 \mathrm{SCFM}$ of nitrogen at $-196^{\circ} \mathrm{C}$. Cooling on a continuous basis thus appears impractical, not only because of the large volumes of precooled nitrogen required, but also because essentially all of the sodium aerosol generated 


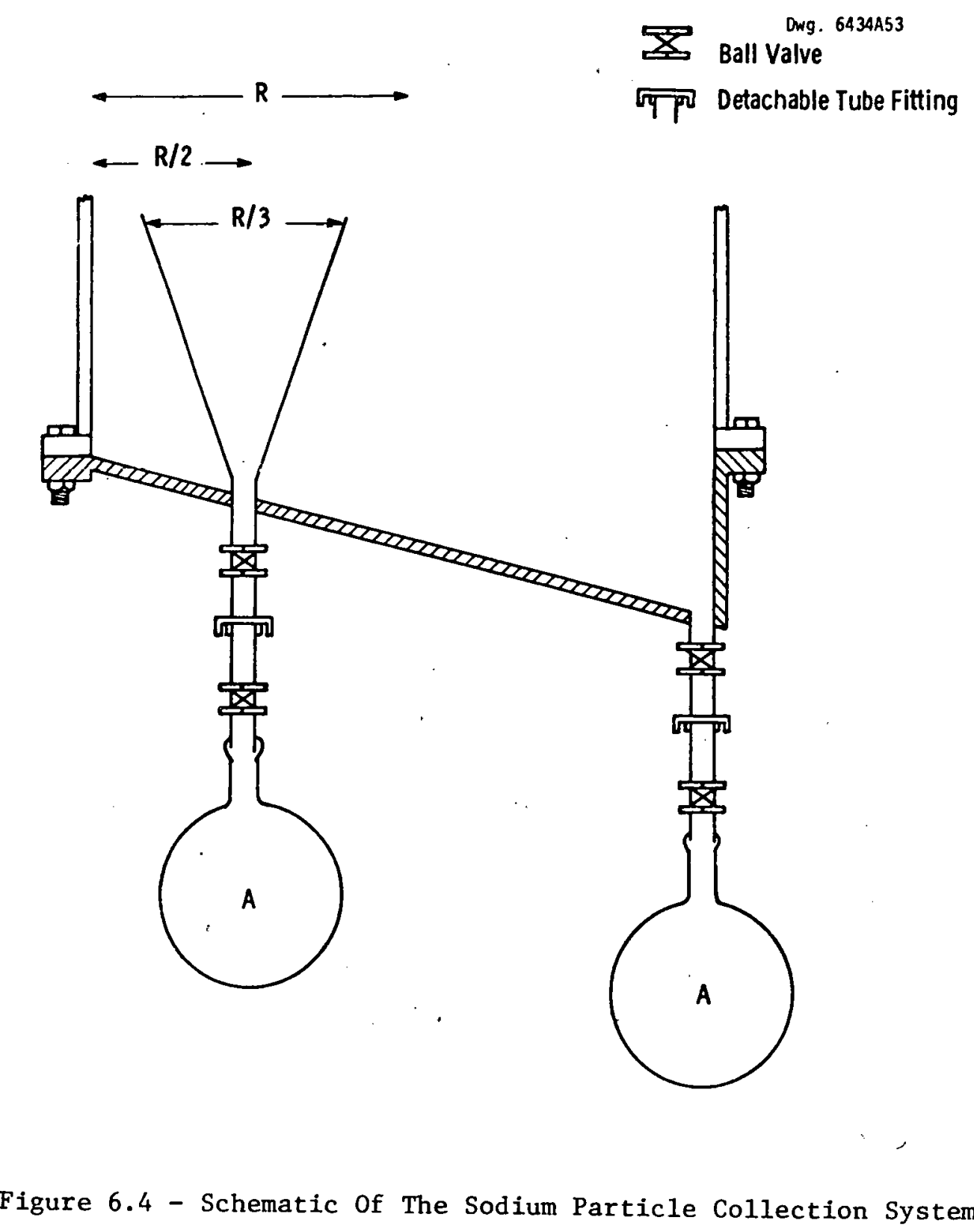




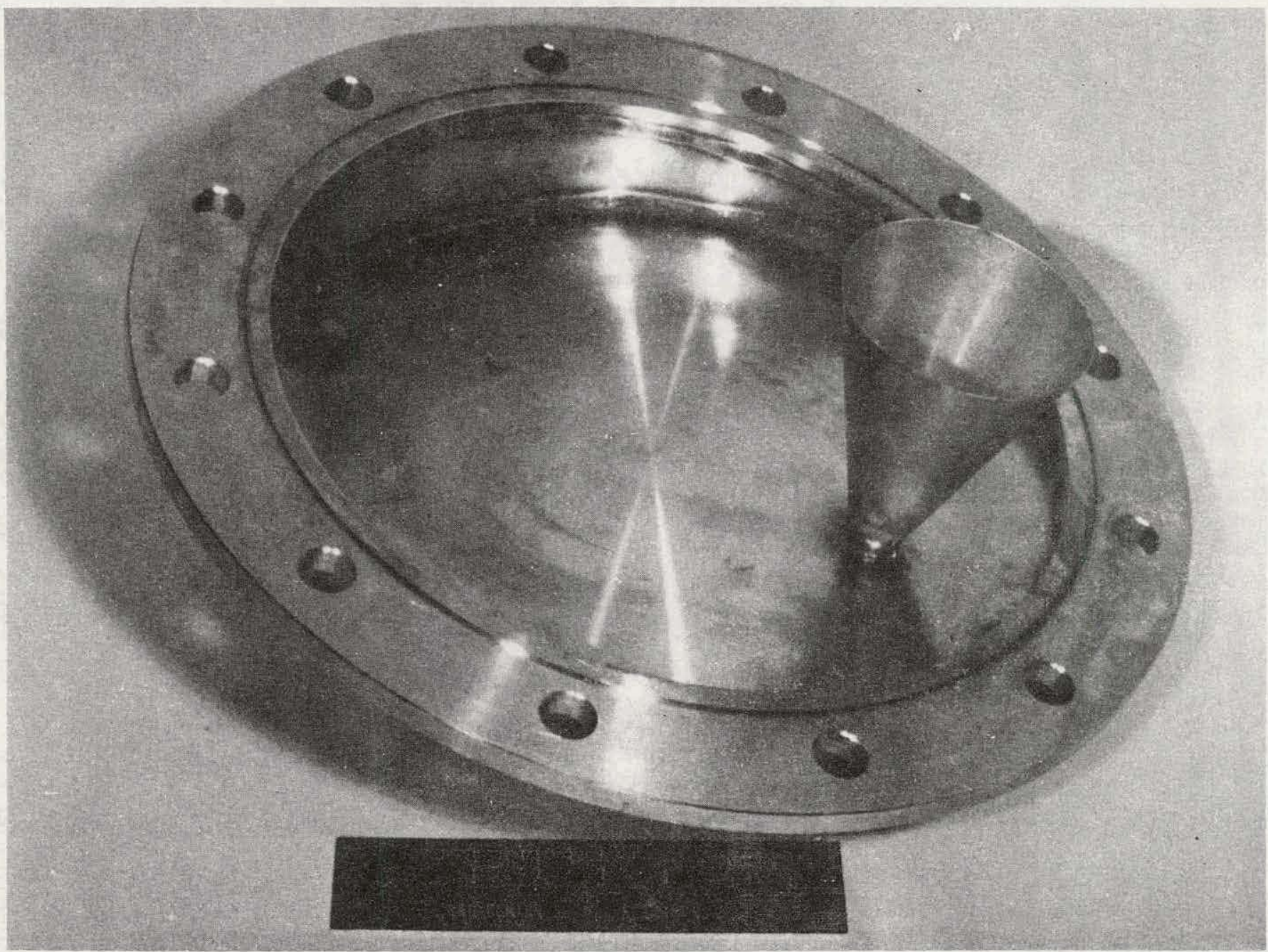

Figure 6.5 - Photograph of The Sodium Chamber Base Flange 
would be swept from the injection chamber by the high velocity cooling gas.

Intermittent operation of the injector appears possible if the test chamber is filled with precooled nitrogen gas just prior to the injection. There is then sufficient cooling capacity stored in the chamber to handle the heat load provided the injection period is short. With the chamber gas cooled to $-100^{\circ} \mathrm{C}$ the maximum injection period is 1 second; for gas at $-196^{\circ} \mathrm{C}$ the allowable period becomes 3.4 seconds. A final aerosol temperature of $50^{\circ} \mathrm{C}$ is assumed here, as in the earlier estimates. As described above, these short injection times will be achievable by solenoid valve control of the nozzle fluids.

\subsubsection{Sodium Testing}

As outlined in the test plan (Appendix A), general nozzle characteristics are being evaluated using water and nitrogen gas prior to the actual sodium injection tests. While these experiments will be only partially applicable to liquid sodium injection, these serve to shakedown some of the experimental aspects of nozzle performance. In addition, the water tests provide a means of evaluating the suitability of monitoring sodium tests with photographic and video techniques. Not only is water a convenient fluid for use in preliminary tests, it will also provide background data on nozzle performance that can be correlated with the sodium test data throughout the study.

Water tests have been performed with the Sonicore nozzle mounted in an adjustable cylindrical shroud, Figure 6.6. The distance, L, can be varied to enable either simple spraying directly into the atmosphere or alternatively a simulation of actual reactor conditions where injection occurs within a closed-end cylinder. In the former mode, 
?.mg. $6428 A 39$

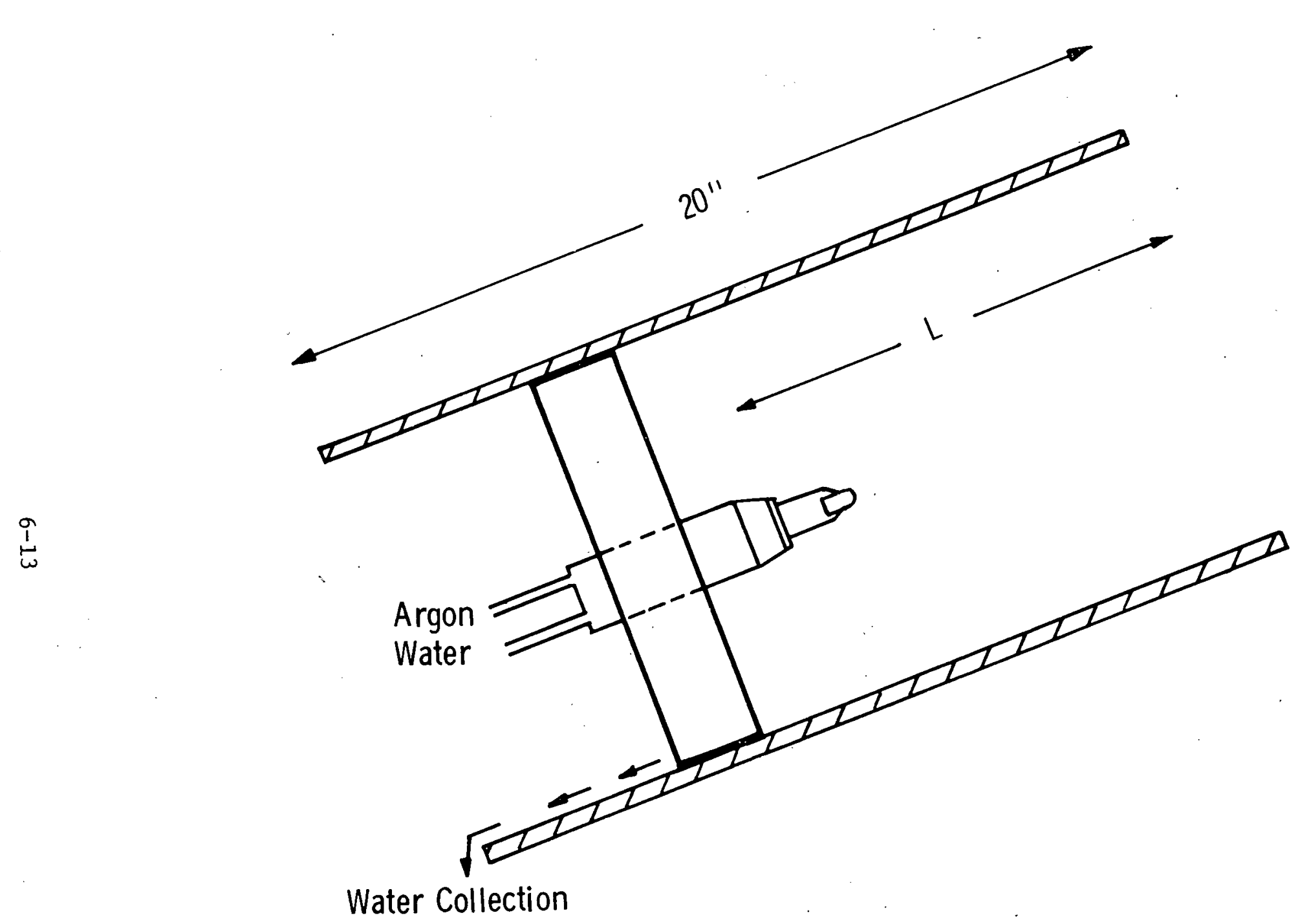

Figure 6.6 - Water Testing Shroud 
visual observations indicated that the nozzle operated satisfactorily producing a voluminous mist of water at a flow rate of $1.5 \mathrm{gpm}$. It was apparent, though, that the spray angle was large $\left(\sim 60^{\circ}\right)$ and that a considerable quantity of high velocity droplets were being projected at high angles. This observation was confirmed by using the wate collection shroud with $L$ varying between 0 and $12^{\prime \prime}$. With the flow rate held at $1.5 \mathrm{gpm}$, water which hit the inner wall of the shroud was collected over a period of 60 seconds. The results are presented in Figure 6.7 as a plot of percentage water recovered versus $L$. With the nozzle $12^{\prime \prime}$ from the edge of the shroud only $\sim 1 \%$ of the injected water emerged from the shroud as a mist. At 8 " the figure was $50 \%$. It was apparent that the high percentage of water collected from the walls was not due to the formation of particularly large droplets but was caused by the wide spray angle. In addition, the stationary atmosphere within the shroud caused the spray angle to increase compared with that in the open atmosphere. For a value of $\mathrm{L}=10^{\prime \prime}$ the angle between nozzle and shroud exit is $60^{\circ}$ yet only $\sim 20 \%$ of the water emerges. In an attempt to facilitate the forward motion of water droplets, the shroud has been adapted to produce a flow of air along the walls. It was hoped that a sufficiently high velocity of gas would turn the water particles away from the wa11. Preliminary results from the use of a gentle gas flow $(20.25 \mathrm{~cm} / \mathrm{s})$ are included in Figure 6.7 but no appreciable effect can be discerned. 


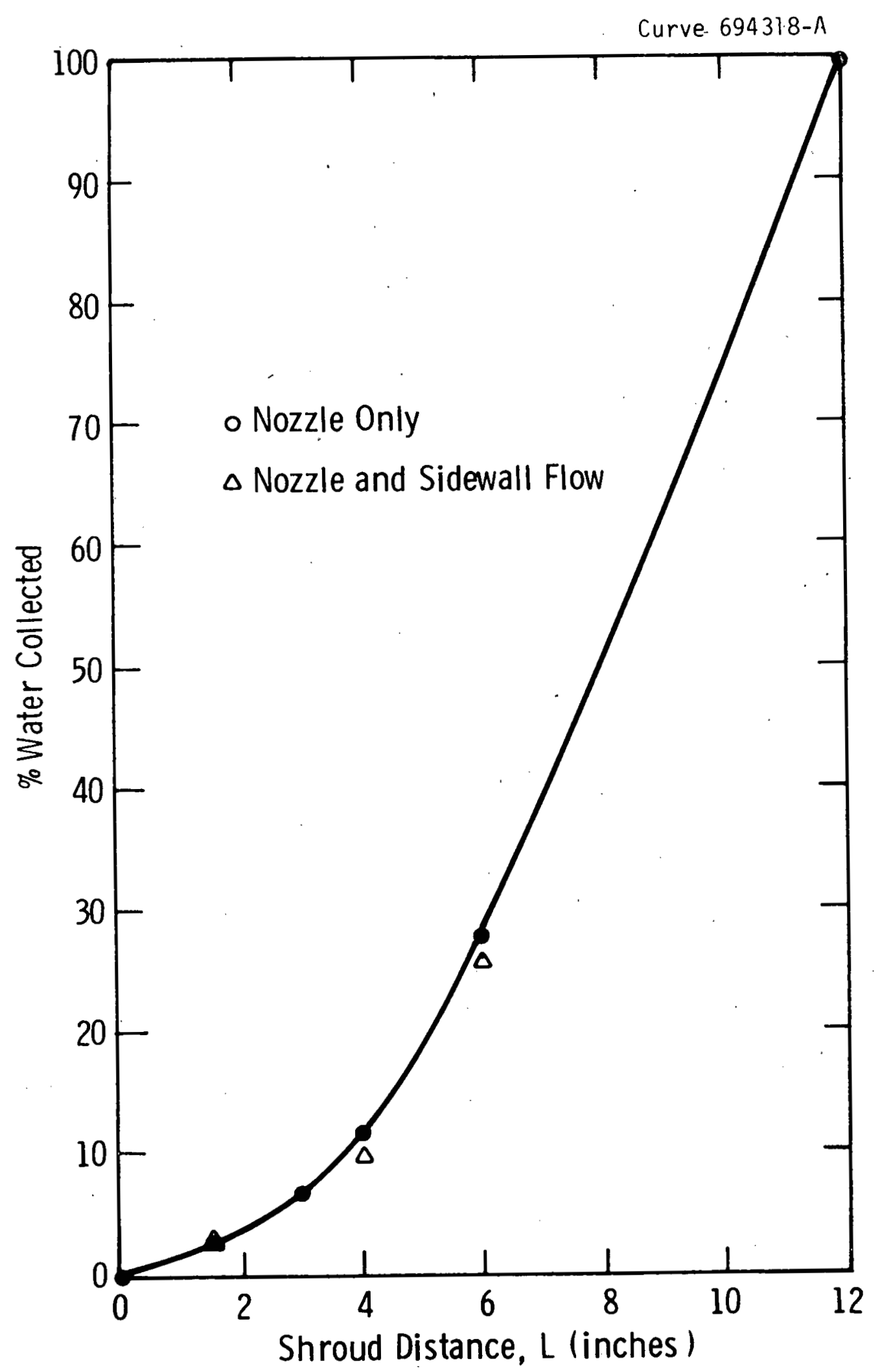

Figure 6.7 - Sonicore Nozzle Performance For Water Spray Tests 


\section{KINETICS STUDY}

Task Investigators: J. V. R. Heberlein, D. F. Ciliberti,

D. W. Feldman, J. F. Lowry, and

F. J. Harvey

\subsection{Summary}

The design of the entire test apparatus, including the injection nozzle, three test sections, scrubber and the $\mathrm{SiCl}_{4}$ injection subsystem, have been finalized. Fabrication of all system components is currently in progress. Initial tests with a tunable dye laser indicate that the laser absorption technique is capable of detecting the presence of silicon vapor. A zirconium oxide filter will be used for particle size determination during initial experiments.

During the next quarter, the Plasmadyne SG 1B $40 \mathrm{~kW}$ plasma torch will be procured and acceptance tests carried out. Fabrication and assemblage of the entire test apparatus will be completed. The laser vapor detection experiments will be finalized and shakedown testing with the test system will be initiated.

\subsection{Task Description}

In this task, the overall kinetics of reaction between $\mathrm{SiCl}_{4}$ and $\mathrm{Na}$ is being investigated in a laboratory scale plasma reactor. The results of these experiments will provide input for the optimum operating conditions of the commercial scale experiments on the arc heater production of solar grade silicon.

The task consists of the following subtasks:

1. Test system design and fabrication;

2. Laser vapor detection;

3. Particle diagnostics;

4. Injection system;

5. Data acquisition. 


\subsection{Work Accomplished}

Test System Design and Fabrication

An overview sketch of the test apparatus is shown in Figure 7.1. The plasma torch is located at the left end of the system. Immediately adjacent to the torch are the reactant injection nozzles. The two test sections to be used for monitoring the progress of the homogeneous reaction are adjacent to the nozzle section. These sections consist of an axial ceramic reaction tube with perpendicular side tubes both of which are enclosed in an outer cylindrical (stainless steel) chamber. Either one or both of these sections can be used as required since a flange arrangement is used for assembly. The product separation test section is located next to the homogeneous reaction segments. A straight tube condenser, which is not shown, can be inserted into the pruduct separation test section to study the overall reaction in a condensation mode. Provisions for sampling the gas stream at the condenser exit for particle size analyses have been made at the right end of the reactor.

A drawing of the injection nozzle is shown in Fig. 7.2. There are three circular plenum chambers for liquid $\mathrm{Na}, \mathrm{SiCl}_{4}$-vapor and high pressure cooling water, respectively. Several small channels extend from the $\mathrm{Na}$ and $\mathrm{SiCl}_{4}$ chambers to the nozzle. The material of construction of the nozzle is 316 stainless steel.

Design drawings of the test sections are shown in Figs. 7.3 and 7.4. Inlets for introducing a tangential flow of gas are located in the side wall of the main cylinder of the test section. This gas will provide both additional temperature control of the inside ceramic tube, as well as a cover gas for the test section. At two axial locations, there is an arrangement of three viewing ports around the chamber periphery. These ports permit access for gas diagnostic measurements using both absorption and scattering techniques. The identical second and third test sections 
Dwg. 6435A37

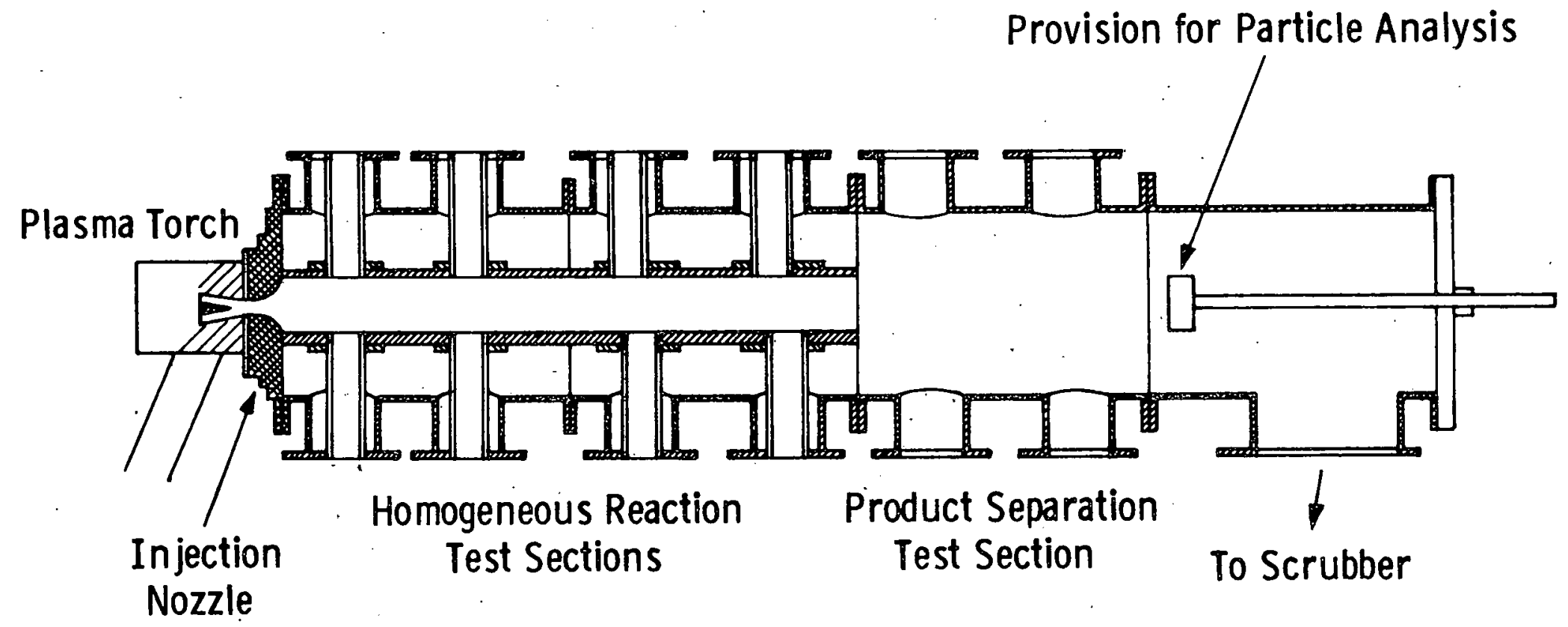

Fig. 7.1-Assembly drawing of test apparatus 


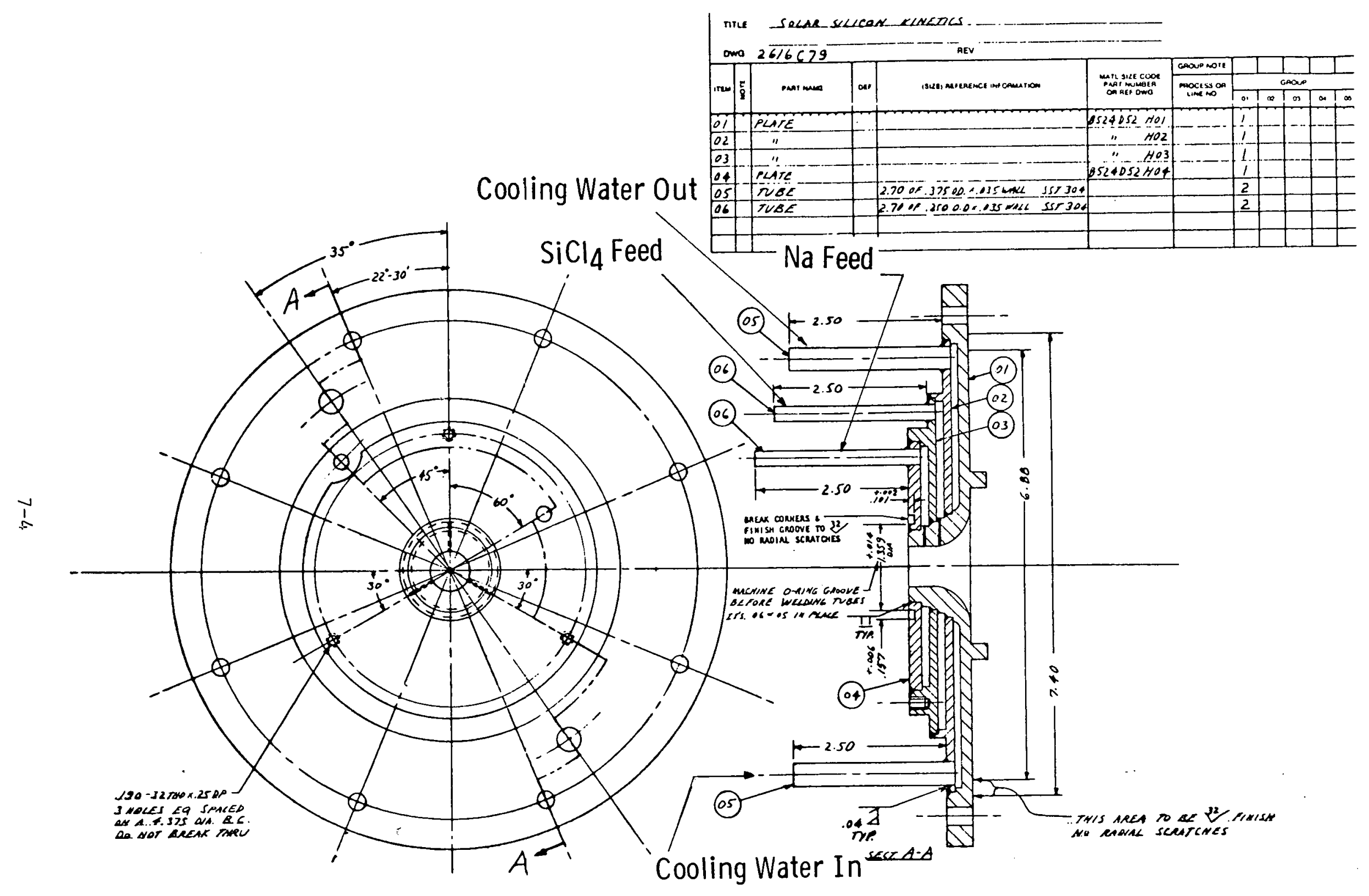

Fig. 7:2-Reactant in jection nozzle 


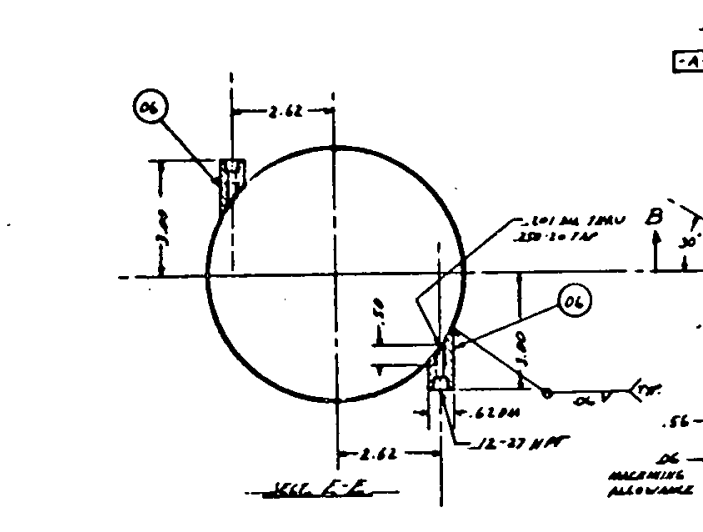

ن

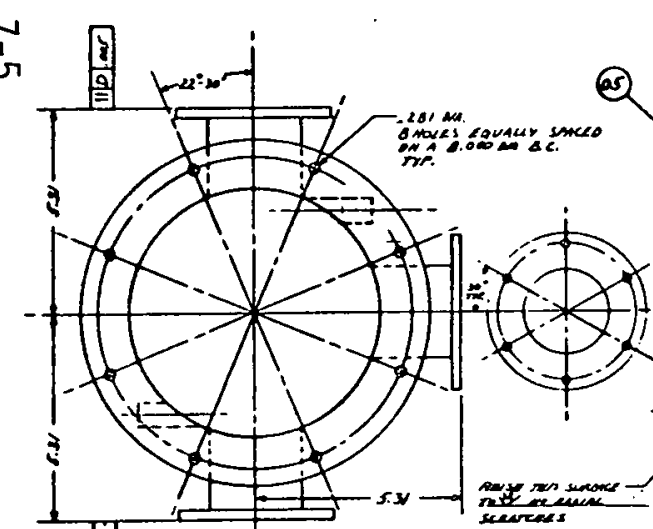

区
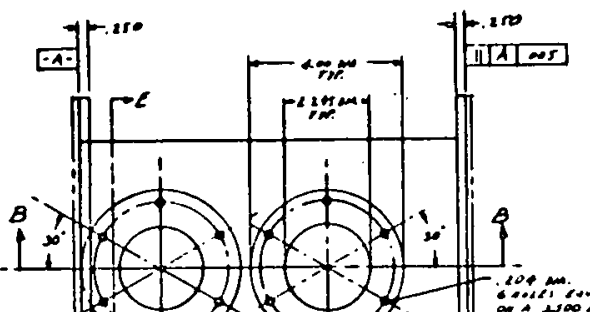

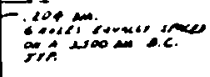

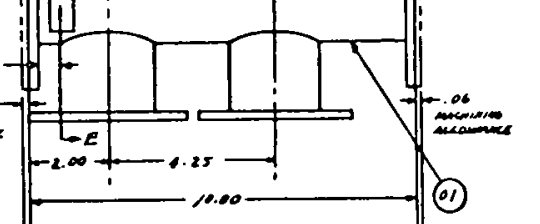

(2)

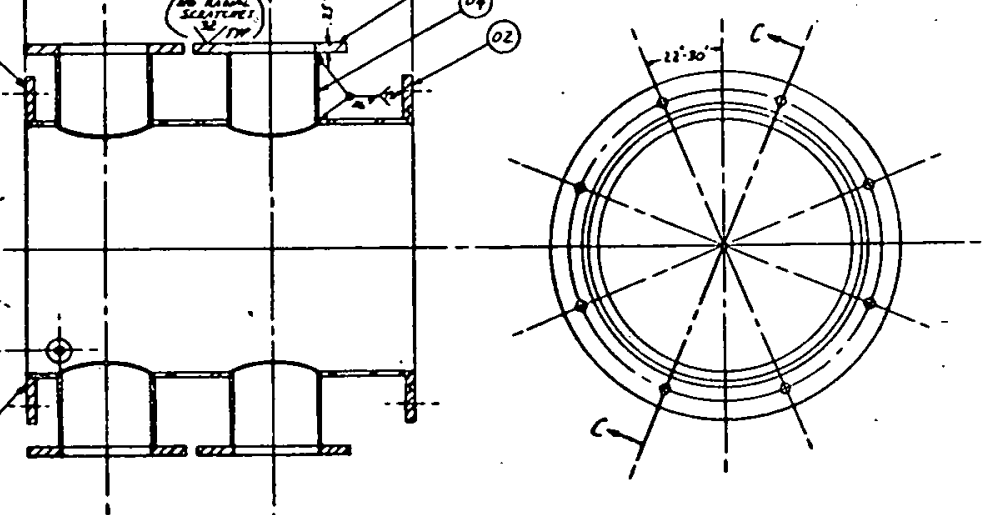

$\sec B \cdot B^{\prime}$

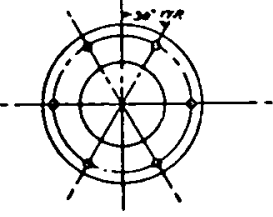

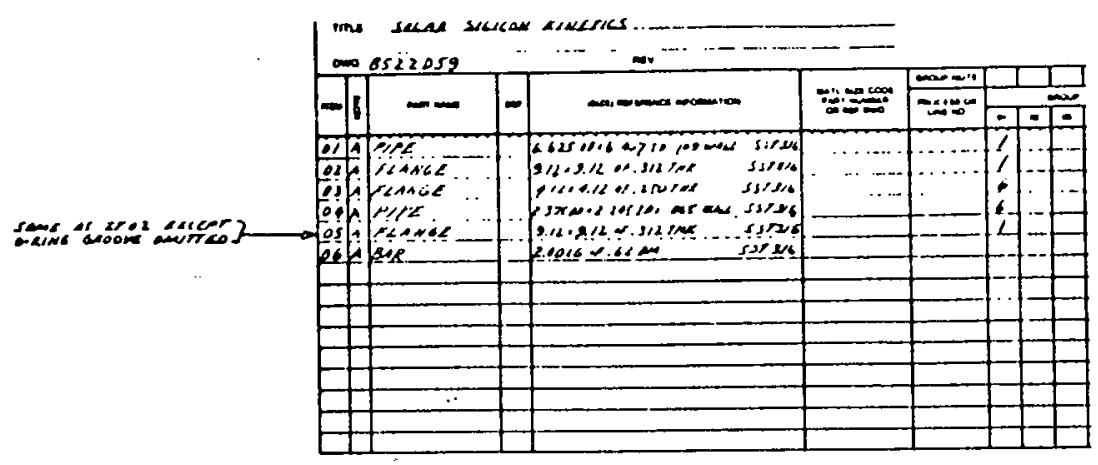

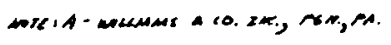

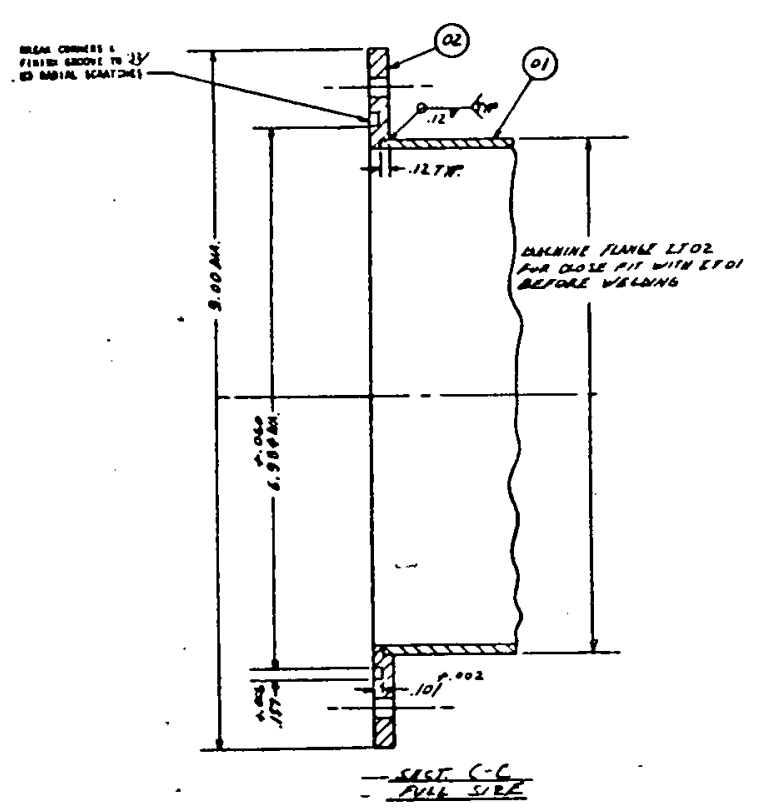

Fig. 7.3-Homogeneous reaction test section 


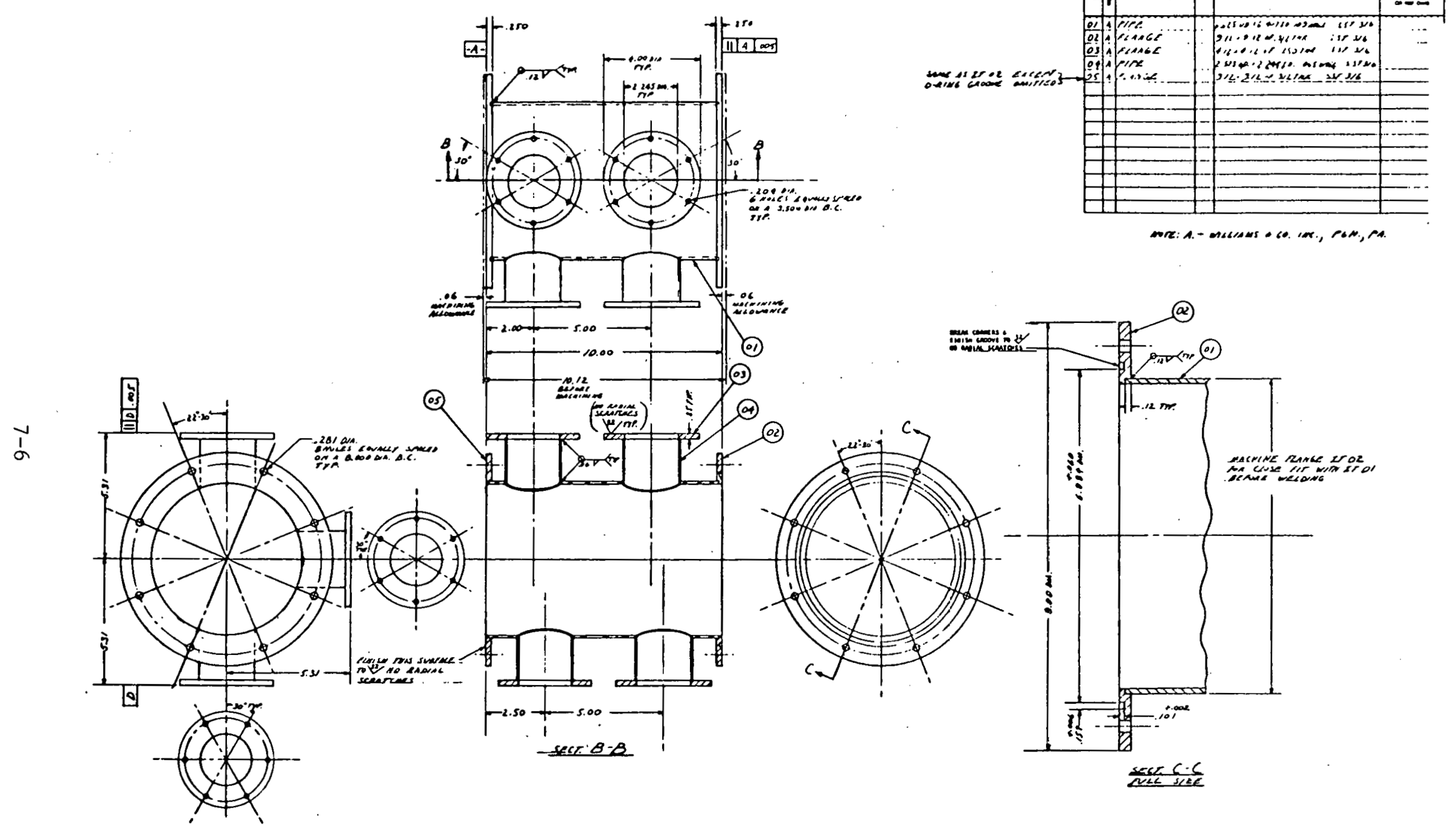

Fig. 7.4-Product separation test section 
(Figure 7.4) differ from the first section in that, the two opposing viewing ports are at slightly different axial locations. The larger scattering angle required for laser scattering techniques can be accommodated in this design. The viewing ports are shown in Fig. 7.5. The quartz window is protected from condensation of reaction products by a shutter. When the shutter is open, its U-shaped flapper provides maximum viewing access: A small amount of gas flow entering close to the window. counteracts the diffusion flow of reaction products from the main stream. The outer chamber of the test section is constructed of stainless steel, while the inner ceramic tube is silicon carbide. Copper tubing will be affixed around the outer chamber for cooling purposes. The end section of the test apparatus is closed with a water-cooled plate with the scrubber connected to a flange at the bottom of the section.

A heat transfer analysis indicates that a considerable portion of the energy from the gas is transferred to the wall by $\mathrm{Na}$ radiation stemming from dissociated $\mathrm{NaCl}$ molecules. Consequently, the gas will cool faster than anticlpated, and heating of the downstream portions of the inner ceramic tube may be required to avoid condensation of $\mathrm{NaCl}$. The heat transfer analysis based on a laminar flow Nusselt number of 2.1 also indicates that radiation cooling of the ceramic wall will be sufficient if the wall temperature is about $2000^{\circ} \mathrm{K}$, and the mean gas temperature is below $4000^{\circ} \mathrm{K}$.

\section{Scrubber Design}

The actual flow conditions will vary greatly throughout the test plan thus, the scrubber has been designed to accommodate the largest gas flow envisioned, which is:

$$
\begin{aligned}
\mathrm{H}_{2} & =0.05 \text { moles } / \mathrm{sec} \\
\mathrm{Ar} & =0.05 \mathrm{moles} / \mathrm{sec}
\end{aligned}
$$

Equilibrium calculations indicate that the mole fractions of $\mathrm{HCl}$ and $\mathrm{SiCl}_{4}$ in the gas leaving the reactor will be as follows: 


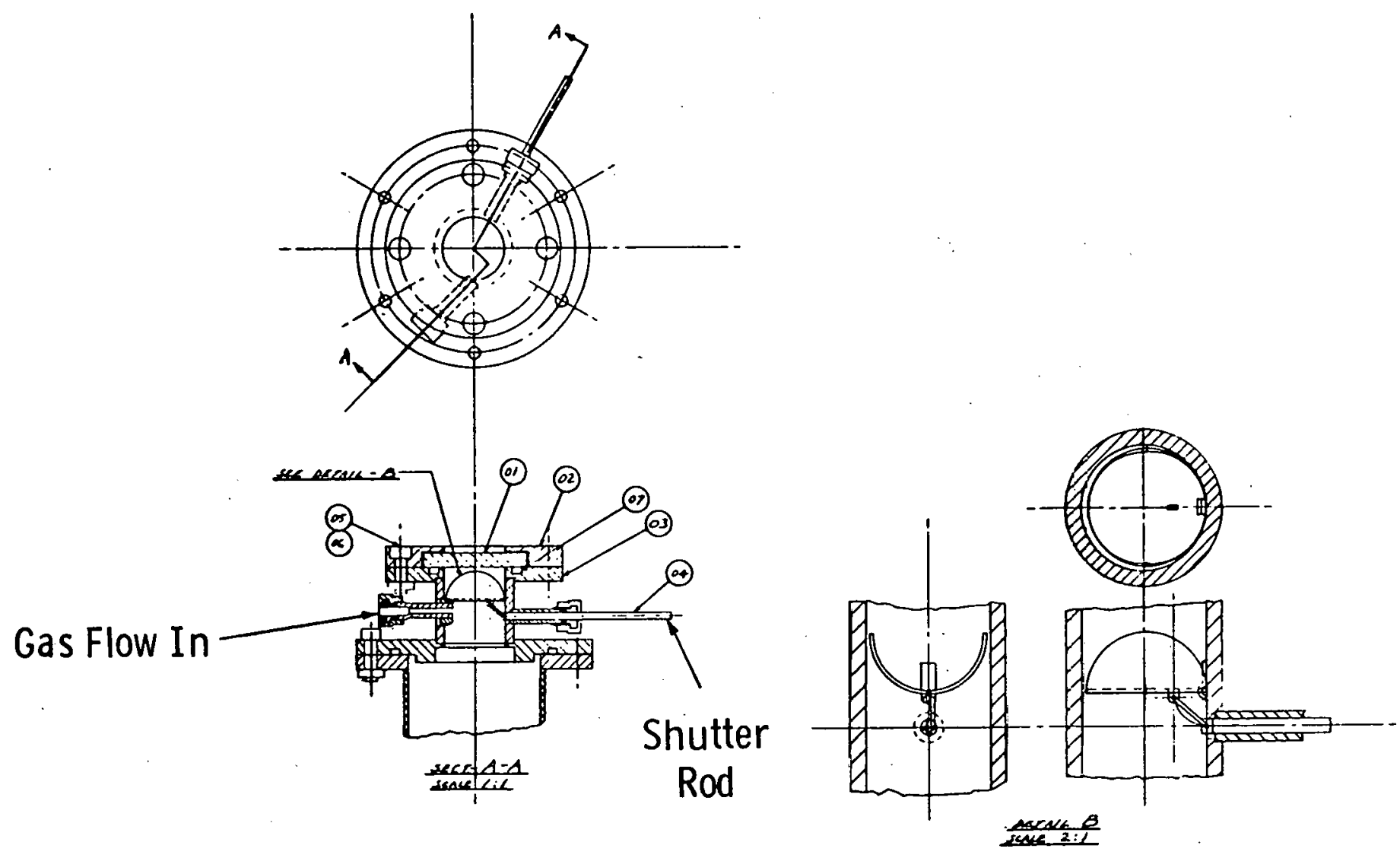

Fig. 7.5-Viewing port assembly 


$$
\begin{aligned}
\mathrm{Y}_{\mathrm{HCl}} & =0.04 \\
\mathrm{Y}_{\mathrm{SiCl}_{4}} & =0.012
\end{aligned}
$$

It has been assumed that all of the $\mathrm{SiCl}_{4}$ will be converted to $\mathrm{HCl}$ when the gas is spray cooled from $600^{\circ} \mathrm{C}$ to $<100^{\circ} \mathrm{C}$ prior to entry into the scrubber. This assumption leads to the following expression for the expected maximum $\mathrm{HCl}$ mole fraction into the scrubber:

$$
Y_{\mathrm{HCl}}=\frac{4 \mathrm{Y}_{\mathrm{SiCl}_{4}}^{\text {out }}+\mathrm{Y}_{\mathrm{HCl}}^{\text {out }}}{1+3 \mathrm{Y}_{\mathrm{SiCl}_{4}}^{\text {out }}}=\frac{(4)(0.012)+(0.04)}{1+3(0.012)}=0.085
$$

It has been assumed that the mole fraction of $\mathrm{HCl}$ in the gas leaving the scrubber is to be reduced to 0.001 ; representing a $99 \%$ removal factor.

Equilibrium Data

The equilibrium data relating the mole fraction of $\mathrm{HCl}$ in the vapor above water containing dissolved $\mathrm{HCl}$ at $30^{\circ} \mathrm{C}$ and 1 atm is presented in Fig. 7.6. From this graph, it can be seen that the equilfbrium partial pressure of $\mathrm{HCl}$ is very small for liquid mole fractions below 0.10 .

\section{Liquid to Gas Ratio}

Ordinarily the minimum molar liquid to gas ratio is determined by an operating line drawn from the desired outlet concentration to the inlet concentration at the point of intersection with the equilibrium curve. In this example, this occurs at an $\tilde{L} / \mathcal{G}$ imoles $\mathrm{H}_{2} \mathrm{O} /\left(\mathrm{hr}-\mathrm{ft}^{2}\right) /$ moles gas $\left./ \mathrm{hr}-\mathrm{ft}^{2}\right)$ \} of 0.391 or a liquid rate of $5.6 \mathrm{lb} / \mathrm{hr}$. For this particular application, however, one must determine if this is enough liquid to dissolve the NaCl entrained in the flow. The mass flow of $\mathrm{NaCl}$ for the assumed conditions is calculated to be $27.8 \mathrm{lb} / \mathrm{hr}$. Using the solubility of $\mathrm{NaCl}$ in water 
Curve 695412-A

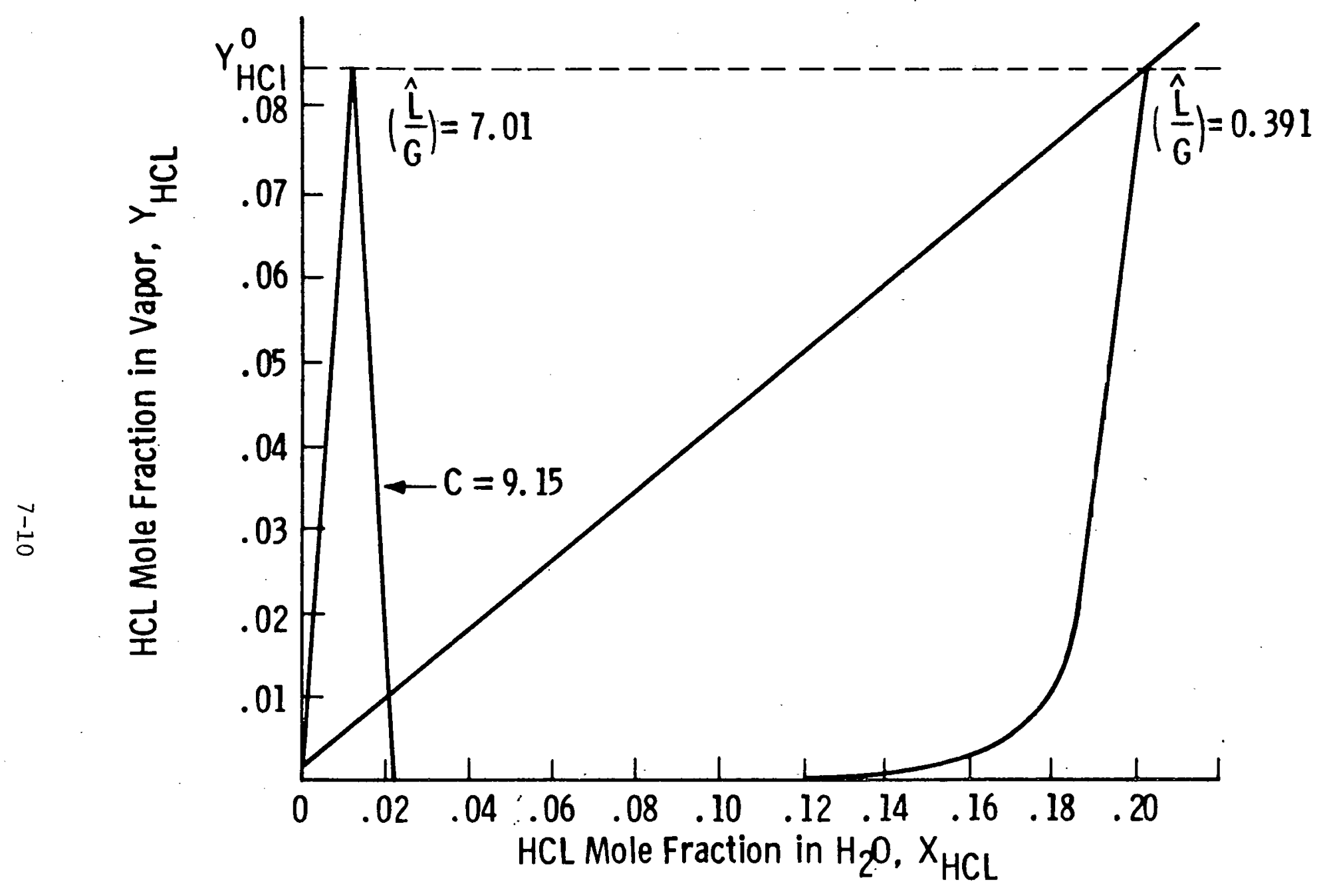

Fig.7.6- $\mathrm{HCL}-\mathrm{H}_{2} \mathrm{O}$ mole fractions 
at $30^{\circ} \mathrm{C}$, the water requirement. is calculated to be $77 \mathrm{lb} / \mathrm{hr}$ or $0.15 \mathrm{gpm}$. For a conservative design, $100 \mathrm{lb} / \mathrm{hr}$ or about $0.2 \mathrm{gpm}$ has been assumed.

Column Diameter

Using standard techniques, one can calculate the gas mass flow rate at flooding. For 0.25 in. Raschig ring packing, the flooding value of $\mathrm{G}$ is $336 \mathrm{lb} / \mathrm{hr}-\mathrm{ft}^{2}$. For a very conservative design it is assumed that the column will be operated at $1 / 2$ flooding velocity or $168 \mathrm{lb} / \mathrm{hr}-\mathrm{ft}^{2}$. From this the cross-sectional area of the column can be calculated to be $0.099 \mathrm{ft}^{2}$ which corresponds to a diameter of $4.26 \mathrm{In}$. Using these same correlations, the pressure drop per unit length of packing can be calculated as 0.009 $1 b / \mathrm{in}^{2} / \mathrm{ft}$.

\section{Scrubber Length}

To calculate the scrubber length the height of a transfer unft for both the liquid phase, $H(l)$, and the gas phase, $H(g)$, must be calculated. These quantities have been correlated by empirical equations of the form: 15,16

$$
\begin{gathered}
\mathrm{H}(\mathrm{g})=\alpha \mathrm{G}^{\rho} \mathrm{L}^{\gamma}\left(\mathrm{Sc}_{\mathrm{g}}\right)^{0.5} \\
\mathrm{H}(\ell)=\phi(\mathrm{L} / \mu)^{\eta}\left(\mathrm{Sc}_{\ell}\right)^{0.5}
\end{gathered}
$$

For the system under consideration, the following values were used :

$$
\begin{array}{ll}
\alpha=2.32 & \phi=0.0018 \\
\rho=0.45 & \eta=0.46 \\
\gamma=-0.47 &
\end{array}
$$

and $\mathrm{Sc}$ is the Schmidt number defined as $\mathrm{Sc}=\mu / \rho \mathrm{D}$. 
For the gas phase, the Schmidt number has been estimated as:

$$
\left(\mathrm{Sc}_{\mathrm{g}}\right)=0.72
$$

and for the liquid phase:

$$
\left(\mathrm{Sc}_{\ell}\right)=335
$$

Combining these results leads to the values of $\mathrm{H}(\mathrm{g})$ and $\mathrm{H}(\ell)$ of :

$$
\begin{aligned}
& \mathrm{H}(\mathrm{g})=0.76 \mathrm{ft} \\
& \mathrm{H}(\mathrm{l})=0.58 \mathrm{ft}
\end{aligned}
$$

The tower length is the product of $\mathrm{N}(\mathrm{g})$ and $\mathrm{H}(\mathrm{g})$ where $N(g)$ is the number of transfer units and is defined by the equation:

$$
N(g)=\int_{Y_{\text {out }}}^{Y_{\text {in }}} \frac{d Y}{Y-Y_{i}}+\frac{1}{2} \ln \frac{1-Y_{\text {out }}}{1-Y_{\text {in }}}
$$

where $\mathrm{Y}_{i}$ is the gas phase mole fraction of $\mathrm{HCl}$ at the interface of the liquid and water. The value of $\mathrm{Y}_{i}$ is usually evaluated graphically by extending a line of slope:

$$
C=-\frac{H(g) \tilde{L}(1-Y) 1 m}{H(l) \tilde{G}(1-X) 1 m}
$$

from various points on the operating line to the equilibrium curve where $Y_{i}$ is read. For the system being designed, the value of $\mathrm{C}$ is about -9.15 . This has the consequence that virtually all the $\mathrm{Y}_{i}$ 's of interest are essentially equal to 0 as can be seen from Fig. 7.1. This allows the integral to be evaluated explicitly and results in the following:

$$
N(g)=\ln \left[\frac{Y_{\text {in }}}{Y_{\text {out }}}\right]+\frac{1}{2} \ln \left[\frac{1-Y_{\text {out }}}{1-Y_{\text {in }}}\right]=4.48
$$


Therefore, the overall tower height is calculated as:

$$
Z=4.48 \times 0.76=3.4 \mathrm{ft}
$$

Scrubber Description

The embodiment of these calculations in hardware is shown in Fig. 7.7 which is a schematic of the scrubber system. From the reactor, the gas enters a $2 \mathrm{ft}$ section of $4.0 \mathrm{in}$. pipe where It is spray cooled from about $600^{\circ} \mathrm{C}$ to less than $100^{\circ} \mathrm{C}$. The cooled gas then flows through a 0.75 in. tube to the scrubber inlet. The gas flows up through a distributor plate into the packed column. The Ifquid level in the bottom is maintained by a trap arrangement and prevents the gas from escaping out through the drain." This section is fitted with a liquid level detector and sight glass to prevent back up in the column. The scrubbing water is admitted at the top of the packed section through a spray nozzle to insure unfform water distribution over the packing. The region above the spray nozzle is packed with glass wool to eliminate the possibility of $\mathrm{HCl}$ carry over in the form of fume. The cleaned gas then exits the scrubber and goes through a burnoff stack into the exhaust system. The actual system will be fitted with a bypass of the entire scrubber system so that it will not be necessary to shut down the reactor immediately should a problem arise in the scrubber system. This bypass system will only spray cool the gas and is intended for short term emergency use. With completion of the scrubber, the design of the test system is essentially complete.

\section{Laser Vapor Detection}

Optical absorption measurements on silicon vapor were performed using a tunable dye laser and a gated signal averager. The generation of silicon vapor was to be accomplished by placing silicon in an evacuated sapphtre test cell which, in turn, is placed into the hot zone of a silicon carbide-resistance furnace. 


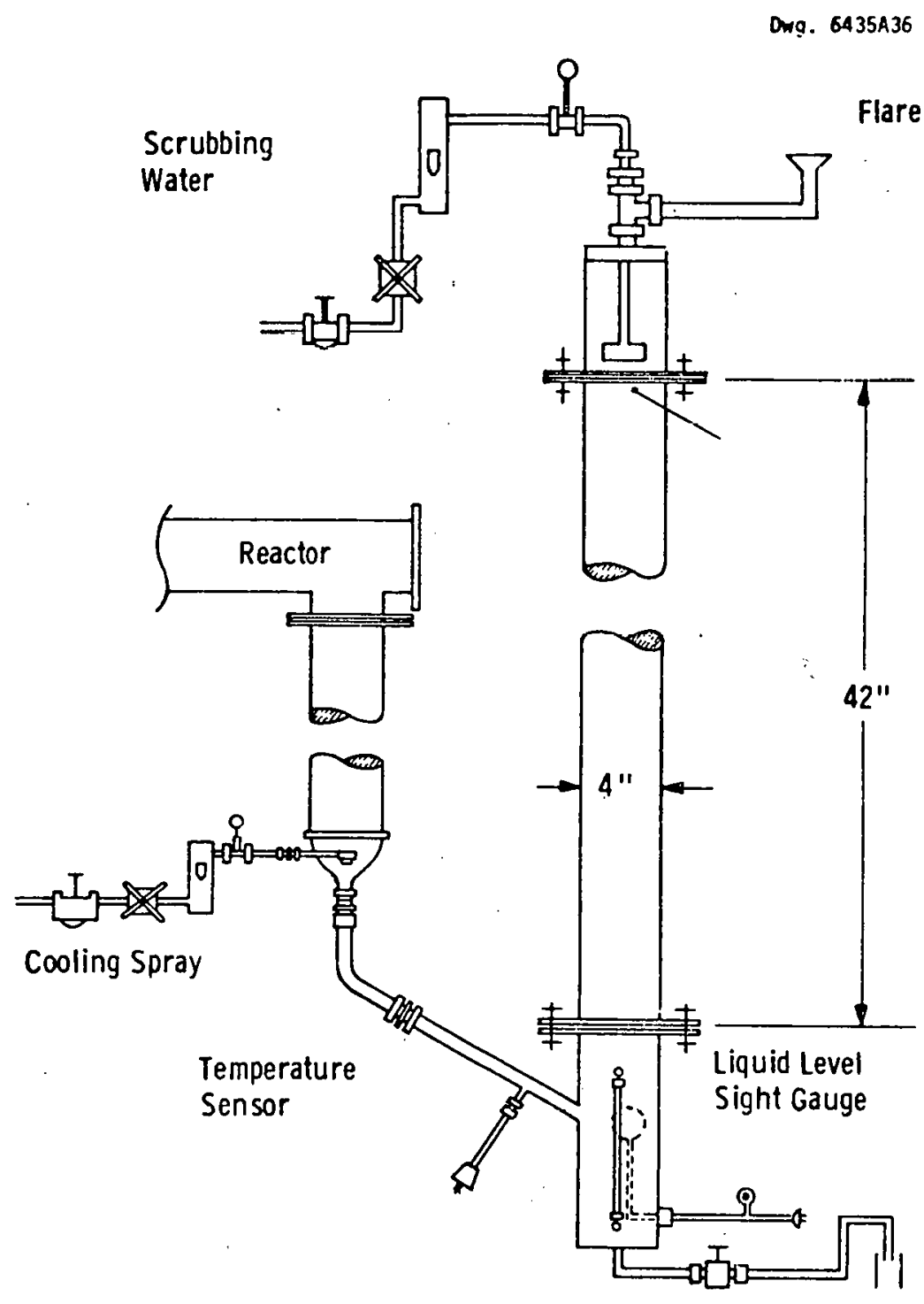

Figure 7.7 - HCl Scrubber System 
However, sealing problems have been encountered with the sapphire cell. For this reason the initial tests were carried out with an alumina cell with small apertures at either end. The principal drawback associated with this latter cell is that oxygen in the furnace environment can react with the silicon forming a layer of silica. Although there still is silicon vapor in the atmosphere above silica; its value is much lower than the equilibrium vapor pressure. In order to minimize oxidation of the silicon the test cell atmosphere was flushed with argon. However, no attempt was made to achieve a tight cell so that some oxygen contamination of the cell environment was probable. On this basis, the initial test results given in the present report are intended to establish the basic feasibility of the laser technique for detecting the presence of silicon vapor in a gas phase rather than provide quantitative information. Pending the outcome of the sealing problem, future measurement will be performed with the sapphire cell or in an inert environment.

With the alumina cell, absorption was noted at several oven temperatures above $21500^{\circ} \mathrm{C}$ at the atomic silicon absorption line of $288.1 \mathrm{~nm}$. As an example, a temperature of $1616^{\circ} \mathrm{C}$ and an $8.6 \mathrm{~cm}$ absorption distance produced a transmission of $9.7 \%$, or an optical density of $0.3 \mathrm{~cm}^{-1}$. This temperature corresponds to a total silicon density of $7.5 \times 10^{14} \mathrm{~cm}^{-3}$ and a density in the excited state from which absorption occurs of $6.2 \times 10^{12} \mathrm{~cm}^{-3}$. The observed line width of the absorption was $20.3 \mathrm{~cm}^{-1}$ which is consistent with the measured line width of the laser source. The observed change in absorption with temperature was found to be consistent with the change in equilibrium pressure. It appears that atomic densities in the excited state of $\sim 10^{12} \mathrm{~cm}^{-3}$ can easily be measured. The total densities corresponding to this excited state density will depend on the temperature, but at the temperatures expected in the test system, a total silicon density of $\sim 10^{14} \mathrm{~cm}^{-3}$ should be readily measurable. 
The alumina cell tests have demonstrated that measurements of silicon vapor can be achieved by laser absorption techniques. In addition, absorption in sodium vapor at comparable densities has been observed and it appears that the same laser and detector system will be capable of measuring sodium densities at the anticipated values.

$\underline{\text { Particle Diagnostics }}$

Particle size determinations in the initial experiments will be performed with a zirconium oxide filter. In a typical test, the filter will be placed into the gas stream at a location where the $\mathrm{NaCl}$ is still in the gas phase. A microscopic examination of the filter will be carried out after the test to obtain an indication of the particle size range in the reacted gas phase.

After positive Identification of particles in the micron size range, a final decision will be made regarding the particle size distribution measuring system. Titanium particle impactors which are placed in the hot gas stream, probes which extract and rapidly quench a sample of the gas stream, and laser scattering techniques are the methods under consideration.

$\mathrm{SiCl}_{4}$ Injection System

A schematic of the $\mathrm{SiCl}_{4}$ supply system is shown in Fig. 7.8. Liquid $\mathrm{SiCl}_{4}$ is loaded into the reservoir which is then attached to the system at the Swagelok union. The reservoir is then pressurized with argon to about $100 \mathrm{lb} / \mathrm{in}^{2}$. The argon pressure is used to deliver $\mathrm{SiCl}_{4}$ through the system to the injection nozzle. The reservoir capacity is approximately $1.5 \mathrm{gal}$, which should permit at least $55 \mathrm{~min}$ of operation. The reservoir has an in-line pressure relief valve, which can be vented to an exhaust hood or some other suitable vent. A flat bottom facilitates placement of the reservoir in a dry box for reloading. A removable top cover plate, sealed with a teflon 0-ring, is provided for cleaning and/or inspection of the interior of the reservoir. All parts are to be fabricated from type 304 stainless steel. 


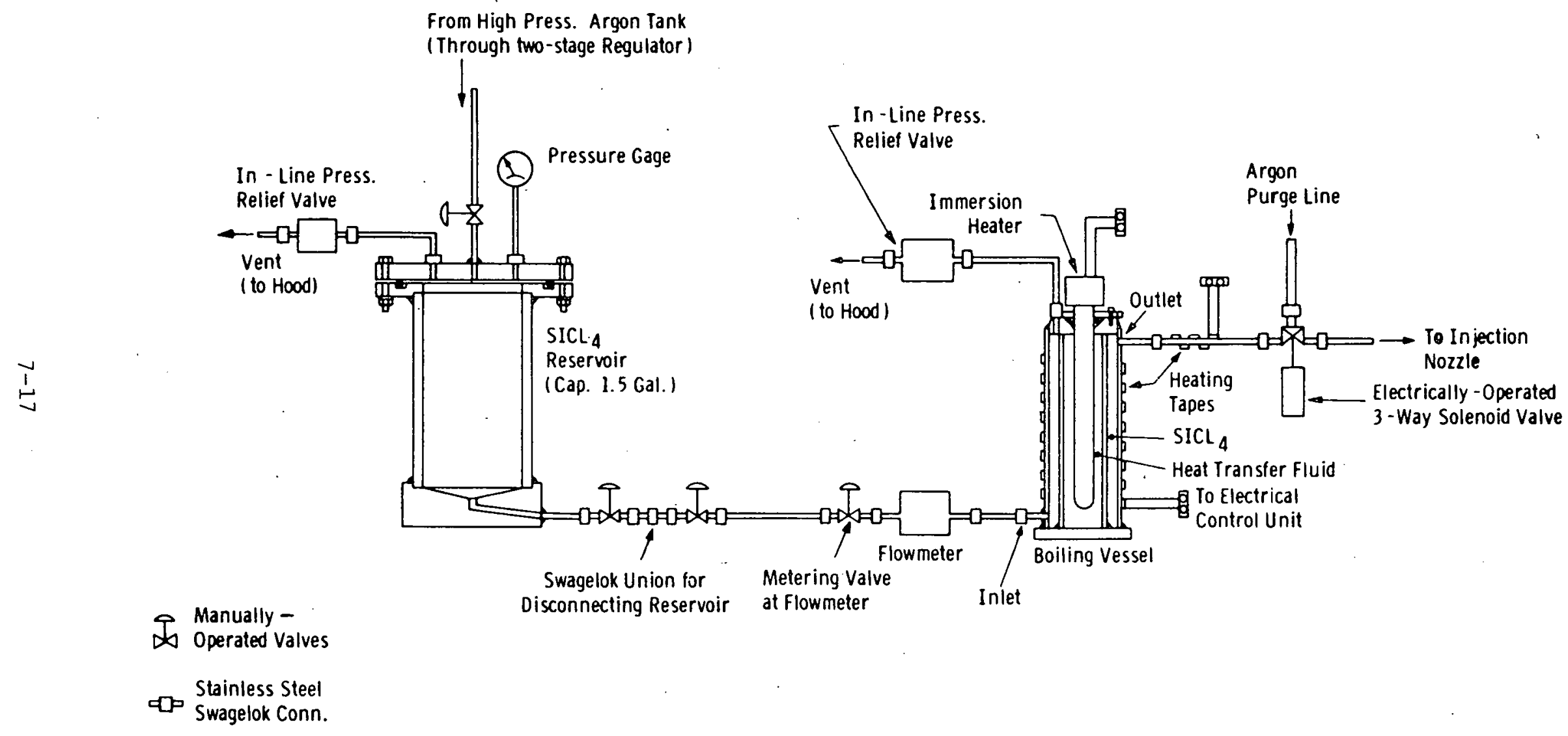

Figure 7.8 - Schematic of The $\mathrm{SiCl}_{4}$ Supply System 
In the boiling vessel, $\mathrm{SiCl}_{4}$ is heated to its boiling point and vaporized. The calculated power requirement is $466 \mathrm{~W}$ for a liquid flow rate of $2.55 \mathrm{gm} / \mathrm{sec}$ and a reservoir (vessel $A$ in $F$ ig. 7.8) temperature of $20^{\circ} \mathrm{C}$, neglecting all heat losses from the boiling vessel. This vessel consists of two cylindrical, coaxial, stainless steel tubes welded to stainless steel end plates. A $1.0 \mathrm{~kW}$ immersion heater is sealed inside the smaller tube, with a suitable heat transfer fluid (for example, Dowtherm A) at atmospheric pressure, used to transfer heat to the $\mathrm{SiCl}_{4}$. A 500-1000 $\mathrm{W}$ heating tape is wound around the outside of the larger tube. Both heating units can be controlled from variacs, or through automatic solid state control units if desired. Liquid $\mathrm{SiCl}_{4}$ enters the bottom of the boiling vessel and passes out as a gas at the top. The tube from the boiling vessel to the injection nozzle is also heated to prevent condensation of $\mathrm{SiCl}_{4}$ vapor.

Two electrically-operated valves are provided for safety purposes: one to quickly stop the flow of $\mathrm{SiCl}_{4}$ by removal of electrical power, and the other to purge the boiling vessel and nozzle system with argon when desired. 


\section{REACTION DEMONSTRATION}

Task Tnvestigators: A. Y. Ranadive, I. F. C1libert1, and F. J. Harvey

\subsection{Summary}

The design of the test system has been completed and the majority of the equipment and system materials of construction have been procured. Fabrication of the sodium and silicon tetrachloride generation subsystems is in progress. Based on a detailed comparison of internal and external generation of sodium vapor, the external approach was selected because of the very large sodium containment crucible required for internal generation. As part of the design of the sodium generation system, set up tests were carried out to determine optimum materials and the basic configuration of the sodium conveying flowtrain and various methods were considered for controlling the sodium flow. The overall system design was discussed in detail by staff from both the R\&D Center and $P C B$ at a task design review.

During the upcoming quarter, fabrication of all system components will be finalized and assembly and installation of the entire apparatus will be completed. A test plan and schedule will be developed and shakedown testing initiated.

\subsection{Work Accomplished}

A schematic of the overall system is shown in Fig. 8.1. Sodium and silicon tetrachloride vapors will be generated externally and each separately introduced into the reaction tube along with an $\mathrm{Ar}-\mathrm{H}_{2}$ carrier gas. The reaction tube will be heated by a tubular globar furnace. Temperatures of up to $1920^{\circ} \mathrm{K}$ can be produced In a constant temperature hot zone which is 26 in. 10 g and 2 in. in internal diameter. Upon entering the furnace, the reactant vapors will be brought up to temperature and then allowed to mix and react in the isothermal reaction zone. The products of the reaction will 


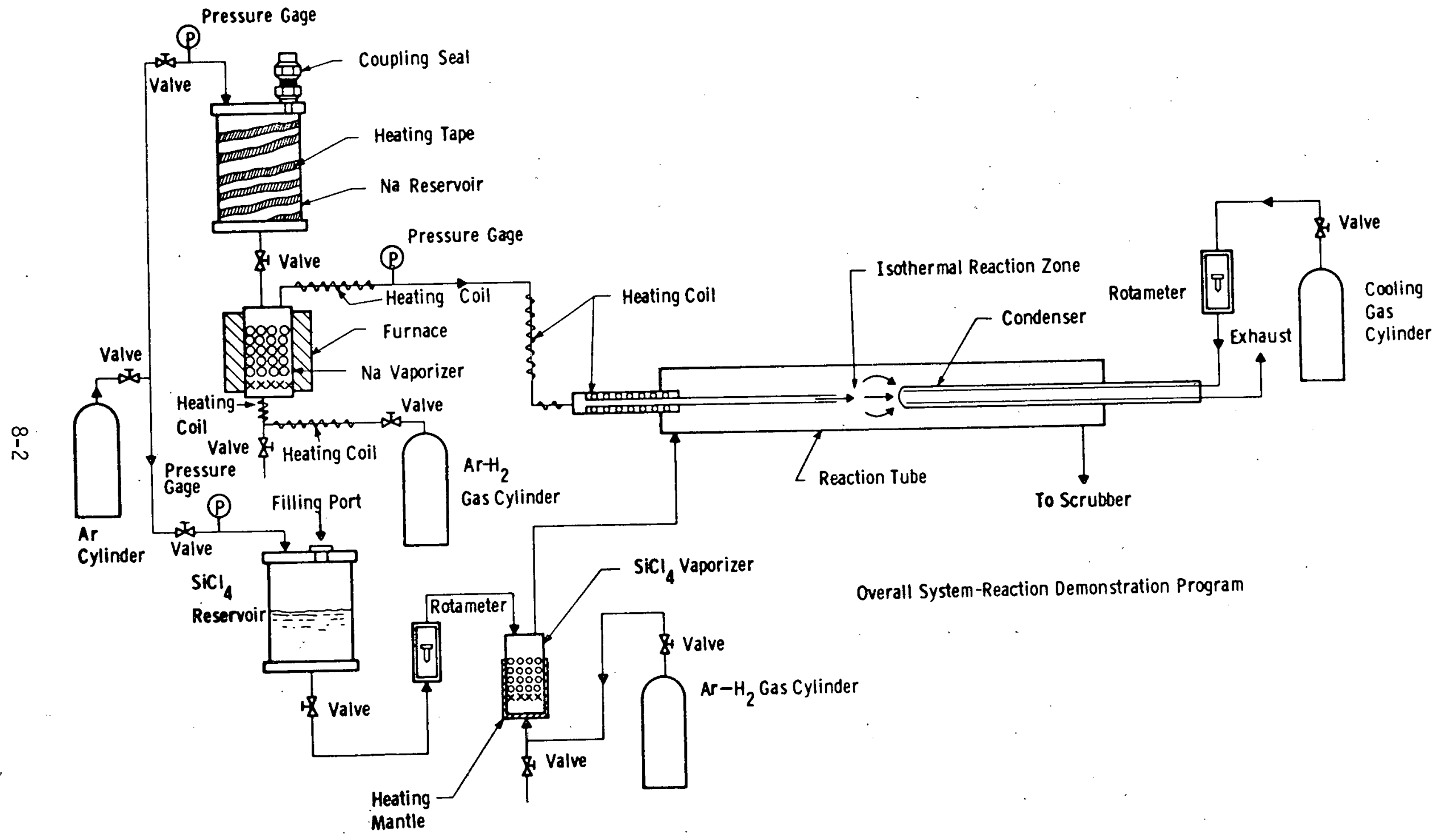

Figure 8.1 - Schematic of The Test System For The Reaction Demonstration Studies 
be condensed out on the surface of a cold finger type condenser while the uncondensed gases will exit from the side tube to a scrubber. The extent of the reaction will be determined by chemically analyzing and weighing the deposit on the condenser and also by determining the concentration of silicon chlorides in the scrubber.

The system is conveniently broken down into three subsystems, (1) The Reaction Tube and Condenser, (2) The $\mathrm{SiCl}_{4}$ System, and (3) The Na System.

As shown in Fig. 8.2, the reaction tube is a high alumina ceramic tube inserted concentrically into the heating tube of the furnace. The annular region between the reaction tube and the heating element will be.continuously swept with Ar. Stainless steel end plates with clamp attachments seal the reaction tube at either end. Sodium vapor from the vaporizer is piped into the reaction tube through an alumina tube wrapped with heating wire and jacketed In an outer tube of Inconel 600 which is connected to the stainless steel end plate by a conax packing gland. The $\mathrm{SiCl}_{4}$ vapor is introduced into the reaction tube through a stainless steel tube welded onto the end plate. The condenser is comprised of a sealed alumina tube which projects to the edge of the reaction zone and through which a cool gas will rapidly flow. The length of the reaction zone can be varied by appropriately varying the position of the condenser. The uncondensed gases will exit through a side tube cemented to the reaction tube at the far end.

The $\mathrm{SiCl}_{4}$ generator is shown in Fig. 8.3. The system consists of the reservoir, a flowmeter, a vaporizer and attendant tubing. Silicon tetrachloride is charged to the reservoir through the filling port. The liquid $\mathrm{SiCl}_{4}$ is transported to the vaporizer by means of the positive pressure of argon maintained over the reservoir. The required $\mathrm{SiCl}_{4}$ flow rate is established by means of the rotameter. The liquid $\mathrm{SiCl}_{4}$ enters the vaporizer where it is gasified and, subsequently, transported from the system by a $\mathrm{H}_{2}-\mathrm{Ar}$ carrier gas. 

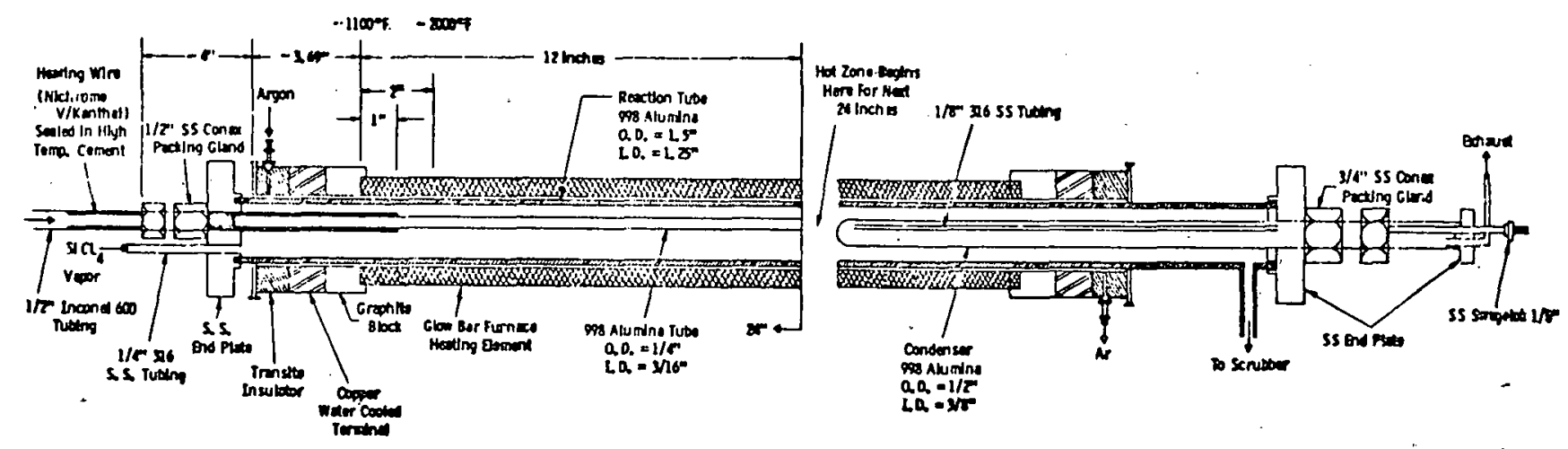

Figure 8.2 - Sketch of The Reaction Tube That Is Inserted In The Glow Bar Furnace 


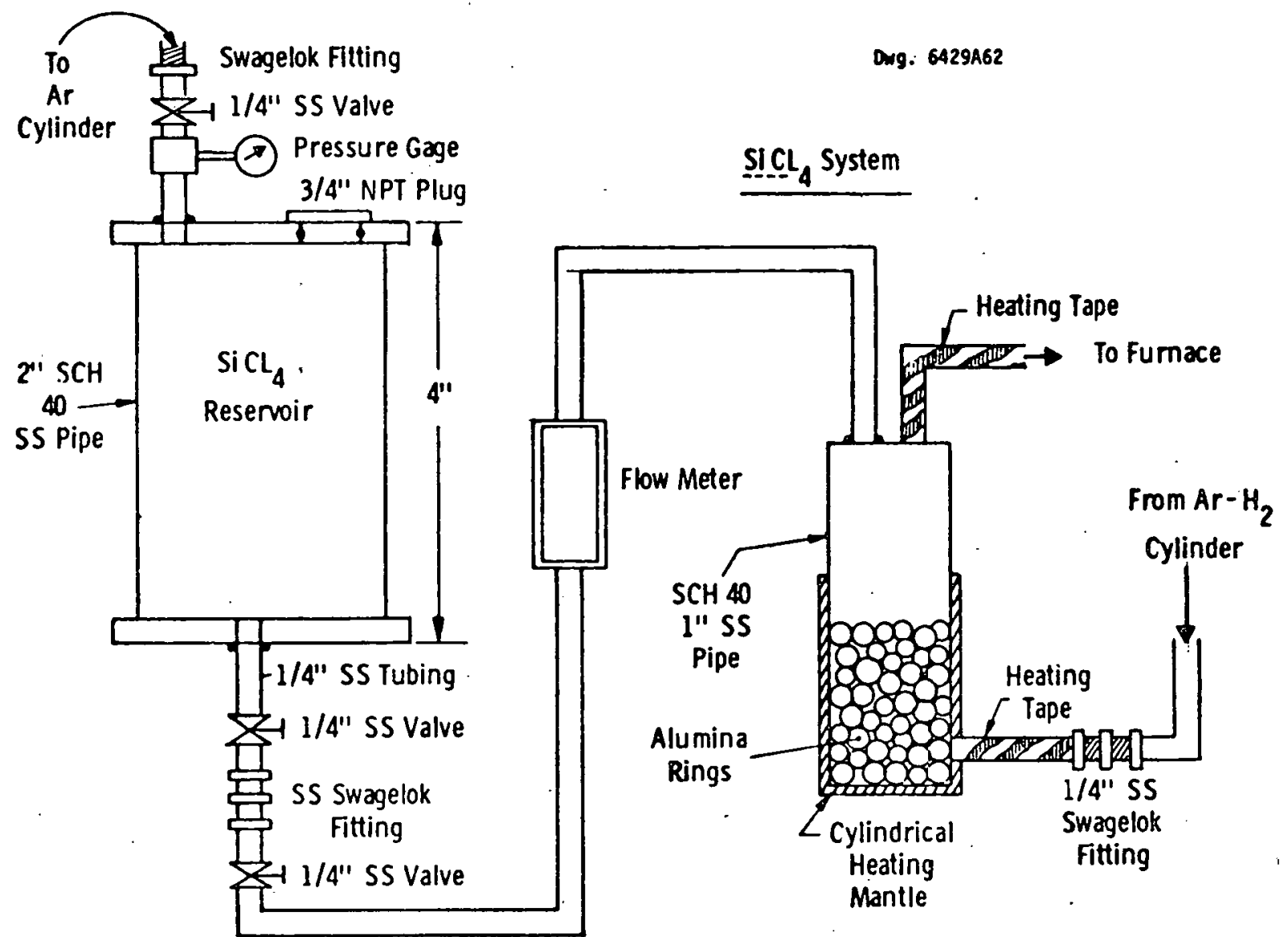

Figure 8.3 - Schematic of The $\mathrm{SiCl}_{4}$ System 
The sodium system shown in Fig. 8.4 is similar to the $\mathrm{SiCl}_{4}$ system with some exceptions which arise because of the higher melting and boiling points of $\mathrm{Na}$. For example, the Na reservoir and tubing are wrapped with heating tape and the $\mathrm{Na}$ vaporizer is enclosed in a furnace to achieve the high vaporization temperatures and heat requirements. Various methods have been considered for controlling the low $\mathrm{Na}$ flow (i.e., $5 \mathrm{ml} / \mathrm{min}$ of liquid $\mathrm{Na}$ ). While this low flow can be achieved using a positive displacement bellows pump, the pulsating output from this pump may be a problem. At the present time, it is planned to use a low flow metering valve to control the flow. A calibration experiment will be carried out to confirm the feasibility of this technique.

A number of set up tests were conducted in order to determine the optimum materials and configuration of the flowtrain between the sodium vaporizer and the reaction. Since vapor will be transported through this line, the temperature in the flowing gas stream must be on the order of $900^{\circ} \mathrm{C}$. Based on the results of these experiments, the flowtrain will consist of an inner alumina tube wrapped with Kanthal wire (11 turns/in.) and an outer Inconel tube. The annular space between the tubes will be filled with a high purity alumina based cement.

The required equipment and materials that have been procurred include a Harper model GTW-2D48-HT30-SP globar furnace (the instrumentation and control system have not yet been obtained), Flowmeters for controlling the $\mathrm{H}_{2}$-Ar-gas and liquid $\mathrm{SiCl}_{4}$ flows, and ceramic tubes for the reactor. Fabrication of all subsystem components is currently in progress. 


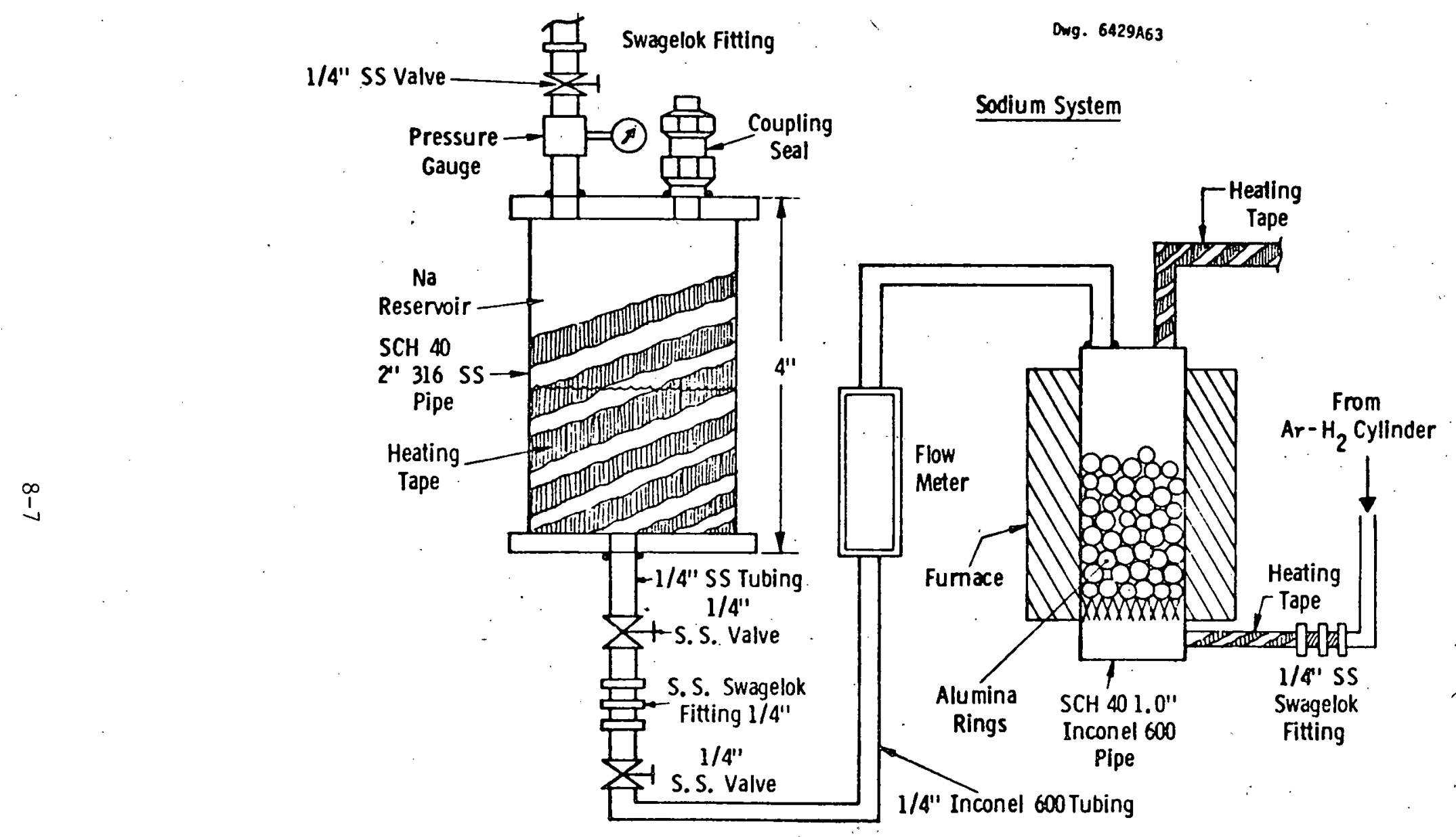

Figure 8.4 - Schematic of The Sodium System 


\section{PRODUCT SEPARATION ANALYSIS}

Task Investigators: F. J. Harvey, T. N. Meyer, D. F. Ciliberti, R. E. Kothmann and J. A. Cyphers

\subsection{Summaxy}

During the quarter, analyses have continued for the purpose of defining a design which provides effective silicon product separation. Two approaches to product separation have been pursued. The first separation mode examines silicon separation via condensation following a high temperature reaction producing superheated silicon vapor. The condensation model results indicate that $80 \%$ of the silicon can be removed via condensed silicon collecting at the reactor wall. The design has been modified (see section 4.2.2) to accomodate the higher temperature process, (e.g., initial product gas stream temperature of $3500^{\circ} \mathrm{K}$.) The basic design configuration has not changed from that previously presented.

The second approach depends upon a heterogeneous reaction mode which permits effective product separation. An analysis examined a partial low temperature reaction followed by a high temperature thermal treatment process step. The success of this approach depended upon:

a) an initial partial reaction with $\mathrm{Na}$ droplets forming large particulate* comprised of $\mathrm{Na}, \mathrm{NaCl}$, and $\mathrm{Si}$ (i.e., 50um in size),

b) a high temperature arc heater gas treatment with the remaining reaction proceeding homogeneously and forming ultrafine submicron silicon particulate, and

c) the final collection of the silicon submicron particles onto the particles formed in step (a).

*The word particulate used in this writing does refer to both the solid and liquid phases. 
The collection mechanisms (i.e., coagulation by Brownian motion and turbulence) known to exist for this mode of reactor flow are not belleved adequate for effective collection. If the actual process does in fact proceed as described in step (b) and is not dominated by some heterogeneous process, the following two alternate heterogeneous modes may be capable of effective product separation:

I) Complete the $\mathrm{Na}, \mathrm{SiCl}_{4}$ reaction at low temperatures followed by a thermal treatment with arc heater gas to vaporize off $\mathrm{Na}$ and $\mathrm{NaCl}$ leaving behind the large molten silicon particles to be separated inertially.

II) Perform an inftial reaction as described in step (a) above and then provide a high temperature reaction with the remalning product silicon existing in the vapor state to be condensed onto the initially form seed material.

From the results of the product separation study, it was concluded that the Phase II design (see section 4.2.2) will be based upon the condensation mode. Even though high product separation efficiency is indicated for a reactor operated in this manner, considerations of both power requirement and reactor product flow rate may justify a slight modification of the reactor to examine heterogeneous mechanisms for the actual process. Fortunately, the basic reactor is rcadily adaptable to the various heterogeneous operating modes.

\subsection{Product Separation By Condensation}

The previously Quarterly Report ${ }^{2}$ described the condensation model development in progress. This quarterly will report:

a) the means by which the one dimensional mass and energy conservation equations are integrated with the fully developed, constant property, turbulent boundary layer analysis,

b) the relations utilized for mass, momentum, and energy 
transport for developing turbulent pipe flow,

c) the additional transport property set required due to a change in the reactant gas stream fraction, and.

d) the results of the condensation analysis.

Relations were developed ${ }^{2}$, to assess the influence of boundary layer condensation upon the mass and energy transport to the wall. Due to the complexity of the physical mechanisms controlling this process, the following assumptions have been made:

a) a constant property universal velocity profile 6 can be used to assess condensation effects upon heat and mass transfer,

b) silicon condensate forming in the boundary layer is collected by the wall,

c) the energy transported to the wall as a result of the molten droplets exceeding the wall temperature is neglected,

d) the Schmidt number is approximately equal to the prandt 1 number,

e) the wall temperature is equal to the silicon melt temperature,

f) as a result of (e) the mass fraction of silicon vapor at the wall is essentially neglibible for assumed equilibrium conditions, and

g) the turbulent heat and mass transfer analogy is valid.

From the results developed in the previous quarterly ${ }^{2}$, the ratio, $R_{m}$, of silicon mass transfered with condensation occurring in the boundary layer to that transferred without condensation occurring in the boundary layer is represented as:*

$$
R_{m}=\frac{T_{s}-T_{w}+\frac{\lambda}{C_{p}} w_{s}}{\left[\left(\frac{d T}{d W}\right)_{*}+\frac{\lambda}{C_{p}}\right]\left|w_{s}-W_{w}\right|}
$$

*A nomenclature table is given at the end of the section. 
Similarly it can be shown that the ratio, $R_{Q}$, of heat transferred at the wall with condensation occurring in the boundary layer to the condition where no condensation occurs is represented as:

$$
R_{Q}=\frac{T_{s}-T_{w}+\frac{\lambda}{C_{p}} W_{s}}{T_{s}-T_{w}}
$$

The one dimensional relation accounting for axial variations resulting from radial mass and heat transport are reviewed with respect to the transport modifiers (see equations 1 and 2 ). 'l'he conservation of silicon flow is given as:

$$
\left.\frac{\mathrm{d} \dot{m}}{\mathrm{dz}}=-\mathrm{Nu}^{\prime} \mathrm{D}_{\mathrm{Si}-\mathrm{M}} \pi \mathrm{C} \mid \mathrm{x}_{\mathrm{Si}}-\mathrm{X}_{\mathrm{Si}}\right) \mathrm{R}_{\mathrm{m}}
$$

The conservation of energy equation can be written as:

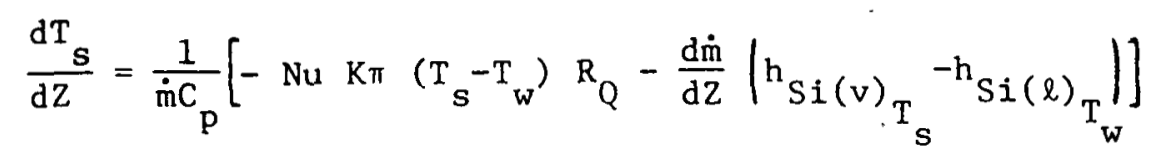

As a consequence of assumptions (e) and (f), all silicon reaches the wall in the liquid state. The diffusion coefficient and thermal conductivity are evaluated at the film temperature.

The consequence of combining these relations reduces to a one dimensional analysis accounting for axial stream property variations while correcting the transport relations based upon a constant property turbulent boundary layer having a universal velocity profile.

The relations above expressing the conservation of mass and energy must include the representation for mass and heat transfer coeffictents. In ordinary turbulent, straight flow in a tube the 
heat transfer coefficient ${ }^{7}$ may be expressed in terms of the friction factor, $\lambda$, as:

$$
\mathrm{Nu}=\frac{\operatorname{Re}_{D} \operatorname{Pr} \sqrt{\lambda / 8}}{.833\left[5 \operatorname{Pr}^{2}+5 \ln (5 \operatorname{Pr}+1)+2.5 \ln \left(\frac{\operatorname{Re}_{D} \sqrt{\lambda / 8}}{60}\right)\right]}
$$

This may be approximated as:

$$
N u=N u_{\infty} \sqrt{\lambda / \lambda_{\infty}}
$$

where:

$$
\mathrm{Nu}_{\infty}=0.023 \operatorname{Re}_{\mathrm{D}} \cdot 8_{\mathrm{Pr}^{1 / 3}}^{1 / 3}
$$

Reference 8 provides a conservative representation of $\lambda / \lambda_{\infty}$ given as:

$$
\left.\frac{\lambda}{\lambda_{\infty}}=1+1.5 \exp \mid-0.25 \frac{\mathrm{x}}{\mathrm{D}}\right)
$$

Boelter and coworkers? experimentally determined local heat transfer coefficients for turbulent flow entering via a right angle bend and their results are shown in Figure 9.1. It can be seen that the use of relations (6) and (8) will yield lower values of $\mathrm{Nu}$ than shown in Figure 9.1. Thus, these relations will predict conservatively and longer reactor lengths required. It should be noted that the reactor Reynolds numbers are nominally 50,000 
Curve 693981-A

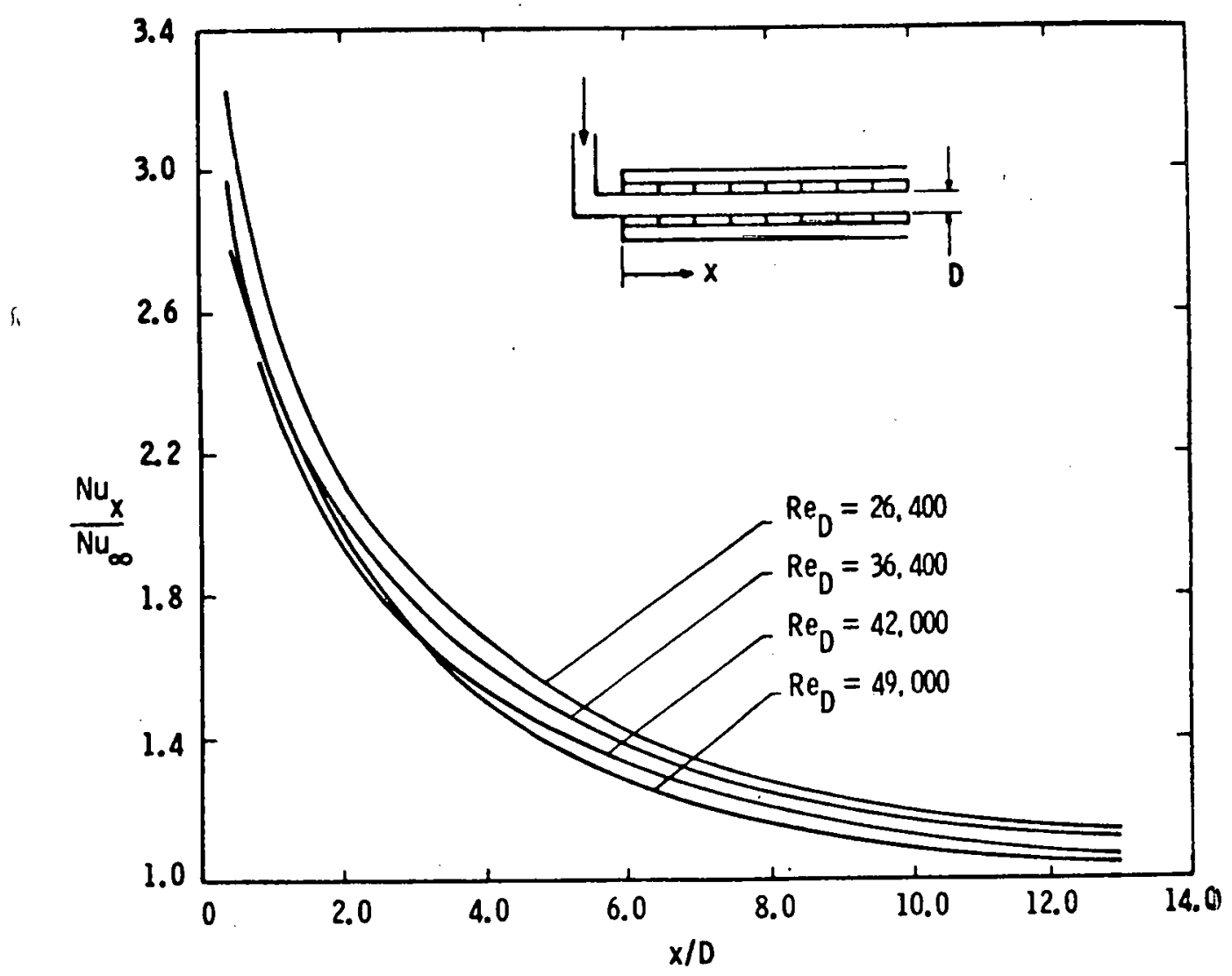

Figure 9.1 - Local Nusselt Number Ratio vs. Distance Ratio Obtained From Boelter \& Coworkers' Measurements

On A Circular Tube With Right Angle Bend Entrance 
and are comparable to the experimental results shown.

As a result of an analysis using the composition described in the previous quarter $1 \mathrm{y}^{2}$ (i.e., $4.0 \mathrm{Na}, 1.0 \mathrm{SiCl}_{4}, 3.31 \mathrm{H}_{2}, 0.83 \mathrm{Ar}$ ), the arc heater characteristics are not compatible with an initially high product temperature (e.g., $3500^{\circ} \mathrm{K}$ ) required to maintain silicon in the superheated state. To obtain a high temperature product gas stream, it became necessary to change to a gas mix having one half the amount of reactants (i.e., $2.0 \mathrm{Na}, 0.5 \mathrm{SiCl}_{4}, 3.31 \mathrm{H}_{2}$, $0.83 \mathrm{Ar})$. For a silicon flow of $1001 \mathrm{~b} / \mathrm{hr}$, an arc heater power input of $1.54 \mathrm{MW}$ is required for the $3500^{\circ} \mathrm{K}$ initial temperature.

The power facility at the East Pittsburgh site and the arc heater are compatible with this new composition and the $1001 \mathrm{~b} / \mathrm{hr}$ flow of silicon. As a result of this change, new property data was determined and this data is displayed in Table 9.1. After the reaction is complete, silicon vapor begins leaving the flowing stream and condensing onto the reactor wall. Thus, the properties must be a function of temperature and the total content of silicon. The equilibrium. properties are determined for:
a) $\underline{\beta^{*}=1.0}$
b) $\underline{\beta}=0.5$
c) $\underline{B}=0.00$
$2.0 \mathrm{Na}$
$2.0 \mathrm{Na}$
$2.0 \mathrm{Na}$
$2.0 \mathrm{C} 1$
$2.0 \mathrm{Cl}$
$2.0 \mathrm{Cl}$
$0.5 \mathrm{Si}$
$0.25 \mathrm{Si}$
$0.00 \mathrm{Si}$
$3.31 \mathrm{H}_{2}$
$3.31 \mathrm{H}_{2}$
$3.31 \mathrm{H}_{2}$
$0.83 \mathrm{Ar}$
$0.83 \mathrm{Ar}$
$0.83 \mathrm{Ar}$

For calculation purposes, all properties except enthalpy and silicon mole fraction were not found to be significantly affected by the relative fraction of silicon remaining in the stream. Thus, this two dimensional numerical interpolation need be performed only for the mole fraction and gas enthalpy during actual calculations.

$*_{f}=1.0$ corresponds to the initial fraction of elemental silicon, $\beta=0.5$ corresponds to the mixture containing 0.5 of the initial fraction of elemental silicon. 


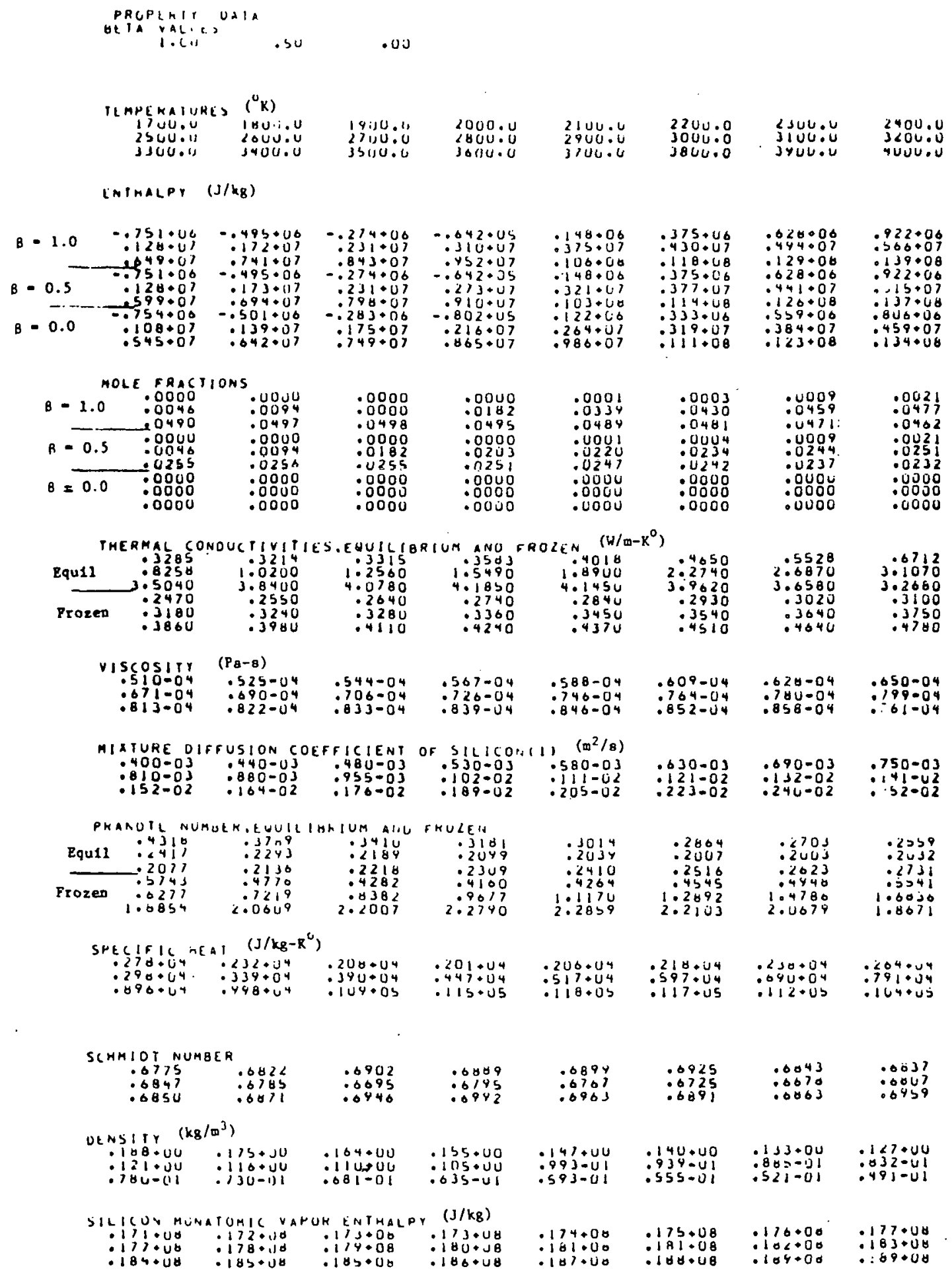

NUMINAL GUMPUSIIION OF 2.0 NA.0.SSI.2.0CL.3.31 HC.O. BSAK

Table 9.1 - Equilibrium Properties 
Table 9.1 lists properties as functions of temperature for a range of $1700^{\circ} \mathrm{K}$ to $4000^{\circ} \mathrm{K}$ (i.e., at a pressure of $1 \mathrm{~atm}$ ). For example, the mixture enthalpy for $T=2800^{\circ} \mathrm{K}$ and $\beta=0.5$ is $0.273 \times 10^{7} \mathrm{~J} / \mathrm{kg}$.

The condensation results are calculated by use of a forward step numerical integration. The calculations included the following assumptions:

a) transition from superheat to saturated conditions occur at a vapor pressure equal to the saturation pressure,

b) the minor fraction of the silicon diffusing from the stream in the form of other species (e.g., $\mathrm{SiCl}, \mathrm{SiCl}_{2}$, $\mathrm{Si}_{2}, \mathrm{Si}_{3}$, and $\mathrm{SiH}$ ) is taken into account by using an effective silicon mole fraction,

c) radiant energy exchange has been neglected, and

d) the inner reactor wall is constant in diameter having a temperature equal to the melting point of silicon (i.e., $1685^{\circ} \mathrm{K}$ ).

Results indicating a reasonable silicon product separation are shown in Figure 9.2. The results shown in Figure 9.2, indicate a product separation of $80 \%$ can be achieved. It is also shown that the saturation point occurs within $1 \mathrm{~cm}$ of the wall for the majority of the product separation. For the case shown in Figure 9.2, a pressure drop of 0.03 atm occurred over a 8.0 meter axial length. Thus, pressure drop is not significant for the $15 \mathrm{~cm}$ internal diameter reactor. It should also be noted that the constant diameter can be approximately realized by simply adjusting the effective wall thermal resistance. Such a wall configuration is now being determined for the nominal operating flow rate for silicon of $1001 \mathrm{~b}_{\mathrm{m}} / \mathrm{hr}$.

\subsection{Heterogeneous Reaction Analysis}

A heterogeneous reaction path by which the arc heater reduction of $\mathrm{SiCl}_{4}$ can be accomplished has been previously outlined ${ }^{2}$ including the basis of two models of simultaneous heat and mass transfer. As 


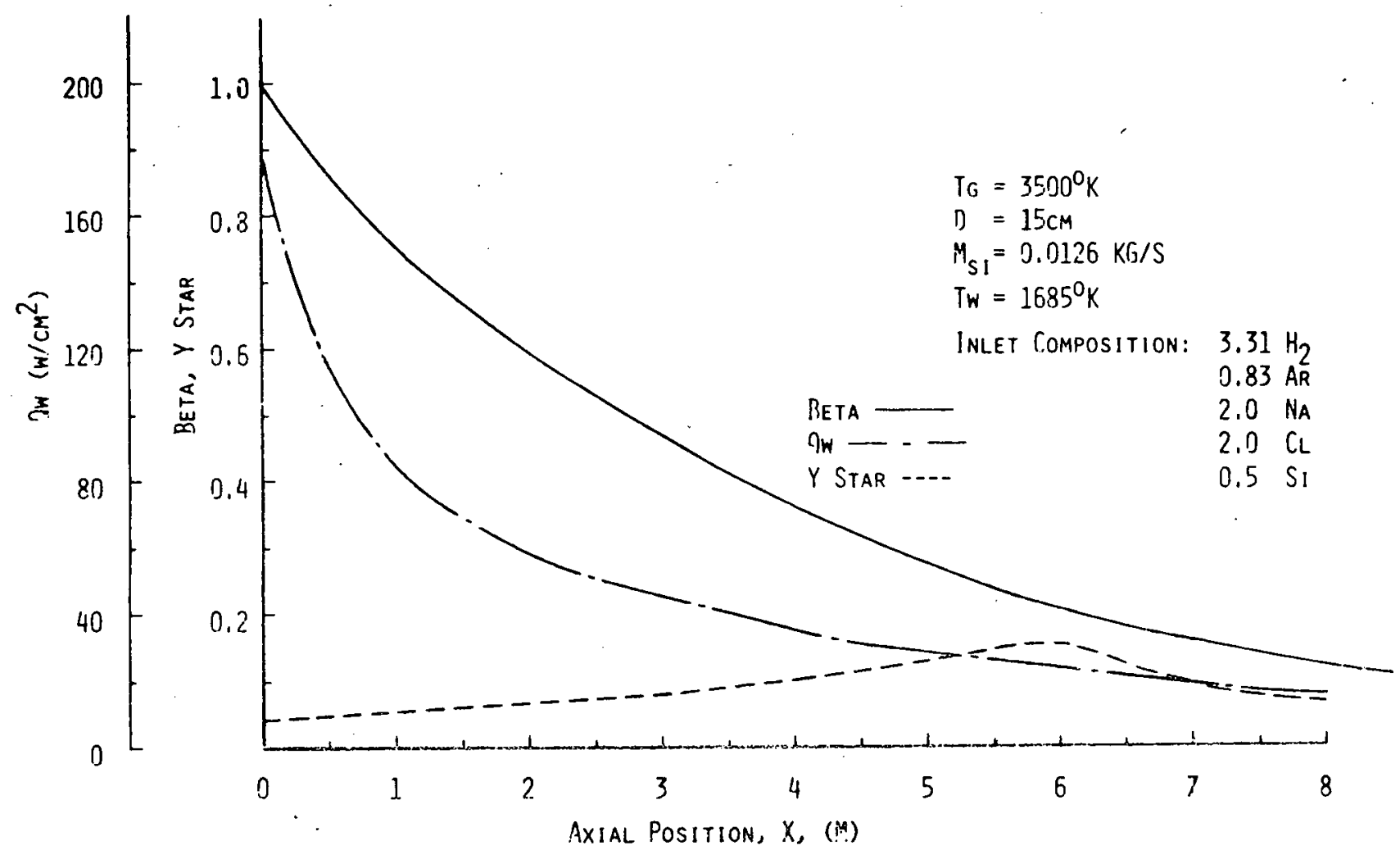

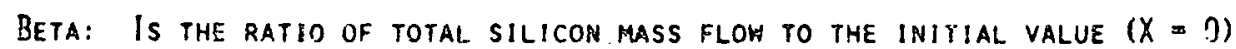

Y STAR: IS THE RATIO OF RADIAL DISTANCE FRDM THE HALL HHERE TRANSITION FROM SATURATION TO SUPERMEAT OCCURS TO THE REACTOR RADJUS.

QW: IS THE REACTOR HALL HEAT FLUX $\left(W / \mathrm{CM}^{2}\right.$ )

Figure 9.2 - Dependence of Product Separation (Beta), Condensation Location (T Star) And Heat Flux (Qw) Upon Axial Position

(Equilibrium) 
TABLE 9.2

NOMENCLATURE (For Condensation Analysis)

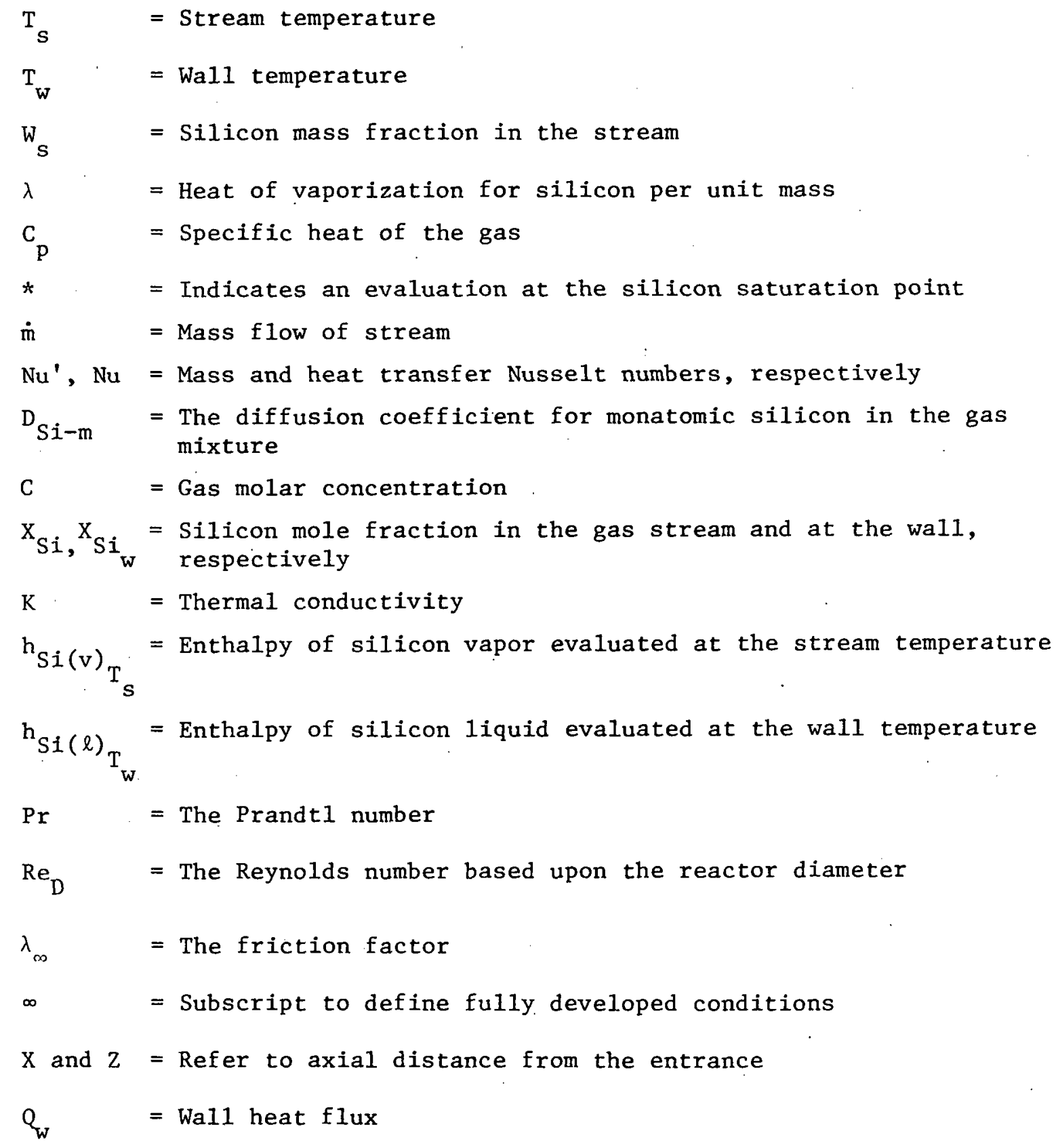


shown in Figure 9.3 this reaction sequence consists of (1) a low temperature reaction between gaseous silicon tetrachloride and liquid sodium producing a multicomponent droplet of $\mathrm{Si}, \mathrm{NaCl}$ and unreacted $\mathrm{Na}$ (if present), and (2) a thermal treatment in which both the Na (if present) and $\mathrm{NaCl}$ are removed from the droplet by vaporization and the silicon is melted. The intended result of the overali process is to produce large droplets of molten silicon which can be collected by inertial means. In concert with the dual nature of this reaction sequence, two analytical models, i.e., a reaction $\mathrm{mrdel}$ and a thermal treatment model, were constructed.

Depending on the composition of the droplet produced in the low temperature reactor, the thermal treatment can be carried out in two different manners. If complete conversion to $\mathrm{NaCl}$ and $\mathrm{Si}$ occurs during the low temperature reaction, then the thermal treatment involves no further chemical reactions* only a physical heat affectation involving vaporization and melting. As previously ciscussed, ${ }^{2}$ the extent of the low temperature reaction may be slowed down by the formation of a solid product skin on the droplets. If the low temperature reaction is impeded then the remaining $\mathrm{SiCl}_{4}$ will react with the unconverted $\mathrm{Na}$ during thermal treatment in a homogeneous manner producing fine droplets. If a scavenging type coljection mechanism is effective, these latter droplets may bc collected by collision with the partially converted larger droplets. In the case that the scavenging mechanism would require an unreasonably large reactor vessel, then the overall reaction can be carried out in a different manner. Only part of the $\mathrm{SiCl}_{4}$ would be introduced into the low temperature reactor with the remainder injected at the exit of the thermal treatment section. In addition, the temperature of this exit gas stream would be above the dew point of liquid silicon. Under these conditions, the reaction between the $\mathrm{Na}$ vapor and gaseous $\mathrm{SiCl}_{4}$ would produce silicon vapor which could be removed from the gas stream by condensation.

*Assuming the $\mathrm{NaCl}$ and $\mathrm{Si}$ products are immiscible. 


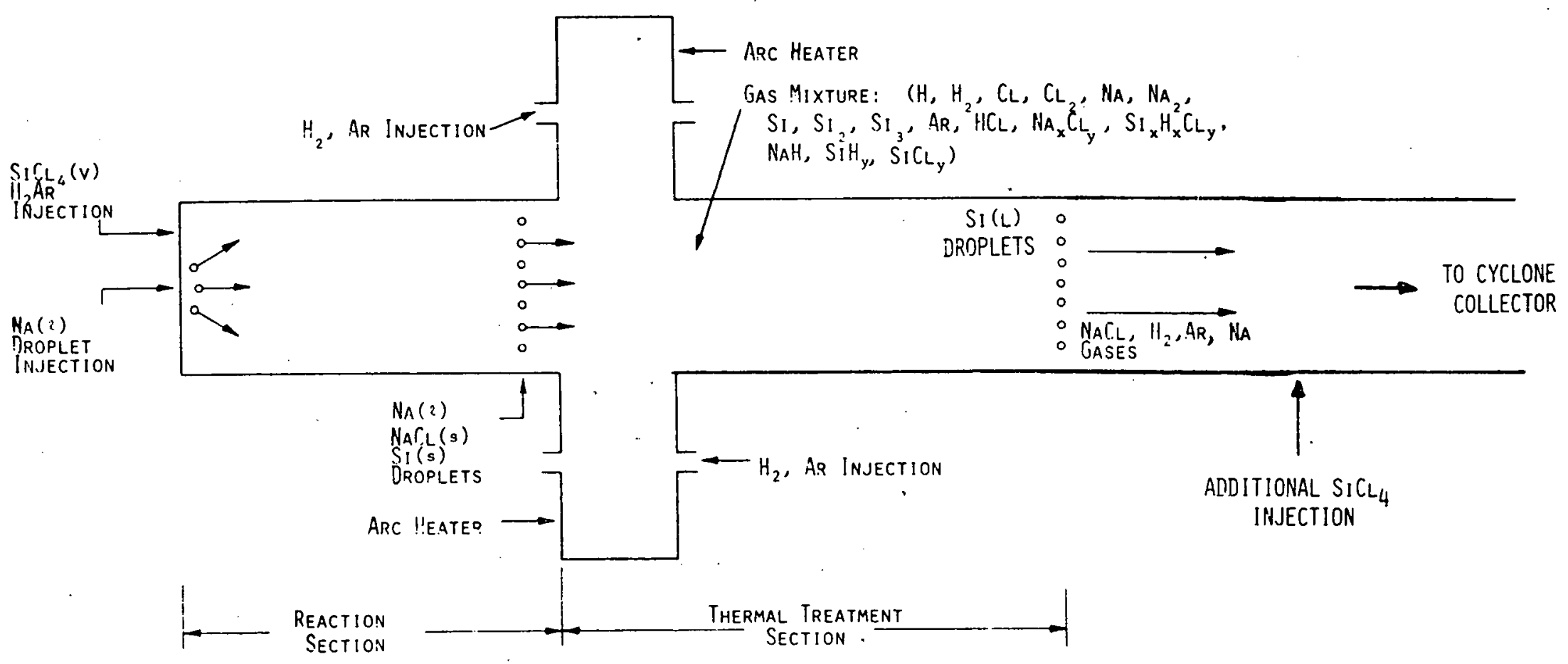

Figure 9.3 - Schematic Representation of Silicon Reactor System In Which The Reduction of $\mathrm{SiCl}_{4}$ Is Carried Out In A Heterogeneous Mode 
The mathematical formulation of the low temperature reaction and thermal treatment models is given below along with some selected results. The latter model will initially be formulated under the assumption that the low temperature reaction is incomplete, i.e., the worst case, and all $\mathrm{SiCl}_{4}$ is added to the gas stream in the reaction section. Consequently, the experimental viability of this thermal treatment approach is dependent on the effectiveness of the scavenging collection mechanism. The plasma reactor configuration in which some of the $\mathrm{SiCl}_{4}$ is added at the exit of the thermal treatment section will be considered in the future.

A potential problem can arise in the formulation of the reaction model as a result of the exothermic nature of the $\mathrm{Na}^{-\mathrm{SiCl}_{4}}$ reaction. A very rapid temperature rise of the droplets may occur depending on the relative rates of heat and mass transfer. If the temperature is high enough, sodium vaporization will commence. The formulation of the reaction model is much simpler if sodium vaporization does not occur during the low temperature reaction, but only during the thermal treatment. Consequently, if a rapid droplet temperature rise does occur, then only part of the $\mathrm{SiCl}_{4}$ will be introduced into the gas stream at the reaction section entrance with the remaining added at the exit of the reaction section, i.e., the entrance to the thermal treatment section (see Figure 9.3). This dual addition of $\mathrm{SiCl}_{4}$ in the reaction section is consistent with the heterogeneous model as presently formulated since only part of the overall reaction is assumed to occur in the reaction section because of solid product formation, while the remainder occurs during thermal treatment. 


\subsubsection{Low Temperature Reaction Model}

\section{Droplet Equations}

The equation describing the extent of reaction as a function of time (or position), is simply given by:*

$$
\frac{\mathrm{d} \xi}{\mathrm{d} t}=\frac{-1}{\mathrm{~N}_{\mathrm{Na}}^{\circ}} \frac{\mathrm{dN} \mathrm{Na}_{\mathrm{d}}}{\mathrm{dt}}=\frac{-4 \omega}{\mathrm{SiCl}_{4}}
$$

where

$$
\xi(Z)=\frac{\mathrm{N}_{\mathrm{Na}}^{\mathrm{O}}-\mathrm{N}_{\mathrm{Na}}(\mathrm{t})}{\mathrm{N}_{\mathrm{Na}}^{\mathrm{O}}}
$$

The initial conditions can be used to replace $\mathrm{N}_{\mathrm{Na}}^{\circ}$ in this equation as follows where $f$ is the fraction of stoichiometric feed ratio of $\mathrm{SiCl}_{4}$ to $\mathrm{Na}$, i.e., $\mathrm{f}=1$ implies a. $1 \mathrm{SiCl}_{4}$ to $4 \mathrm{Na}$ feed ratio, $\mathrm{f}=1 / 2$ implies only $1 / 2$ the amount of $\mathrm{SiCl}_{4}$ required by stoichiometry is fed.

$$
4\left(\mathrm{CV}_{\mathrm{g}} \mathrm{y}_{\mathrm{SiCl}_{4}}\right)_{\mathrm{Z}=0}=\mathrm{f}\left(\mathrm{N}_{\mathrm{Na}} \cdot \lambda \mathrm{V}_{\mathrm{D}}\right)_{\mathrm{Z}=0}
$$

or

$$
\mathrm{N}_{\mathrm{Na}}^{\circ}=\left[\frac{\mathrm{C}_{\mathrm{g}} \mathrm{y}_{\mathrm{SiCl}_{4}}}{\mathrm{f \lambda}}\right]_{\mathrm{Z}=0}
$$

\footnotetext{
*A nomenclature table is given at the end of the section.
} 
This leads to the following form of the extent equation:

$$
\frac{d \xi}{d z}=\left(\frac{-f \lambda}{C_{g}{ }^{S_{S i C 1_{4}}}}\right)_{z=0}\left(\frac{{ }^{\omega} \mathrm{SiCl}_{4}}{\mathrm{v}_{D}}\right)
$$

A heat balance on the droplet that includes convective transfer to the gas, radiative transfer to the walls and heat of reaction on the droplet surface leads to the following equation for the droplet temperature:

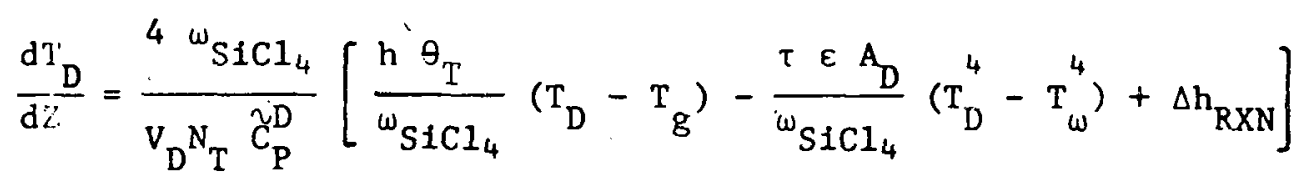

where

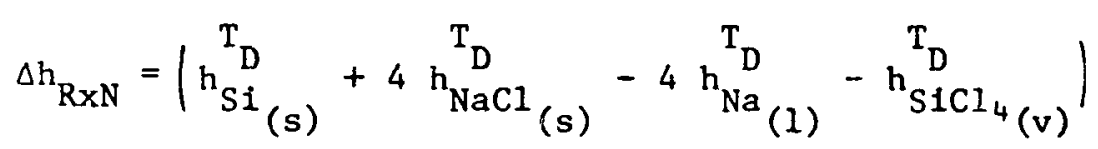

In this expression the convective heat transfer coefficient has been corrected for high mass transfer rates. Appropriate expressions for $h$ and $\theta_{T}$ are given in the discussion of the thermal treatment model.

\section{Gas Equations}

A general expression for the heat balance on the gas flow is stated as:

$$
\nabla \circ\left(\tilde{C}_{g \cdot g} \mathrm{~V}_{g}\right)=-\dot{S}+\lambda \tau \in\left(T_{D}^{4}-T_{\omega}^{4}\right)
$$




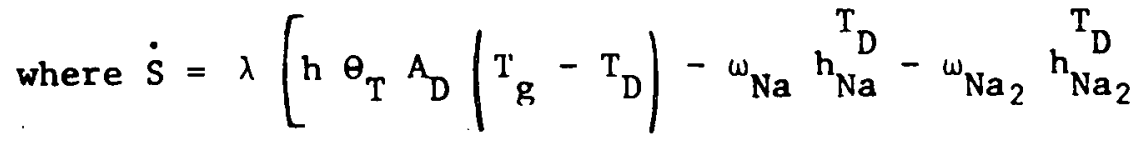

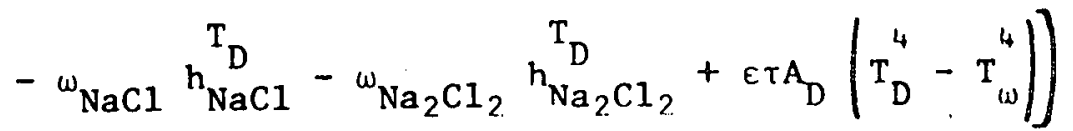

After manipulation, equation (8) can be rearranged in the following manner for the case at hand:

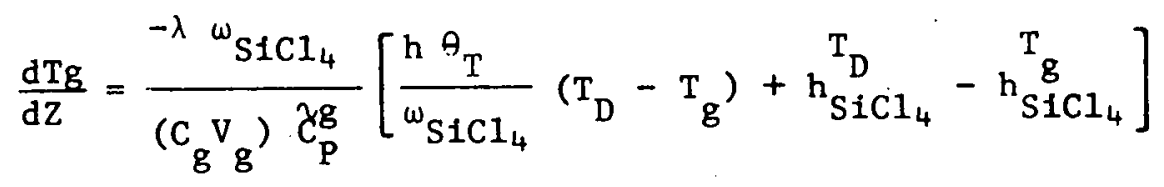

The total molar gas flow and species mole fractions can be obtained by use of an overall balance and a species balance, respectively. This results in the following set of equations for the gas phase flow and composition:

$$
\begin{aligned}
& \frac{d\left(C_{g} v_{g}\right)}{d z}=\lambda \omega_{\mathrm{SICl}_{4}} \\
& \frac{{ }^{d y_{S_{C C 1}}}}{d z}=\frac{{ }^{\lambda}{ }^{\omega}{ }_{\mathrm{SiCl}_{4}}}{{ }_{g} V_{g}}\left(1-y_{\mathrm{SiCl}_{4}}\right) \\
& \frac{d y_{H_{2}}}{d z}=\frac{-\lambda{ }^{\omega}{ }_{S 1 C 1_{4}}}{C_{g} V_{g}} y_{H_{2}} \\
& \mathrm{y}_{\mathrm{Ar}}=1-\mathrm{y}_{\mathrm{SICl}_{4}}-\mathrm{y}_{\mathrm{H}_{2}}
\end{aligned}
$$


A zero molar flow of $\mathrm{H}_{2}$ and $\mathrm{Ar}$ to the droplet surface is implicit in these equations. The $\mathrm{SiCl}_{4}$ flow to the droplet is the only non zero flow and is given by:

$$
{ }^{\omega_{S i C l}}{ }_{4}=k_{\mathrm{SiCl}_{4}-\mathrm{m}} \mathrm{A}_{\mathrm{D}} \ln \left[\frac{1-\mathrm{y}_{\mathrm{SiCl}_{4}}}{1-\mathrm{y}_{\mathrm{SiCl}_{4}}^{\mathrm{s}}}\right]
$$

The surface mole fraction, $\mathrm{y}_{\mathrm{SiCl}_{4}}^{\mathrm{s}}$, can be obtained from the equilibrium constant for the $\mathrm{SiCl}_{4}-\mathrm{Na}$ system.10

The mass transfer coefficient for $\mathrm{SiCl}_{4}$ through the mixture, and corrected for high rates was oblained in the same fashion that was employed in the thermal treatment analysis presented below.

This analysis has resulted in six differential equations, $5,6,10,11,12$ and 13 , for $\xi, T_{D}, T_{g},\left(C_{g} V_{g}\right), y_{S_{i C l}}$ and $\mathrm{y}_{\mathrm{H}_{2}}$. It is apparent that only three of these equations are Independent as the equations for $\xi,\left(\mathrm{C}_{g} \mathrm{~V}_{\mathrm{g}}\right)$ and $\mathrm{y}_{\mathrm{H}_{2}}$ can be solved in terms of $\mathrm{y}_{\mathrm{SiCl}_{4}}$. The resulting system of three differential equations and the concomitant algebraic equations can be solved using standard numerical integration techniques.

\subsubsection{Thermal Treatment Model}

\section{Droplet Equations}

The equations describing the steady state exchange of heat and mass across the surface of a single spherical droplet under the previously discussed assumptions are: ${ }^{2}$ 


$$
\begin{aligned}
& \frac{\mathrm{dN}_{\mathrm{Na}}^{\mathrm{D}}}{\mathrm{dZ}}=\frac{1}{\mathrm{v}_{\mathrm{D}}}\left|\omega_{\mathrm{Na}}+2 \omega_{\mathrm{Na}_{2}}\right| \\
& \frac{\mathrm{dN} \mathrm{NaCl}_{\mathrm{N}}^{\mathrm{D}}}{\mathrm{dZ}}=\frac{1}{\mathrm{v}_{\mathrm{D}}}\left|\omega_{\mathrm{NaCl}}+2 \omega_{\mathrm{Na}_{2} \mathrm{Cl}}\right| \\
& \frac{\mathrm{dN} \frac{\mathrm{S}}{\mathrm{dZ}}=0}{}
\end{aligned}
$$

$$
\frac{d r_{D}}{d Z}=-\frac{1}{4 \pi r_{D}^{2} v_{D}}\left(\frac{{ }_{\mathrm{Na}}+2 \omega_{\mathrm{Na}}}{\rho_{\mathrm{Na}}}+\frac{{ }_{\mathrm{NaC1}}+2 \omega_{\mathrm{Na}} \mathrm{Cl}_{2}}{\rho_{\mathrm{NaCl}}}\right)
$$$$
\left.\frac{d T_{D}}{d Z}=\frac{3}{4 \pi r_{D}^{3} v_{D} C_{P}^{D}}\left(h \theta_{T} A_{D}\left(T_{g}-T_{D}\right)-\varepsilon T \Lambda_{D} \mid T_{D}^{\prime \prime}-T_{W}^{4}\right)+Q_{N a}+Q_{N a C 1}\right)
$$

where

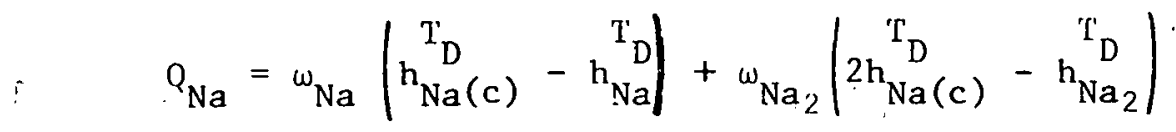

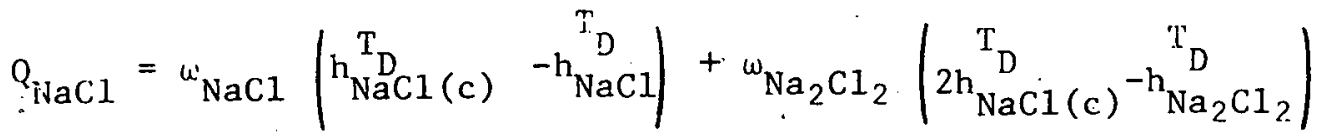

*Wa11 losses are assumed negligible. 
The heat transfer correction coefficient for mass transfer is given by the expression: ${ }^{11}$

$$
\theta_{\mathrm{T}}=\frac{\emptyset_{\mathrm{T}}}{\mathrm{e}^{\emptyset_{\mathrm{T}}-1}}
$$

where

$$
\emptyset_{T}=\frac{\sum_{j}^{\omega_{j} / A_{D}} \tilde{c}_{P}^{j}}{h}
$$

Under conditions that the melting point of the sodium chloride or silicon is reached, then the temperature derivative in equation (20) is zero. For the case of NaCl fusion, a droplet energy balance yields the following equations:

$$
\begin{aligned}
& \frac{d f_{N a C l}^{M}}{d Z}=\frac{1}{N_{N a C l}^{D o} V_{D} h_{N a C l}^{M}}\left[{ }_{T} A_{D}\left|T_{g}^{-T_{N a C l}^{M}}\right|+\right. \\
& \left.-\varepsilon \tau A_{D}\left|T_{N a C l}^{M}-T_{w}{ }^{4}\right|+Q_{N a}+Q_{N a C l}\right]
\end{aligned}
$$

where $\mathrm{f}_{\mathrm{NaCl}}^{\mathrm{M}}$, the fraction melted, can be represented as:

$$
\mathrm{f}_{\mathrm{NaCl}}^{\mathrm{M}} \stackrel{\sim}{=} \frac{\mathrm{N}_{\mathrm{NaC1}}^{\mathrm{Do}}-\mathrm{N}_{\mathrm{NaCl}}^{\mathrm{D}}}{\mathrm{N}_{\mathrm{NaCl}}^{\mathrm{Do}}}
$$

A similar formulation can be performed for silicon melting. 
In order to solve the above sets of non-linear, coupled differential equations, a knowledge of the gas temperature, $T_{g}$, the gas velocity, $\mathrm{V}_{\mathrm{g}}$ and the molar rates, $\omega^{\prime}$ s are required. The molar flow of any species, $i$, is given by the equation:

$$
\omega_{i}=k_{i-M} \theta_{i-M} M^{A} D\left(x_{i}^{s}-x_{i}^{g}\right)+x_{i}^{s} \sum_{j} w_{j}
$$

where the multicomponent mass transfer coefficient, $k_{i-M}$, is given by the expression:

$$
k_{i-M}=\frac{C_{E} D_{i-M}}{2 r_{D}} N_{i-M}
$$

The effective binary diffusion coefficient is calculated in the usual manner. 11

The mass transfer correction factor, $\theta_{i-M}$, is given by the equation:

$$
\theta_{i-M}=\frac{\emptyset}{e^{\emptyset} i-M}-1
$$

where

$$
\emptyset_{i-M}=\frac{\sum_{j}{ }^{\omega_{j} / A_{D}}}{k_{i-M}}
$$


Substitution of equation (29) through (30) into (27) yields :

$$
\omega_{i}=\frac{\left(x_{i}^{s}-x_{i}^{g}\right) \sum_{j} \omega_{j}}{\left|e_{j}^{\sum} \omega_{j} / A_{D} k_{i-M}\right|}+x_{i}^{s} \sum_{j} \omega_{j}
$$

There are six relations of the form given in equation (31), i.e., one for each of the diffusing species ( $\mathrm{Na}, \mathrm{Na}_{2}$, $\mathrm{NaCl}, \mathrm{Na}_{2} \mathrm{Cl}_{2}, \mathrm{H}_{2}, \mathrm{Ar}$ ). Introduction of these six equations has resulted in an additional twelve unknowns, $s i x_{i} x_{i}^{\prime}$ and six $x_{1}^{g}$ 's. The gas phase compositions are obtained by solving the complex equilibria as outlined below. The surface concentrations of the four vaporizing species ( $\mathrm{Na}, \mathrm{Na}{ }_{2}$, $\mathrm{NaCl}, \mathrm{Na}_{2} \mathrm{Cl}_{2}$ ) are given by four equations of the form:

$$
\mathrm{x}_{i}^{\mathbf{s}}=\frac{\mathrm{e}^{\left(-\Delta G_{i}^{0} / R T_{D}\right)}-1}{\mathrm{P}_{\mathrm{T}}}
$$

Two other applicable equations are:

$$
\omega_{\mathrm{H}_{2}}=\mathrm{O}
$$

that is, the hydrogen is stagnant, and

$$
\sum_{i} x_{i}^{s}=1
$$

The twelve equations given in (31), (32), (33) and (34) In conjunction with the transport coefficient equations (28), (29) and (30) constitute a set of twelve equations and twelve unknowns (for known $x_{i}^{g}$ ) which can be solved numerically. This set of equations must, of course, be solved in. 
conjunction with the coupled set of droplet differential equations.

\section{Gas Equations}

The remaining unknowns in the droplet differential equations are the gas temperature, velocity and composition. The gas temperature is obtained from the gas energy balance equation in conjunction with gas composition which, in turn, is calculated from the complex equilibrium analysis.

However, the equilibrium calculation requires a knowledge of the temperature so that the solution must be carried out simultaneously. The gas energy balance is:

$$
\left.\frac{d}{d z}\left(C_{g} V_{g} \underset{g}{H}\right)=-\dot{s}+\lambda\left[\varepsilon \tau A_{D} \mid T_{D}^{\prime \prime}-T_{W}^{\prime \prime}\right)\right)
$$

where $\dot{S}$, the heat lost per unit volume to the droplets, is given by the equation:

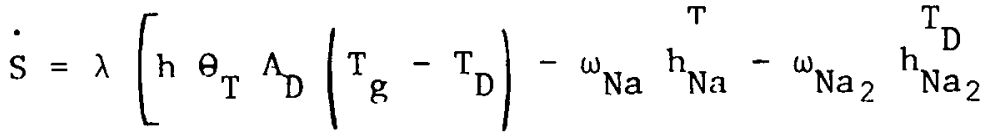

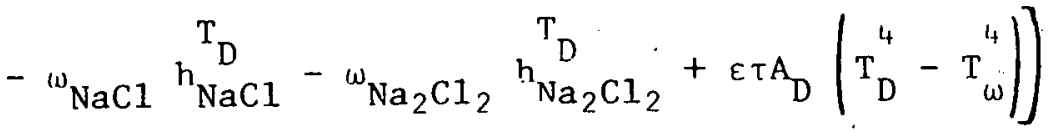

and $\lambda$, the number of droplets per unit volume, is:

$$
\lambda=r_{D I} / 4 / 3 \pi r_{D I}^{3} \rho_{D I} v_{D}
$$

The gas temperature can be obtained from the enthalpy flux, $\mathrm{C}_{\mathrm{g}} \mathrm{V}_{\mathrm{g}} \tilde{\mathrm{H}}_{\mathrm{g}}$, in conjunction with the gas composition calculation (as described below) since

$$
\tilde{H}_{g}=\sum_{i} x_{i}^{g} h_{i}^{g}
$$


and

$$
\mathrm{C}_{\mathrm{g}}=\mathrm{P} / \mathrm{R} \mathrm{T}_{\mathrm{g}}
$$

The gas velocity can be calculated directly from the argon continuity equation:

$$
v_{g}=\frac{\left(x_{A r}^{g} C_{g} v_{g}\right) \text { initial }}{x_{A r}^{g} C_{g}}
$$

Under the assumptions of the model, the gas phase is always at equilibrium. Consequently, the composition can be obtained by solving the complex equilibria. For these calculations, silicon will be assumed to be in the gaseous state at all positions. During the thermal treatment, the gas phase can contain the following twenty three species: $\mathrm{Si}, \mathrm{Si}_{2}, \mathrm{Si}_{3}, \mathrm{SiCl}_{4}, \mathrm{SiCl}_{3}, \mathrm{SiCl}_{2}, \mathrm{SiCl}, \mathrm{SiHCl}_{3}, \mathrm{SiH}_{2} \mathrm{Cl}_{2}$, $\mathrm{SiH}_{3} \mathrm{Cl}, \mathrm{H}, \mathrm{H}_{2}, \mathrm{SiH}, \mathrm{SiH}_{4}, \mathrm{HCl}, \mathrm{Cl}, \mathrm{Cl}_{2}, \mathrm{Na}, \mathrm{Na}_{2}, \mathrm{NaH}, \mathrm{NaCl}$, $\mathrm{Na}_{2} \mathrm{Cl}_{2}$ and $\mathrm{Ar}$. The equilibrium constant méthod was used to solve the complex equilibria. This formulation is based on substitution of the equilibrium constant equations into the conservation equations and has been previously described in detail. 12

The solution to the various equations requires expressions for the thermodynamic and transport properties. Appropriate expressions and values of the required enthalpies, heat capacties and equilibrium constant are available in thermochemical compilation. 10,13

The viscosity, thermal conductives, and binary diffusivities can be calculated from the kinetic theory of gases. ${ }^{14}$ All properties are evaluated at the film temperature and concentration. 
The simultaneous solution of the five droplet and two gas differential equations in conjunction with the twelve flux equations, the five gas phase equilibrium equations, the enthalpy flux equation and the various property equations will yield the temperature, composition and velocity of both the gas and droplet. A computer program based on standard numerical techniques was formulated to solve the above system of equations.

\subsubsection{Results}

Initial calculations with the low temperature reaction model showed that the temperature of the droplets rapidly rises to the boiling point of sodium. As previously discussed, the reaction model has been formulated on the basis that vaporization of sodium does not take place during the reaction. Acceptable droplet temperatures were achieved if a maximum of $10 \%$ of the $\mathrm{SiCl}_{4}$ required, i.e., $\mathrm{f}=0.1$, was introduced into the gas stream at the entrance of the reaction section. The extent of reaction as a function of axial distance for the case in which $\mathrm{f}=0.1$ is shown in Figure 9.4. The various flowrates given in the figure correspond to a silicon production rate of $200 \mathrm{lb} / \mathrm{hr}$. The results indicate that the maximum possible conversion is achieved in a very short distance, approximately $6 \mathrm{~cm}$. The droplet temperature corresponding to this conversion is $950^{\circ} \mathrm{K}$.

The results of a calculation using the thermal treatment model are shown in Figure 9.5. Based on the above reaction model results, the initial droplet is only $10 \%$ converted and $90 \%$ of the required $\mathrm{SiCl}_{4}$ is introduced at the entrance of the thermal treatment section. These caj.culations indicate that the necessary fusion and vaporization which result in collectable liquid silicon droplets occurs in an acceptable reactor length. In parallel with the thermal treatment, 


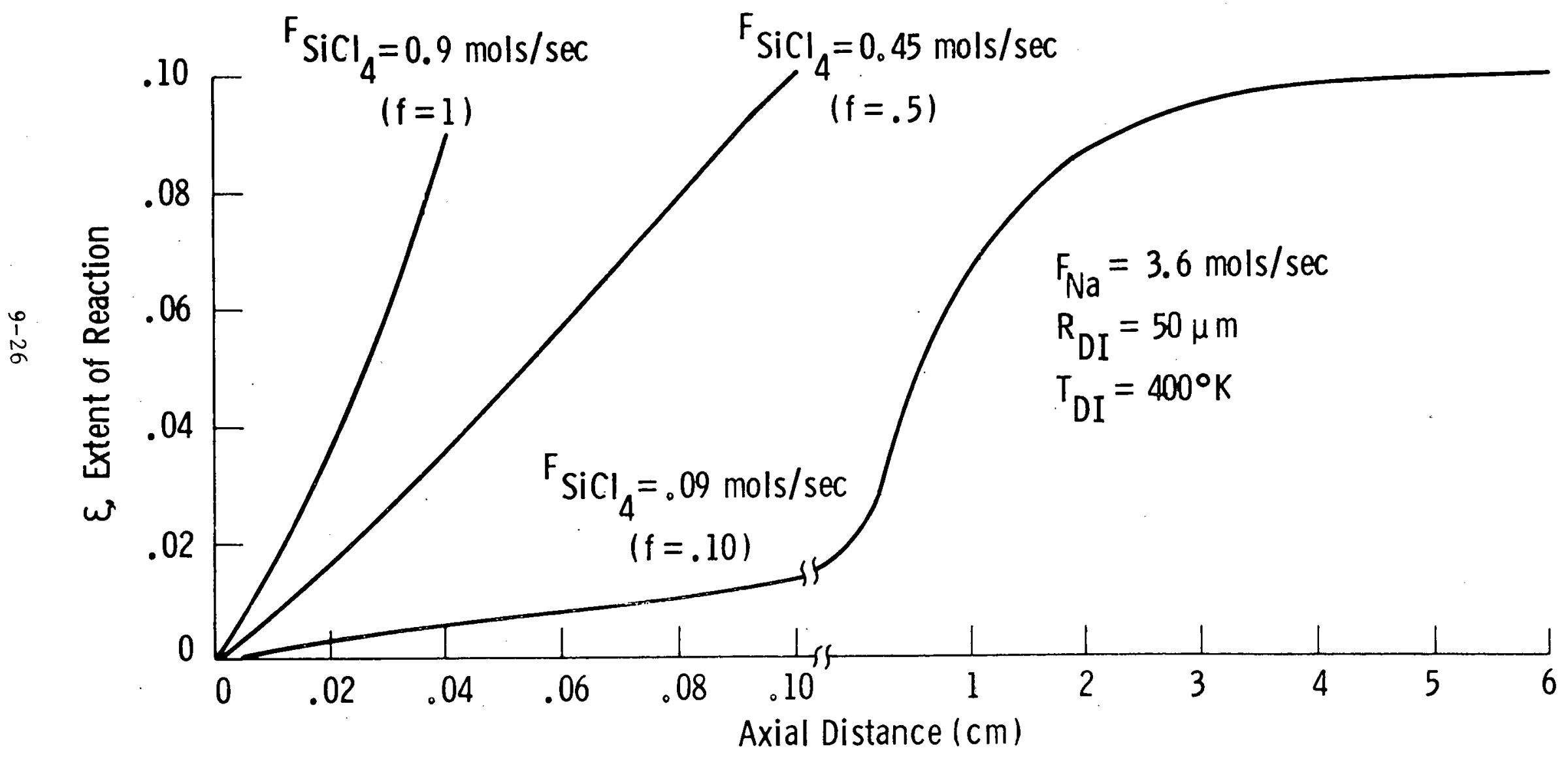

Figure 9.4 - Extent of Reaction, $\xi$, As A Function of The Axial

Distance For The Reaction Model 
Curve 693972-A

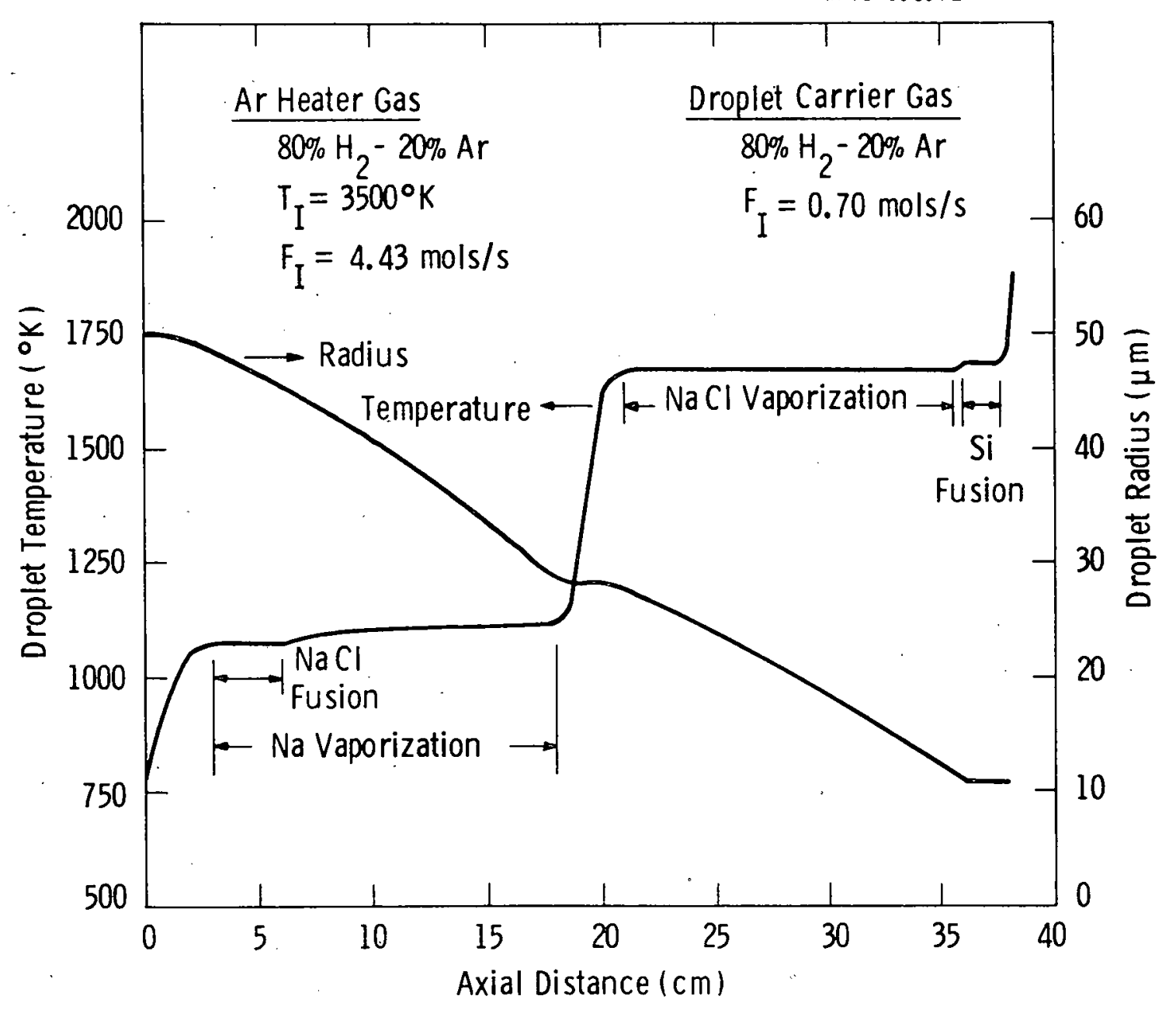

Figure 9.5 - Temperature And Radius Results For Droplets With An Initial Sodium Flowrate of $3.6 \mathrm{Mols} / \mathrm{s}$, An Initial Silicon Tetrachloride Flowrate of 0.9 Mols/s And $10 \%$ Conversion 
vaporized sodium reacted with $\mathrm{SiCl}_{4}$ to form fine droplets of silicon. The fine droplets can be collected by the larger droplet provided that a scavenging mechanism is an effective means of collection. Calculations based on available informatiun indicate that fine droplet collection by scavenging would require unreasonably long reactor length. For this reason the arc heater reduction of $\mathrm{SiCl}_{4}$ carried out by partial low temperature reaction followed by a thermal treatment in which fine droplets are produced cannot be considercd viable at the present time. This does not infer that fine droplets will indeed form in the actual process. It may be that reaction paths, in which either a majority of the conversion occurs during the low temperature reaction or unreacted $\mathrm{SiCl}_{4}$ is added after the thermal treatment, can be considered as acceptable routes for the heterogeneous reduction of $\mathrm{SiCl}_{4}$ by sodium.

\subsection{Reactor Design}

As a result of work accomplished under the Product Separation Task, it was concluded that the design will be based upon the condensation analysis. The associated design work is reported in Section 4.2.2. Since the reactor wall heat fluxes are considerably higher than the previous lower temperature process, additional considerations are made with respect to the shell configuration and final material selection. Similar considerations are being given to the refractory liner design. This design effort will be reported here and in the future quarterly reports under the section entitled Plasma Reactor Design. 
TABLE 9.3

NOMENCLATURE (For Heterogeneous Reaction Analysis)

$\mathrm{A}_{\mathrm{D}} \quad=$ Surface area of droplet

$\mathrm{C}_{\mathrm{f}} \quad=$ Film molar density, i.e., $\mathrm{P} / \mathrm{RT}_{\mathrm{f}}$

$\mathrm{C}_{\mathrm{g}} \quad=$ Molar density of gas

$\tilde{\mathrm{C}}_{\mathrm{PD}}^{\mathbf{i}} \quad=$ Molar heat capacity of species $i$ in droplet

$\tilde{\mathrm{C}}_{\mathrm{P}}^{\mathrm{i}}=$ Molar heat capacity of species $i$ in gas

$\widetilde{C}_{\mathrm{P}}^{\mathrm{D}} \quad=$ Molar heat capacity of droplet.

$\mathrm{D}_{i j} \quad=$ Binary diffusion coefficient

$D_{i-M}=$ Effective binary diffusivity

$\mathrm{f}=$ Fraction of stoichiometric feed ratio of $\mathrm{SiCl}_{4}$ to $\mathrm{Na}$

$f_{i}^{M} \quad=$ Fraction of $i$ melted

$G_{D}, G_{D I}=$ Molar flux and initial molar flux of droplets, respectively $\begin{aligned} \Delta G_{i}^{0} \quad= & \text { Standard Gibbs free energy of formation of species } i \text { at the } \\ & \text { droplet temperature }\end{aligned}$

$\mathrm{h}=$ Uncorrected heat transfer coefficient

$h_{i(c)}^{T} \quad=$ Enthalpy of condensed species $i$ at droplet temperature

$h_{i}^{T} \quad=$ Enthalpy of gas phase species $i$ at droplet temperature

$\underset{\mathrm{h}}{\mathrm{T}} \stackrel{\mathrm{T}}{\mathrm{i}}=$ Enthalpy of gas phase species $i$ at gas temperature

$h_{i}^{M} \quad=$ Heat of fusion of species $i$

$\widetilde{\mathrm{H}}_{\mathrm{g}} \quad=$ Molar enthalpy of gas

= Multicomponent uncorrected mass transfer coefficients 


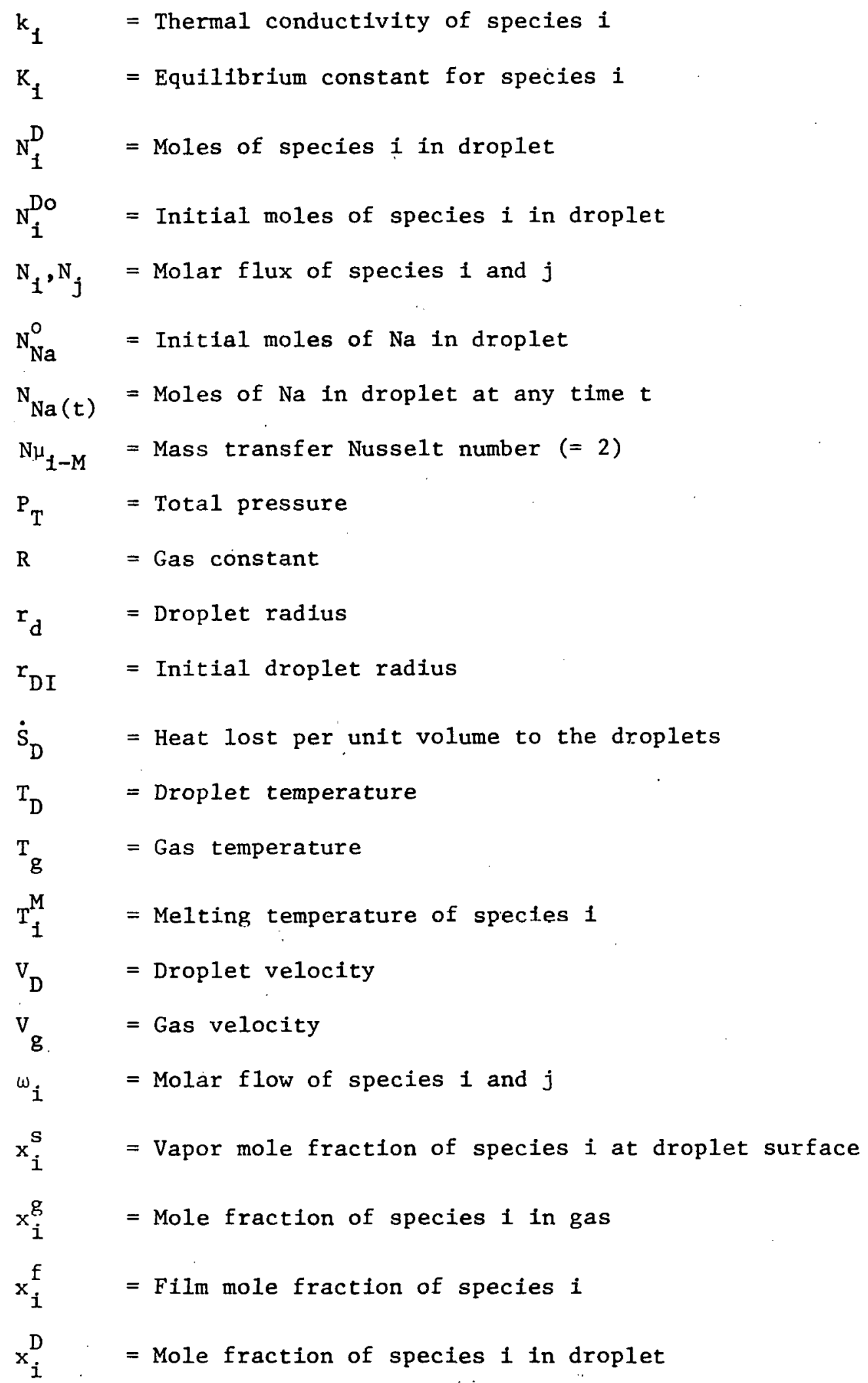




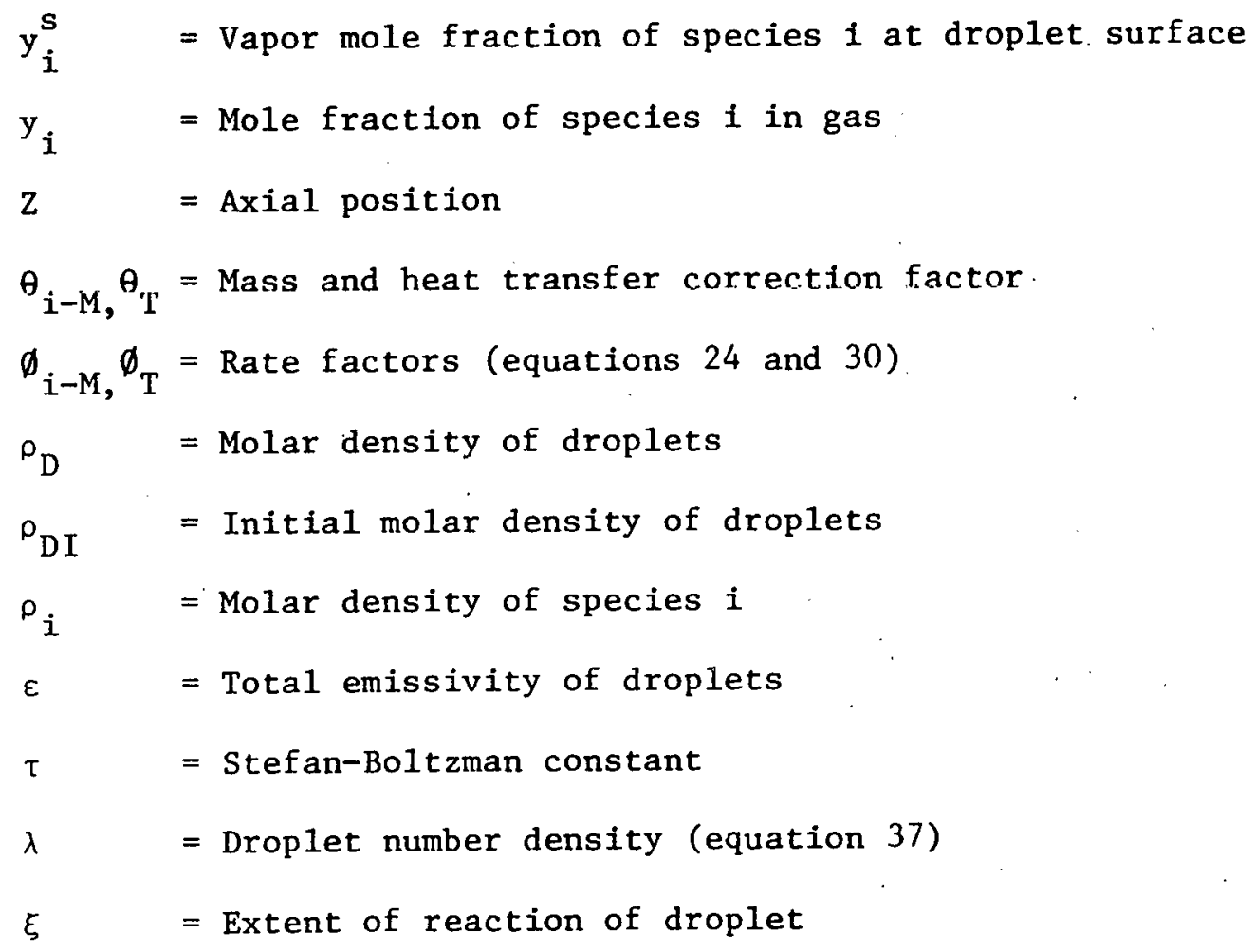




\section{CONCLUSIONS}

- System Purity Analyses have indicated that only phosphorus, aluminum, and manganese concentrations are reduced during the arc heater-silicon process based on the sodium reduction scheme; while the impurity concentrations of boron, chromium, copper, iron, molybdenum, titanium, vanadium, and zirconium, are approximately the same for the feedstock impurity content versus the silicon product level.

- Based on the revised economic analysis for a homogeneous reaction mode, the arc heater process for silicon production can meet the 1985 DOE/JPL cost goal of $\$ 10 / \mathrm{kg}$ of silicon.

- Preliminary silicon vapor measurements using the laser absorption technique indicates that silicon vapor can be measured accurately in the Kinetics experiment.

- Adequate methods (sieving and particle impactors) have been identified for sodium particle measurement during the Injection Techniques study.

- Based upon the Product Separation Analyses; a) Silicon can be effectively separated from the reactor gas stream via a condensation operating mode. b) The condensation mode was selected as the basis for the final reactor design. c) The basic reactor configuration has not changed from that previously described. 


\section{PROJECT STATUS}

\subsection{Present Status}

The System Purity Analysis was completed during the quarter thus, all aspects of the Process Engineering Analysis have been accomplished. Detailed design of the system components for the experimental verification unit continued as well as initiating procurement of system components. The complimentary research programs (i.e., Kinetics, Injection Techniques, and Reaction Demonstration) continued with the completion of designs and initiating procurement and fabrication of the respective experimental hardware. The Product Separation Analysis was completed and results of this analysis were presented to JPL at a design review in February.

\subsection{Future Activity}

- Complete detailed design for the experimental verification unit and the associated subsystems.

- Continue procurement of the system components for the verification unit.

- Complete fabrication and assembly of the experimental hardware for the complimentary research programs.

- Initiate testing for the respective research programs. 


\section{REFERENCES}

1. M. G. Fey, et al, Quarterly Report, DOE/JPL 954589-76/2, Silicon Materials Task, JPL Contract 非954589, Nov.-Dec., 1976.

2. M. G. Fey, et a1, Quarterly Report, DOE/JPL 954589-77/4, Silicon Materials Task, JPL Contract 非954589, Oct.-Dec., 1977.

3. MCA Data Sheet, SD-102 Chlorosilanes, proposed final draft dated June, 1976. Received from Dow Corning Corp.

4. H. Lubanska, J. Meta1s, 1970, p. 45.

5. J. Gretzinger, W. R. Marsha11, A.I.Ch.E. Journa1, 1961, $\underline{7}$ (2), p. 312 .

6. E. R. G. Eckert, R. M. Drake, Jr., Heat And Mass Transfer, McGraw-Hill, New York, 1959, 2nd Edition.

7. W. M. Kays, Convective Heat And Mass Transfer, McGraw-Hil1 Book Co., 1966 , p. 162 .

8. V. K. Mijay, J. K. Golubev, "Friction And Heat Transfer In Turbulent Swir1 Flow With A Variable Swir1 Generator In a Pipe", Heat Transfer-Soviet Research, Vol. 2, No. 3, May 1970.

9. L. M. K. Boelter, G. Young, E. W. Iverson, "An Investigation of Aircraft Heaters XXVII - Distribution of Heat Transfer Rate In The Entrance Section of A Circular Tube", NACA TN1451, July 1948.

10. JANAF Thermochemical Tables, 2nd Ed., 1971, NSRDS, National Bureau of Standards, Washington, D.C.

11. R. B. Bird, W. E. Stewart and E. N. Lightfoot, Transport Pnenomena, 1960, John Wiley \& Sons Inc., New York.

12. Ibid 1, Quarterly Progress, Aug.-Oct. 1976.

13. K. K. Kelley, U.S. Bureau of Mines, Bulletin 584, Washington, D.C., 1960 .

14. J. 0. Hirschfelder, J. O. Curtiss and R. B. Bird, Molecular Theory of Gases And Liquids, 1954, John Wiley and Sons, Inc., New York.

15. R. E. Treybol, Mass Transfer Operations, McGraw-Hil1 Book Co., New York, 1955.

16. T. K. Sherwood, R. L. Pigford, Absorption And Extraction, 2nd Ed., McGraw-Hil1 Book Co., New York, 1952. 
APPENDIX

TASK (09) INJECTION TECHNIQUES

Test Plan

1.0 This test plan is designed to provide a systematic approach to reach the task objective of evaluating and characterizing candidate injectors for the silicon production reactants.

\subsection{Sodium Injection}

A sonic atomizing nozzle, Sonicore Model 312 from Sonic Development Corporation, Upper Saddle, New Jersey, has been selected as the prime candidate for sodium injection. Two of these nozzles have been purchased for evaluation in this task.

\subsection{Water Test (Video Monitor)}

This test will consist of operating the Sonicore nozzle with water and nitrogen to investigate large droplet formation, angle of spray and general nozzle operating characteristics.

A television recording system $\mathrm{Tm}$ Instar will be used for this purpose as well as visual observations. Water and nitrogen flowrates will be varied to determine effective operating range. TV recordings will be played back in slow motion to study the nozzle performance.

\subsection{Water Test (Collection Shroud)}

This test will be conducted with the Sonicore nozzle again using water and nitrogen. A metal shroud will be positioned around the nozzle so that large droplets will be collected while the small droplets will not. A measurement of the collected water will be compared to the total water flow in order to quantify the mass of large droplet formation. 


\subsection{Sodium Test \#1}

This initial sodium test with the Sonicore nozzle will. use argon as the atomizing gas. The purpose of this test is to shakedown the test system and determine gross effects of nozzle operation with sodium. The test procedure will be:

- Precool the test chamber and gas atmosphere in the chamber.

- Start hot argon flow to the nozzle then quickly inject a 1 sec burst of $\mathrm{Na}$ then Immediately stop argon flow.

- Collect frozen Na particles, transfer to glove box and analyze.

\subsection{Sodium Test $\# 2$}

This test will be the same as sodium test \#1 except more instrumentation w11l be used. Either high speed photography or the television Instar system will be used to record the test. A cascade impactor will be utilized for small particle analysis.

\subsection{Sodium Test \#3}

This test will be the same as sodium test \#2 except with a longer sodium flow time determined from above tests.

\subsection{Sodium Test $\$ 4$}

This test will be the same as sodium test \#3.

\subsection{Sodium Test \#5}

This will be a long duration test (up to 1 minute) to determine if nozzle operating characteristics are uniform and consistent.

\subsection{Silicon Tetrachloride Injection}

Hydraulic atomizing nozzles, model 1/4 LNN6, from Spraying Systems Co., Wheaton, Illinois were selected as the prime candidate 
for silfcon tetrachloride $\left(\mathrm{SiCl}_{4}\right)$ injection. Ten of these nozzles will be required to supply the desired $\mathrm{SICl}_{4}$ flowrate into the chemical reactor. Two of these nozzles are being procured for injection techniques testing.

\subsection{Water Test (Video Monitor)}

This test will be the same as the test described in Section 2.1 except the model $1 / 4$ LNN6 hydraulic nozzle will be used instead of the Sonicore nozzle.

\subsection{Water Test (Collection Shroud)}

This test will be the same as the test described in Section 2.2 except with the $1 / 4$ LNN6 hydraulic nozzle.

\section{$3.3 \quad$ SiC14 Test $\# 1$}

$\mathrm{SiCl}_{4}$ will be injected tnto the test chamber through the 1/4 LNN6 hydraulic atomizing nozzle at its normal operating pressure and flowrate. Either high speed photography or the television Instar system will be used to record the test.

\section{$3.4 \mathrm{SiCl}_{4}$ Test $\# 2$}

$\mathrm{SICl}_{4}$ test $\|_{1} 1$ will be repeated with any required modifications for more complete analysis.

\section{0 $\mathrm{Na} / \mathrm{SiCl}_{4}$ Colnjection Testing}

The Sonicore Model 312 nozzle utilizes a gas sonic shock wave to atomize the liquid. Because $\mathrm{SiCl}_{4}$ has a low boiling point $\left(57^{\circ} \mathrm{C}\right)$ it is possible to use the $\mathrm{SiCl}_{4}$ in the gaseous state to produce the sonic shock wave. Thus coinjection of the $\mathrm{Na}$ and $\mathrm{SiCl}_{4}$ through the same nozzle may be possible.

\subsection{Coinjection Test \#1}

The purpose of this test is to investigate the feasibility of coinjecting $\mathrm{Na}$ and $\mathrm{SiCl}_{4}$. A mixture of argon, $90 \%$, and ' $\mathrm{SiCl}_{4}$ vapor, $10 \%$, will be flowed through the nozzle, then a $1 \mathrm{sec}$. 
burst of $\mathrm{Na}$ w1ll be introduced. High speed photography will be used to study the reaction. Reaction products will be analyzed and bulldup of reaction product on the nozzle will be investigated.

\subsection{Coinjection Test \#2}

This test will be the same as coinjection test 1 except the fluid ratios will be adjusted after analysis of test \#1.

\subsection{Coinfection Test \#3}

This test will be the same as coinjection test \#2 except that adjustments w111 be made after analysis of test $\| 2$. 